Opportunity \&

Inclusive Growth

T]

$\rightarrow$ M

FEDERAL RESERVE BANK OF MINNEAPOLIS

INSTITUTE WORKING PAPER

No. 38

\title{
The Indirect Fiscal Benefits of Low-Skilled Immigration
}

October 2020

\section{Mark Colas \\ University of Oregon \\ Dominik Sachs \\ University of Munich}

DOI: https://doi.org/10.21034/iwp.38

Keywords: Immigration; Fiscal impact; General equilibrium

JEL classification: H20, J31, J62, J68

The views expressed herein are those of the authors and not necessarily those of the Federal Reserve Bank of Minneapolis or the Federal Reserve System. 


\title{
The Indirect Fiscal Benefits of Low-Skilled Immigration*
}

\author{
Mark Colas \\ University of Oregon
}

\section{Dominik Sachs}

University of Munich

September 29, 2020

\begin{abstract}
Low-skilled immigrants indirectly affect public finances through their effect on native wages \& labor supply. We operationalize this general-equilibrium effect in the workhorse labor market model with heterogeneous workers and intensive and extensive labor supply margins. We derive a closed-form expression for this effect in terms of estimable statistics. We extend the analysis to various alternative specifications of the labor market and production that have been emphasized in the immigration literature. Empirical quantifications for the U.S. reveal that the indirect fiscal benefit of one low-skilled immigrant lies between $\$ 770$ and $\$ 2,100$ annually. The indirect fiscal benefit may outweigh the negative direct fiscal effect that has previously been documented. This challenges the perception of low-skilled immigration as a fiscal burden.
\end{abstract}

JEL codes: H20, J31, J62, J68

Keywords: Immigration, Fiscal Impact, General Equilibrium

\footnotetext{
*mcolas@uoregon.edu and dominik.sachs@econ.lmu.de. We would like to thank Daniele Coen-Pirani, Jonathan M.V. Davis, Juan Dolado, Ben Elsner, Axelle Ferriere, Sebastian Findeisen, Lisandra Flach, Tommaso Frattini, Ulrich Glogowsky, Emanuel Hansen, Gaurav Khanna, Wojciech Kopczuk, Fabian Lange, Jonas Loebbing, Andreas Peichl, Panu Poutvaara, Florian Scheuer, Monika Schnitzer, Stefanie Stantcheva, Kjetil Storesletten, Jan Stuhler, Juan Carlos Suárez-Serrato, Uwe Thuemmel, Aleh Tsyvinski, Alessandra Voena, Nicolas Werquin, Simon Wiederhold, Andreas Winkler and Woan Foong Wong as well as seminar participants at the CEPR Public Economics Symposium "Public Finance: Macro Insights", CESifo Public Sector Economics Area Conference, CRC "Rationality and Competition" Retreat as well as seminar participants at Ben Gurion University, University of Bonn, KU Ingolstadt, University of Pennsylvania, University of Pittsburgh, and University of Regensburg for helpful comments and suggestions. We also thank Mehmet Ayaz, Lea Fricke, Oleksandr Morozov and Taylor Watson for great research assistance.
} 


\section{Introduction}

Low-skilled immigrants are widely considered a fiscal burden in the United States. ${ }^{1}$ In his widely-read blog, Nobel Laureate Paul Krugman (2006) concludes the following on this issue: "the fiscal burden of low-wage immigrants is also pretty clear... I think that you'd be hard pressed to find any set of assumptions under which Mexican immigrants are a net fiscal plus." More recently, the National Academy of Sciences (NAS) recently published a detailed report on the economic and fiscal consequences of immigration in the U.S. (National Academy of Sciences, 2017). For most of the fiscal scenarios that the report considered, low-skilled immigrants have negative effects on public finances. ${ }^{2}$ This NAS report was politically influential and cited by Donald Trump in his first address to congress in 2017, where he stated: "(a)ccording to the National Academy of Sciences, our current immigration system costs America's taxpayers many billions of dollars a year." 3

The NAS report focuses on immigrants' direct fiscal effects - taxes paid by the immigrants minus costs for benefits and services they receive - and abstracts away from indirect fiscal effects - changes in natives' tax payments that result from general equilibrium effects. Concretely, the authors write:

"(b)eyond the taxes they pay and the programs they use themselves, the flow of foreign-born also affects the fiscal equation for many natives as well, at least indirectly... In a comprehensive analysis, these ripple effects in the economy would be accounted for; however, due to the complexity of operationalizing a general equilibrium approach into the accounting framework, they typically are omitted. The fiscal impacts literature has generally concluded that these kinds of impacts are minor relative to overall economic activity." (National Academy of Sciences, 2017, p.263)

In this paper we take on this issue and operationalize the indirect fiscal effect that lowskilled immigrants have through their effect on native wages and native labor supply and find that it is of first-order importance. ${ }^{4}$ Specifically, we derive closed-form expressions for this

\footnotetext{
${ }^{1}$ Alesina, Miano, and Stantcheva (2018) found that $15 \%$ of respondents to a survey in the United States believed that an average immigrant received more than twice the amount in government transfers as the average citizen. According to a 2019 Gallup poll, $42 \%$ of Americans believed immigration was making the tax situation in the U.S. worse, compared to only $20 \%$ who believe immigration improved the U.S. tax situation. This $42 \%$ is larger than the percentage of respondents who believe immigration made the US worse off in terms of 1) the economy in general, 2) job opportunities, and 3) social and moral values (https://news.gallup. com/poll/1660/immigration.aspx). The public's perception of the effect of immigration on public finances plays a large role in shaping natives' perceptions of immigration (Dustmann and Preston, 2007; Boeri, 2010).

${ }^{2}$ George Borjas, a member of the NAS panel, writes "(r)egardless of which scenario, it is obvious that low-skill immigrants impose a fiscal burden in the long run..." (Borjas, 2016a, p.14).

${ }^{3}$ https://www.whitehouse.gov/briefings-statements/remarks-president-trump-joint-address-congress /

${ }^{4}$ High-skilled immigration also leads to indirect fiscal effects. Since low-skilled immigration is much more politically controversial, we focus on low-skilled immigrants. As we discuss in the conclusion, high-skilled immigrants could lead to indirect fiscal effects through their effect on productivity and innovation, in addition to their effect on relative wages and labor supply.
} 
indirect fiscal effect in various models of immigration and the labor market. The formulas provide an intuitive understanding of the economic forces at work and allow for a transparent quantification. We evaluate these formulas by combining existing empirical evidence with a detailed empirical quantification of the U.S. tax-transfer system. One low-skilled immigrant that enters the U.S. adds between $\$ 770$ and $\$ 2,100$ annually to public finances through this indirect effect. This outweighs the direct fiscal costs for the more optimistic scenarios of the NAS report and significantly reduces the burden in the other scenarios. It should be accounted for when calculating the fiscal effects of immigration.

The insight that low-skilled immigration has a positive indirect fiscal effect relies on a simple economic mechanism. As a first step, consider the most simple textbook setup with two imperfectly substitutable skill levels and exogenous labor supply of natives. ${ }^{5}$ In this setup, low-skilled immigration raises high-skilled wages and lowers low-skilled wages. Consequently, tax payments of high-skilled natives increase whereas tax payments of low-skilled natives decrease. If immigrants are paid their marginal product, what they contribute to aggregate income is equal to what they receive. Therefore, they affect the distribution of native income, but not the overall size of national income accruing to natives. Hence, what the low-skilled natives lose is what high-skilled natives gain. As a consequence, tax revenue from natives increases if high-skilled individuals face higher marginal tax rates than low-skilled individuals. We show that this effect boils down to the size of the wage effects as measured by the ownwage elasticity of low-skilled labor and the progressivity of the tax system as measured by the difference in the marginal tax rates of the two skill types.

We then turn to our main model specification that includes two major extensions: workers can respond to immigrant inflows via both intensive and extensive labor supply adjustments and individual productivity levels are continuously distributed conditional on skill level, as in the so-called "canonical model" (Acemoglu and Autor, 2011). In particular, we also allow for labor supply elasticities to differ with income, gender and family status. ${ }^{6}$ The labor supply responses of natives alter the indirect fiscal benefit because they have fiscal consequences themselves; if immigration decreases native labor supply, for example, this would decrease tax revenue. Further, these labor supply responses themselves induce wage effects which mitigate the initial wage shocks. Following Sachs, Tsyvinski, and Werquin (2020), we formalize the implied fixed point problem in terms of integral equations and show that the indirect fiscal effect can be expressed as a closed-form expression of estimable statistics: own-wage

\footnotetext{
${ }^{5}$ We generally use the term "natives" to refer to all individuals already in the country at the time of an immigrant inflow, including foreign-born workers who immigrated earlier. In Sections 6.2 and 6.4 , we distinguish between native-born and foreign-born workers. This distinction has been highlighted as having important wage implications in the more recent literature (Peri and Sparber, 2009; Card, 2009; Ottaviano and Peri, 2012; Manacorda, Manning, and Wadsworth, 2012; Dustmann, Schönberg, and Stuhler, 2016).

${ }^{6}$ E.g. Dustmann, Schönberg, and Stuhler (2016, p. 44) emphasize that "wage and employment responses need to be studied jointly to obtain an accurate picture of the labor market impacts of immigration". These authors also highlight that it is important to allow for labor supply responses that vary between different groups of natives. Dustmann, Schönberg, and Stuhler (2017) demonstrate the importance of this heterogeneity in labor supply responses empirically in the German context.
} 
elasticities, income-weighted averages of (i) labor supply elasticities, (ii) marginal effective tax rates, as well as (iii) products of participation (marginal) tax rates and extensive (intensive) marginal labor supply elasticities - all conditional on skill level. Component (i) captures mitigation of wage effects by native labor supply responses. Component (ii) captures fiscal effects from the changes in relative wages holding labor supply fixed as described in the previous paragraph. Component (iii) captures fiscal effects that arise from changes in native labor supply and thus constitute fiscal externalities. As we discuss, the distinction between (ii) and (iii) is interesting from a welfare point of view.

We evaluate this formula for the indirect fiscal benefit by combining data from the American Community Survey (ACS), the 1979 National Longitudinal Survey of Youth (NLSY79), and the Survey of Income and Program Participation (SIPP). We use the tax calculator TAXSIM to assign effective tax rates to each individual in our main dataset, the ACS. However, TAXSIM does not account for welfare-transfer programs nor does it account for future social security receipts, both which vary with income. To account for this, we use the SIPP to estimate Supplementary Nutrition Assistance Program (SNAP) and Temporary Assistance for Needy Families (TANF) receipts as a function of income and household characteristics. We use the NLSY79 and the ACS to understand how changes in current income, combined with the distribution of the individual's earnings over the life cycle, affect their receipt of social security payments in the future. Another main component of the empirical quantification regards the labor supply elasticities along both the intensive and the extensive margin. We consider different values from the empirical literature and allow these elasticities to vary with family structure, gender and income.

Combining our empirical quantification of the U.S. tax system with our closed-form solutions for the indirect fiscal effect, we find that the indirect fiscal effect of one low-skilled immigrant is between $\$ 770$ and $\$ 1,470$ per year if we consider a plausible range for the elasticity of substitution between high and low-skilled labor (Card, 2009). We set these numbers into relation to the direct fiscal effects as reported by the National Academy of Sciences (2017). We calculate an annualized direct fiscal cost associated with low-skilled immigrants under a number of scenarios which vary the marginal cost of public goods and the education of the immigrant. In almost all cases, the direct fiscal effect is negative and of a similar magnitude to the indirect fiscal effects we calculated. In some of the scenarios we consider, accounting for the indirect fiscal costs of immigrant turns the total fiscal effect from a fiscal burden to a fiscal surplus. While this result of 'turning the sign' does not hold for all scenarios, this clearly shows that the indirect fiscal effect of low-skilled immigration can be of the same order of magnitude as the direct fiscal effect and of the opposite sign.

There is some controversy in the literature over the appropriate model to analyze and estimate the wage effects of immigration. A natural concern is that the indirect fiscal effects are also sensitive to these modeling choices. Therefore, we extend our model to allow for a variety 


\begin{tabular}{|c|c|c|c|}
\hline Specification & Indirect Effect & Section & Main Reference/Source of Estimates \\
\hline Simple Textbook Model & $\$ 1,104$ & Section 2 & Borjas (2014) \\
\hline Canonical Model & & Sections $3-5$ & Acemoglu and Autor (2011), Card (2009) \\
\hline Exogenous Native Labor Supply & $\$ 975$ & & \\
\hline Intensive Margin Adjustments & $\$ 1,113$ & & Chetty (2012), Bargain, Orsini, and Peichl (2014) \\
\hline Extensive Margin Adjustments & $\$ 1,074$ & & " \\
\hline Both Intensive and Extensive & $\$ 1,186$ & & " \\
\hline Education and Experience Groups & $\$ 1,873$ & Section 6.1 & Borjas (2003) \\
\hline Domestic- and Foreign-Born Complementarity & $\$ 1,065$ & Section 6.2 & Ottaviano and Peri (2012) \\
\hline Skills by Position in Wage Distribution & $\$ 1,017$ & Section 6.3 & Dustmann, Frattini, and Preston (2013) \\
\hline Endogenous Task Supply & $\$ 2,131$ & Section 6.4 & Peri and Sparber (2009) \\
\hline Decreasing Returns to Scale & $\$ 1,057$ & Section 6.5 & Burnside (1996) \\
\hline
\end{tabular}

Table 1: Estimates of annual indirect fiscal effect of one low-skilled immigrant under different model specifications. For the "Simple Textbook Model" and the "Canonical Model" we use our results associated with an elasticity of substitution between high-skilled and low-skilled workers of 2 , the central value we use in our quantification. For the "Canonical Model" with labor supply adjustments, we display our results with common labor supply elasticities. For all specifications, we show the indirect effect for the average low-skilled immigrant. See text for details on each specification.

of different production functions and labor supply responses. These extensions and the associated indirect fiscal effects are summarized in Table 1. First, we consider three alternative production specifications that have been utilized in the immigration literature: 1) production with four imperfectly substitutable education groups and imperfect substitution between experience levels, as utilized by Borjas (2003), 2) production with imperfectly substitutable foreign-born and domestic-born workers, as in Ottaviano and Peri (2012), and 3) production where $\mathrm{s}+$ ills are defined by an individual's position in the wage distribution, rather than their education, as in Dustmann, Frattini, and Preston (2013). We show that our formula extends naturally to these more elaborate production technologies. Next, we combine these expressions for the indirect fiscal effects with our empirical quantification of the effective tax rates to calculate the indirect fiscal effects in each setting. For all three specifications, we find annual indirect fiscal effects of the average low-skilled immigrant in the range of $\$ 1,000$ to $\$ 1,870$. When we use the same elasticity of substitution between skill levels in all three specifications, the indirect fiscal effects all lie within $\$ 250$ of each other.

Next, we consider a model with endogenous task supply as in Peri and Sparber (2009). ${ }^{7}$ In the model, low-skilled workers may react to additional low-skilled immigration by 'upgrading' their occupation and increasing their supply of communication tasks. This upgrading of occupations leads to an additional fiscal effect because these workers earn higher wages and therefore pay higher taxes. As such, we find an indirect fiscal benefit of over $\$ 2,130$ in this framework, roughly half of which is due to occupation upgrading of domestic-born workers.

Finally, we calculate the indirect fiscal effect when production exhibits decreasing returns to scale. When production exhibits decreasing returns to scale, immigrant inflows not only

\footnotetext{
${ }^{7}$ See also Foged and Peri (2016) and Patt, Ruhose, Wiederhold, and Flores (2020) for evidence of native task supply responses to immigrant inflows. Llull (2018) highlights the importance of occupation adjustments in mitigating the wage effects of immigration on natives.
} 
change the relative wages between imperfectly substitutable worker groups, but also increase firm profits at the cost of total worker compensation. We show that this additional effect can accommodated with an additional term in our indirect fiscal benefits formula which accounts for this shift in distribution of national income from workers to firms. Using an estimate of marginal profit tax rates, we show that the indirect fiscal effect with decreasing returns is unlikely to be significantly different from the case with constant returns to scale.

Related Literature The literature that studies the fiscal effects of immigration has primarily focused on the direct fiscal effect. Preston (2014) provides a comprehensive overview on the topic. Economists have employed a variety of methods to measure this direct fiscal impact of immigration. Borjas and Hilton (1996) quantify how much more likely immigrants are to participate in welfare programs. Dustmann and Frattini (2014) provide a detailed accounting approach for the UK and find that EEA (non EEA) immigrants on average contributed more (less) to public finances than public costs they cause. They emphasize the importance of accounting for the use of public goods and potential congestion externalities. Monras, Vázquez-Grenno, and Elias (2018) find that a policy which legalized 600,000 undocumented immigrants in Spain led to increases in payroll tax revenues. ${ }^{8}$

Storesletten (2000) takes a more macroeconomic model-based perspective and quantifies the net present value of fiscal contributions of an immigrant as a function of age and education for the U.S. Storesletten (2003) provides a similar calculation for Sweden. Relatedly, several papers use quantitative equilibrium models to study the effects of immigration in the presence of progressive taxation (Battisti, Felbermayr, Peri, and Poutvaara, 2018; Busch, Krueger, Ludwig, Popova, and Iftikhar, 2020). ${ }^{9}$

We are the first paper to quantify the indirect fiscal effects of low-skilled immigration, which we show to be of a similar magnitude, but the opposite sign, of the direct effects of immigration estimated in the literature. While such indirect fiscal effects have been mentioned previously, the conjecture was that the effects are of second order compared to the direct fiscal effects. ${ }^{10}$

Roadmap We progress as follows. In Section 2 we use a simple benchmark model to illustrate the mechanism behind the indirect fiscal effect transparently. Section 3 presents our main quantitative model and Section 4 presents our empirical quantification. Section 5 presents our main quantitative results. These first five sections contain the main findings of the paper. The remaining sections contain additional extensions and results for the interested reader. In

\footnotetext{
${ }^{8}$ The authors estimate the causal effect of the amnesty program on province-level payroll tax revenue. They find that the policy led to increases labor market opportunities for immigrants who were given amnesty. The effects on payroll tax revenue they find includes both direct and indirect fiscal effects.

${ }^{9}$ Coen-Pirani (2011) analyzes the effects of immigrant inflow of public education funding in California through the lens of a quantitive political-economy model.

${ }^{10}$ Preston (2014) writes "(w)hile interesting, the implied tax effects are not plausibly large relative to the effects that will be found by a simple accounting approach."
} 
Section 6, which evaluate the indirect fiscal effects under various alternative environments. Section 7 discusses further issues and Section 8 concludes.

\section{The Simple Benchmark Model}

To highlight our result transparently, we start with the simple textbook model for the impact of immigration on native wages (Borjas, 2014; Bodvarsson and Van den Berg, 2009). Consider an economy that is populated by individuals that are either high-skilled or low-skilled. The mass of low-skilled individuals is $N_{u}$ and the mass of high-skilled individuals is $N_{s}$. Denote individual labor supply by $h_{u}$ and $h_{s}$. Production of the single consumption good, whose price is normalized to one, is described by a constant returns to scale production function $Y=F\left(\mathscr{L}_{u}, \mathscr{L}_{s}\right)$ where $\mathscr{L}_{u}=N_{u} h_{u}$ and $\mathscr{L}_{s}=N_{s} h_{s}$ denote the aggregate labor of each respective skill level. We assume that low- and high-skilled labor are imperfect substitutes in production of the single final good, the price of which is normalized to one. In equilibrium, profits are zero and wages are equal to marginal products, i.e. $w_{e}=\frac{\partial F}{\partial \mathscr{L}_{e}}$ for $e=u, s$. Finally, denote income of the two types of workers by $y_{s}=h_{s} w_{s}$ and $y_{u}=h_{u} w_{u}$ and denote aggregate income of the skill levels by $Y_{s}=y_{s} N_{s}$ and $Y_{u}=y_{u} N_{u}$.

For simplicity, we consider a very stylized tax system. $\tau_{u}$ is the tax rate on low-skilled income and $\tau_{s}$ is the tax rate on high-skilled income, where $\tau_{u}<\tau_{s}$ is a stylized way of capturing tax progressivity. Further, let $C_{u}$ and $C_{s}$ represent per-person costs which do not depend on income, representing, for example, public goods or schooling costs associated with each low- and high-skilled individual, respectively. Tax revenue in this economy is given by

$$
\mathscr{R}=N_{u}\left(\tau_{u} y_{u}-C_{u}\right)+N_{s}\left(\tau_{s} y_{s}-C_{s}\right)
$$

In the following, we formally study how tax revenue $\mathscr{R}$ changes due to a small influx of low-skilled immigrants $d N_{u}$. This influx has a direct fiscal effect

$$
d \mathscr{R}_{d i r}=\left(\tau_{u} y_{u}-C_{u}\right) \times d N_{u}
$$

One low-skilled immigrant contributes $\left(\tau_{u} y_{u}-C_{u}\right)$ to the public budget. As stated above, this direct fiscal effect has already received much attention in the literature and is not the subject of this paper. ${ }^{11}$

The immigration influx also has an indirect fiscal effect. Given that labor of different skill levels are imperfect substitutes in production, the increase of the low-skilled (high-skilled)

\footnotetext{
${ }^{11}$ The report of the National Academy of Sciences (2017) includes federal, state and local taxes, incarceration costs, scholarship and student loan costs, education costs, government healthcare costs, veteran's benefits, refugee support costs, public good costs, and a variety of federal and state level transfer programs in their calculation of direct fiscal effects.
} 
workforce by $d N_{u}$ decreases (increases) the wage of low-skilled (high-skilled) workers and therefore their tax payment. We are interested in the sum of these two effects, which reads as

$$
d \mathscr{R}_{i n d}=N_{u} h_{u} \tau_{u} \frac{\partial w_{u}}{\partial N_{u}} d N_{u}+N_{s} h_{s} \tau_{s} \frac{\partial w_{s}}{\partial N_{u}} d N_{u}
$$

The following lemma helps to relate the size of the wage increase of the low-skilled and the wage increase of the high-skilled.

Lemma 1. If the production function is characterized by constant returns to scale, then aggregate native labor income is unchanged:

$$
\begin{aligned}
& N_{u} h_{u} \frac{\partial w_{u}}{\partial N_{u}} d N_{u}+N_{s} h_{s} \frac{\partial w_{s}}{\partial N_{u}} d N_{u}=0 \\
& \Rightarrow \gamma_{s, \text { cross }}=\left|\gamma_{u, \text { own }}\right| \times \frac{w_{u} \mathscr{L}_{u}}{w_{s} \mathscr{L}_{s}},
\end{aligned}
$$

where $\gamma_{u, o w n}$ is the own-wage elasticity of low-skilled labor and defined by $\gamma_{u, o w n}=\frac{\partial w_{u}}{\partial \mathscr{L}_{u}} \frac{\mathscr{L}_{u}}{w_{u}}$ and $\gamma_{s, \text { cross }}$ is the cross-wage elasticity of high-skilled labor and defined by $\gamma_{s, \text { cross }}=\frac{\partial w_{s}}{\partial \mathscr{L}_{u}} \frac{\mathscr{L}_{u}}{w_{s}}$.

Proof. Note that with constant returns to scale one has $F\left(N_{u} h_{u}, N_{s} h_{s}\right)=w_{u} N_{u} h_{u}+w_{s} N_{s} h_{s}$. Differentiating both sides w.r.t. to $N_{u}$ and using $\frac{\partial F}{\partial \mathscr{L}_{u}}=w_{u}$ yields the result.

Intuitively, immigrants obtain their marginal product and do not affect the size of the overall pie accruing to natives. Immigrants only affect the distribution of the pie between high- and low-skilled natives. The income loss of one group equals the income gain of the other group. ${ }^{12}$ This relation is formally given by (3) and it provides a direct relation between the cross-wage elasticity of high-skilled labor $\gamma_{s, \text { cross }}$ and the own-wage elasticity of low-skilled labor $\gamma_{u, o w n}$. Based on Lemma 1, we can easily simplify the indirect fiscal effect and rewrite it as stated in the following proposition. ${ }^{13}$

Proposition 1. If native labor supply is exogenous, the indirect fiscal effect of low-skilled immigration $d N_{u}$ is given by

$$
d \mathscr{R}_{\text {ind }}=\left(\tau_{s}-\tau_{u}\right) \times\left|\gamma_{u, \text { own }}\right| \times y_{u} \times d N_{u}
$$

Proof. First, note that (3) implies $N_{s} h_{s} \frac{\partial w_{s}}{\partial N_{u}}=-N_{u} h_{u} \frac{\partial w_{u}}{\partial N_{u}}$. Inserting this into the indirect fiscal effect as defined in (2) yields:

$$
d \mathscr{R}_{i n d}=N_{u} h_{u} \tau_{u} \frac{\partial w_{u}}{\partial N_{u}} d N_{u}-\tau_{s} N_{u} h_{u} \frac{\partial w_{u}}{\partial N_{u}} d N_{u}=\left(\tau_{u}-\tau_{s}\right) \mathscr{L}_{u} \frac{\partial w_{u}}{\partial \mathscr{L}_{u}} h_{u} d N_{u}
$$

\footnotetext{
${ }^{12}$ If the immigration influx is not infinitesimal, then there would indeed be an immigration surplus, i.e. aggregate native labor income would increase. However, the immigration surplus would be second order compared to the distributional implications, see e.g. (Borjas, 2014, Chapter 7).

${ }^{13}$ As discussed in Footnote 4, we focus on low-skilled immigration since it is more politically controversial. However, it is straightforward to do the analysis for high-skilled immigrants, where the formula would read as $\left(\tau_{u}-\tau_{s}\right) \times\left|\gamma_{s, o w n}\right| \times y_{s} \times d N_{s}$.
} 
which then yields (4).

The formula for the indirect fiscal effect (4) is very simple and allows for a straightforward interpretation. ${ }^{14}$ Since the change in overall income of natives is unaffected as shown in Lemma 1, the change in tax payment of natives would be zero if $\tau_{s}=\tau_{u}$. However, if taxes are progressive $\left(\tau_{s}>\tau_{u}\right)$, aggregate tax payment of natives increases. High-skilled individuals, whose income increases, are taxed at a higher rate than low-skilled individuals, whose income decreases. The size of the effect is proportional to low-skilled income and the own-wage elasticity of low-skilled wages. ${ }^{15}$

Formula (4) allows for a straightforward quantification. As a normalization, we set $d N_{u}=1$, i.e. we normalize it to one marginal immigrant. For a CRS production function, the own-wage elasticity is given by $\gamma_{u, o w n}=\frac{\frac{N_{s} y_{s}}{N_{u} y_{u}+N_{s} y_{s}}}{\sigma}$, where $\sigma$ is the elasticity of substitution, which we assume to be in [1.5, 2.5] (Card, 2009). Importantly, as we show in Appendix A.1, this relation does not require the elasticity of substitution to be constant - we are not imposing a CES production function. To quantify this, we use data from the 2017 American Community Survey (ACS). Average earnings of high school and college-education were $y_{u}=\$ 36,079$ and $y_{s}=\$ 67,432$, respectively. Further, we know that the share of workers with and without college education was .65 and $.35 .{ }^{16}$ As a final step, we need to quantify $\tau_{s}-\tau_{u}$. We take the approximation of the U.S. tax code by Heathcote, Storesletten, and Violante (2017) which implies $\tau_{s}=0.254$ and $\tau_{u}=0.180$. This implies that the indirect fiscal effect is given by

$$
d \mathscr{R}_{i n d} \in[828,1380]
$$

This is a sizeable number even if we consider the lower range of wage effects (i.e. $\sigma=2.5) .{ }^{17}$ This indicates that the indirect fiscal effect should not be ignored in policy discussions. We will now be more serious about its calculation and address various shortcomings of this simple model. First, wage effects are likely to be smaller since native labor supply (or native behavior

\footnotetext{
${ }^{14} \mathrm{~A}$ result that may be surprising, is that it is independent of the size of the native population. To understand this intuitively, consider two countries where skills are distributed in the same way, but the first country is twice as large as the second. In the first country, the wage changes of natives due to one immigrant are smaller by a factor of two - one immigrant is 'smaller' in relative terms in country 1 as compared to country 2. However, at the same time, there are twice as many natives whose tax payment is affected in country 1. Thus, the fiscal effect is the same in both economies.

${ }^{15}$ Note that the increase in tax revenue comes at the cost of native net incomes. However, in modern welfare analysis income gains of different individuals and tax revenue are not weighted equally and therefore this redistribution between individuals and the government has first-order welfare effects (Hendren, 2020), see also our discussion in Section 3.2. Additionally, when we account for endogenous labor supply of natives in the next sections, low-skilled immigration causes fiscal externalities which also have immediate welfare implications (Hendren, 2015).

${ }^{16}$ Throughout the paper, we follow Borjas (2003), Peri and Sparber (2009), and Ottaviano and Peri (2012), and define low-skilled workers as those without any college experience and define high-skilled workers as workers with at least some college experience. In Appendix C.2, we consider an alternative skill classification, in which we divide workers with some college between the two skill groups as in Katz and Murphy (1992) or Card (2009). In Section 6.3, we define worker skills by their position in the wage distribution, rather than their education.

${ }^{17} \mathrm{We}$ find $d \mathscr{R}_{\text {ind }}=\$ 1,104$ given our intermediate value for the elasticity of substitution of $\sigma=2$.
} 
more generally - they may move or change their occupation) is endogenous. Second, the production structure is simplistic in the sense that all workers of the same skill level have exactly the same productivity. Other production structures may be equally likely: e.g. even conditional on skill, natives and immigrants may be imperfect substitutes. Further, one can change the assumptions about the elasticity of capital supply (which was assumed to be infinite so far), returns to scale and perfect competition. Finally, the tax function considered here is too simplistic.

We address these issues one by one. First, in the next section, we move to what we consider our main or benchmark model. We extend the simple model by (i) allowing for a continuum of productivities (and therefore income levels) conditional on skill and (ii) accounting for endogenous labor supply of natives along the extensive and intensive margin. In Section 4, we introduce our quantification of tax-transfer system, which accounts for social security payments and welfare receipts in addition to income and payroll taxes. In Section 6, we then consider the robustness of the results for the other mentioned issues like skill-stratification, occupational choice of natives, imperfect substitutability of natives and immigrants etc.

\section{The Main Model: Heterogeneity and Endogenous Labor Supply of Natives}

We generalize the findings from the previous section in two important ways. First, we consider the so-called canonical model (Acemoglu and Autor, 2011) with two skill levels (corresponding with individuals with and without college education), and a continuous distribution of productivity for each skill level. We also allow individuals also to differ in other variables that may affect their tax payment. Second, we account for endogenous labor supply of natives along both the extensive and the intensive margin. We introduce the additional heterogeneity and show how the formula for the indirect fiscal effect in Proposition 1 extends to this setting in Section 3.1. We then extend the setting to endogenous labor supply of natives in Section 3.2.

\subsection{Incorporating Heterogeneity}

An individual is indexed by its type $i \in \mathcal{I}$. A type contains many characteristics. First, individuals differ in their skill level $e_{i} \in\{u, s\}$. Second, they differ in their productivity $\omega_{i}$. Third, they differ in terms of their tax payments: even if they have the same income, they may face a different tax schedule because of family status, living in a different state etc. Finally, different types differ in their participation rates $\nu_{i}$ and their labor supply elasticities: $\varepsilon_{i}$ is the hours elasticity, $\eta_{i}$ is the participation elasticity and $\xi_{i}=\varepsilon_{i}+\eta_{i}$ is the total hours elasticity. Denote by $L_{i}=h_{i} \nu_{i} m_{i}$ aggregate labor of type $i$, where $h_{i}$ is hours worked of type $i$ and $m_{i}$ is the measure of type $i$. We first focus on the case of exogenous labor supply of natives and therefore set $\varepsilon_{i}=\eta_{i}=0$ and $\nu_{i}=1$ for all $i$. In Section 3.2, we remove this assumption. 
Aggregate effective labor of each skill level is given by:

$$
\mathscr{L}_{e}=\int_{\mathcal{I}_{e}} L_{i} \omega_{i} d i
$$

for $e \in\{u, s\}$, where $\mathcal{I}_{u}\left(\mathcal{I}_{s}\right)$ is a subset of $\mathcal{I}$ made up of low-skilled (high-skilled) types.

The production function reads as $\mathscr{F}\left(\mathscr{L}_{u}, \mathscr{L}_{s}\right)$ and we assume constant returns to scale. Wages are equal to marginal products $\left(w_{e}=\frac{\partial \mathscr{F}}{\partial \mathscr{L}_{e}}\right)$ and aggregate income is given by $Y_{e}=w_{e} \mathscr{L}_{e}$. Hence, an individual of type $i$ has gross income $y_{i}=h_{i} \omega_{i} w_{e_{i}}$, where the latter element, the skill price $w_{e}$ is endogenous w.r.t. the skill ratio, $\frac{\mathscr{L}_{s}}{\mathscr{L}_{u}}$. We again define the own-wage elasticities $\gamma_{e, \text { own }}=\frac{d w_{e}}{d \mathscr{L}_{e}} \frac{\mathscr{L}_{e}}{w_{e}}$ and the cross-wage elasticities $\gamma_{e, \text { cross }}=\frac{d w_{e}}{d \mathscr{L}_{e^{\prime}}} \frac{\mathscr{L}_{e^{\prime}}}{w_{e}}$ with $e \neq e^{\prime}$. The following lemma generalizes the relationship between the own- and cross-wage elasticities given by Lemma 1 to this setting.

Lemma 2. The cross- and own-wage elasticities are related through:

$$
\gamma_{s, \text { cross }}=\left|\gamma_{u, \text { own }}\right| \times \frac{w_{u} \mathscr{L}_{u}}{w_{s} \mathscr{L}_{s}}
$$

Before we show how Proposition 1 extends to this setting, we need to specify the taxtransfer system. We incorporate a flexible nonlinear tax-transfer system $T(y, i)$ that maps a (potentially negative) tax payment to each level of gross income $y$ and type $i$. Proposition 1 generalizes as follows:

Proposition 2. Assume that labor supply of natives is exogenous. The fiscal effect of one immigrant of type $i$ with low education (i.e. $e_{i}=u$ ) is given by:

$$
d \mathscr{R}_{\text {ind }}^{e x}(i)=\left|\gamma_{u, o w n}\right| \times y_{i} \times\left(\bar{T}_{s}^{\prime}-\bar{T}_{u}^{\prime}\right)
$$

where $\bar{T}_{e}^{\prime}$ is the income-weighted average marginal tax rate of education group e.

Proof. See Appendix A.2.1.

The formula is very similar to the formula in Proposition 1 but there are two differences. First, we have to specify not only the education level of the immigrant but also the type $i$ and therefore the income $y_{i}$. A type with higher income $y_{i}$ supplies a greater amount of effective labor and therefore has a larger effect on native wages. Second, since there are more than two marginal tax rates in this economy, the objects of interest are the income-weighted average marginal tax rates of the two skill groups. Intuitively, wages of all college (high-school) workers increase (decrease) by the same factor. An individual with a higher income level will therefore experience a larger absolute change in earnings. To calculate the fiscal effect, the marginal tax rate of an individual with a higher income therefore receives a higher weight. 


\subsection{Incorporating Endogenous Native Labor Supply}

With endogenous labor supply, the changes in the wages for low- and high-skilled labor affect labor supply decisions along the intensive and extensive margin of workers with non-zero elasticities. The implied changes in labor supply, in turn, affect the equilibrium wages again, which then triggers a change in labor supply and so on and so forth. All these adjustment effects will imply additional fiscal effects.

To formalize this, as a first step, note that tax revenue is formally given by:

$$
\mathscr{R}=\int_{\mathcal{I}_{u}}\left(T\left(y_{i}, i\right) \nu_{i}+T(0, i)\left(1-\nu_{i}\right)\right) m_{i} d i+\int_{\mathcal{I}_{s}}\left(T\left(y_{i}, i\right) \nu_{i}+T(0, i)\left(1-\nu_{i}\right)\right) m_{i} d i
$$

where $T(0, i)$ is the effective tax paid by type $i$ if they earn zero income. The following lemma states how tax payments of natives change due to low-skilled immigration.

Lemma 3. Consider a low-skilled immigrant with effective labor supply $L^{\text {Im }}$ that implies equilibrium changes in wages of $\frac{d w_{u}}{w_{u}}$ and $\frac{d w_{s}}{w_{s}}$. The implied change in tax payment of natives is given by:

$$
\begin{aligned}
d \mathscr{R}_{\text {ind }}= & \int_{\mathcal{I}_{u}} T^{\prime}\left(y_{i}, i\right) y_{i} \frac{d w_{u}}{w_{u}}\left(1+\varepsilon_{i}\right) \nu_{i} m_{i} d i+\int_{\mathcal{I}_{s}} T^{\prime}\left(y_{i}, i\right) y_{i} \frac{d w_{s}}{w_{s}}\left(1+\varepsilon_{i}\right) \nu_{i} m_{i} d i \\
& +\int_{\mathcal{I}_{u}} T_{\text {part }}\left(y_{i}, i\right) y_{i} \frac{d w_{u}}{w_{u}} \eta_{i} \nu_{i} m_{i} d i+\int_{\mathcal{I}_{s}} T_{\text {part }}\left(y_{i}, i\right) y_{i} \frac{d w_{s}}{w_{s}} \eta_{i} \nu_{i} m_{i} d i
\end{aligned}
$$

where $T_{\text {part }}\left(y_{i}\right)=\frac{T\left(y_{i}, i\right)-T(0, i)}{y_{i}}$ is the participation tax rate of a type $i$ individual that earns $y_{i}$. Proof. See Appendix A.2.2.

In the first line, the indirect fiscal effects as described in Proposition 1 are scaled up by the intensive margin elasticities. The second line of (6) captures the change in tax revenue due to changes in labor force participation of natives. Note that the relevant tax rate here is not the marginal tax rate, but the participation tax rate. The participation tax rate captures the increase in public finances that occurs if the individual starts to work.

An important issue, however, is that the wage changes $\frac{d w_{u}}{w_{u}}$ and $\frac{d w_{s}}{w_{s}}$ are endogenous w.r.t. to the labor supply responses. To obtain an expression for these wage changes and hence obtain a closed form solution, we follow Sachs, Tsyvinski, and Werquin (2020) and formalize the associated fixed point in terms of integral equations. ${ }^{18}$ First, note that these equilibrium wage changes can be divided into the effects arising from immigrant inflows, low-skilled native labor supply responses, and high-skilled native labor supply responses as

$$
\frac{d w_{u}}{w_{u}}=\gamma_{u, \text { own }} \frac{L^{I m}}{\mathscr{L}_{u}}+\gamma_{u, \text { own }} \int_{\mathcal{I}_{u}} \frac{d L_{j}}{L_{j}} \frac{L_{j} \omega_{j}}{\mathscr{L}_{u}} d j+\gamma_{u, \text { cross }} \int_{\mathcal{I}_{s}} \frac{d L_{j}}{L_{j}} \frac{L_{j} \omega_{j}}{\mathscr{L}_{s}} d j .
$$

\footnotetext{
${ }^{18}$ Sachs, Tsyvinski, and Werquin (2020) study nonlinear tax reforms in a general equilibrium setting with endogenous labor supply and also highlight that a decrease in the skill ratio can trigger tax revenue effects in the case of progressive taxation.
} 
The first term captures the wage change induced by immigration directly since $\frac{L^{I m}}{\mathscr{L}_{u}}$ captures the relative increase in effective low-skilled labor supply due to one immigrant with effective labor $L^{I m}$. The second term captures the own-wage effects implied by the change in low-skilled aggregate labor of natives and the third term captures the cross-wage effects implied by the change in high-skilled aggregate labor. Similarly, the equilibrium wage change for high-skilled workers is given by

$$
\frac{d w_{s}}{w_{s}}=\gamma_{s, \text { cross }} \frac{L^{I m}}{\mathscr{L}_{u}}+\gamma_{s, \text { cross }} \int_{\mathcal{I}_{u}} \frac{d L_{j}}{L_{j}} \frac{L_{j} \omega_{j}}{\mathscr{L}_{u}} d j+\gamma_{s, \text { own }} \int_{\mathcal{I}_{s}} \frac{d L_{j}}{L_{j}} \frac{L_{j} \omega_{j}}{\mathscr{L}_{s}} d j
$$

How the equilibrium changes in relative wages translate into labor supply changes directly follows from the definition of labor supply elasticities. The integral equations that describes the relative change in total hours worked for low-skilled workers can therefore be written as:

$$
\forall i \in \mathcal{I}_{u}: \frac{d L_{i}}{L_{i}}=\xi_{i}\left(\gamma_{u, \text { own }} \frac{L^{I m}}{\mathscr{L}_{u}}+\gamma_{u, \text { own }} \int_{\mathcal{I}_{u}} \frac{d L_{j}}{L_{j}} \frac{L_{j} \omega_{j}}{\mathscr{L}_{u}} d j+\gamma_{u, \text { cross }} \int_{\mathcal{I}_{s}} \frac{d L_{j}}{L_{j}} \frac{L_{j} \omega_{j}}{\mathscr{L}_{s}} d j\right)
$$

The bracket on the right hand side captures the equilibrium change in the relative wage $\frac{d w_{u}}{w_{u}}$. The relative change in labor supply of type $i$ individuals is then simply given by the total hours elasticity $\xi_{i}$ multiplied with the relative wage change. Equivalently, for high-skilled labor, the integral equation reads as

$$
\forall i \in \mathcal{I}_{s}: \frac{d L_{i}}{L_{i}}=\xi_{i}\left(\gamma_{s, \text { cross }} \frac{L^{I m}}{\mathscr{L}_{u}}+\gamma_{s, \text { cross }} \int_{\mathcal{I}_{u}} \frac{d L_{j}}{L_{j}} \frac{L_{j} \omega_{j}}{\mathscr{L}_{u}} d j+\gamma_{s, \text { own }} \int_{\mathcal{I}_{s}} \frac{d L_{j}}{L_{j}} \frac{L_{j} \omega_{j}}{\mathscr{L}_{s}} d j\right)
$$

The expressions given by (9) and (10) constitute a system of integral equations. In Appendix A.2.3 we derive the following result, which relates wage changes to the immigration inflow and the weighted average of labor supply elasticities.

Lemma 4. Consider a small influx of an low-skilled immigrant with effective labor $L^{I m}$. The equilibrium changes in wages are described by

$$
\begin{aligned}
\frac{d w_{u}}{w_{u}} & =\frac{\gamma_{u, o w n}}{1+\bar{\xi}^{u}\left|\gamma_{u, o w n}\right|+\bar{\xi}^{s}\left|\gamma_{s, \text { own }}\right|} \frac{L^{I m}}{\mathscr{L}_{u}} \\
\frac{d w_{s}}{w_{s}} & =\frac{\gamma_{s, \text { cross }}}{1+\bar{\xi}^{u}\left|\gamma_{u, \text { own }}\right|+\bar{\xi}^{s}\left|\gamma_{s, \text { own }}\right|} \frac{L^{I m}}{\mathscr{L}_{u}},
\end{aligned}
$$

where $\bar{\xi}^{u}$ and $\bar{\xi}^{s}$ are the income-weighted total hours elasticities of the two skill groups. ${ }^{19}$

Proof. See Appendix A.2.3.

Note that absent native labor supply responses, an immigrant inflow leads to percentage low-skilled wage change of $\frac{d \hat{w}_{u}}{w_{u}}=\gamma_{u, \text { own }} \frac{L^{I m}}{\mathscr{L}_{u}}$ and a percentage high-skilled wage change of

${ }^{19}$ Formally, these are given by $\bar{\xi}^{e}=\frac{\int_{\mathcal{I}_{e}} y_{i}\left(\eta_{i}+\varepsilon_{i}\right) \nu_{i} m_{i} d i}{Y_{e}}$ for $e \in\{u, s\}$. 
$\frac{d \hat{w}_{s}}{w_{s}}=\gamma_{s, \text { cross }} \frac{L^{I m}}{\mathscr{L}_{u}}$. We'll refer to these wage effects without labor supply responses as "firstround effects". This lemma shows that, with labor supply responses, the changes in equilibrium wages are given by these first-round effects scaled by $\frac{1}{1+\bar{\xi}^{u}\left|\gamma_{u, o w n}\right|+\bar{\xi}^{s}\left|\gamma_{s, \text { own }}\right|}<1$, capturing how much these first-round effects are mitigated by labor supply responses. Greater labor supply responsiveness, as measured by the income-weighted total hours elasticities of the different groups, implies a larger mitigation of the first round effects. This effect plays an important role because it mitigates the indirect fiscal effects that follow from the wage changes.

However, in addition to mitigating wage effects, the labor supply changes of natives also have fiscal implications themselves. The changes in equilibrium hours, participation, and aggregate labor supply directly follow from Lemma 4 and the definition of the elasticities

$$
\forall i \in \mathcal{I}_{e}: \frac{d h_{i}}{h_{i}}=\varepsilon_{i} \frac{d w_{e}}{w_{e}}, \quad \frac{d \nu_{i}}{\nu_{i}}=\eta_{i} \frac{d w_{e}}{w_{e}}, \quad \frac{d L_{i}}{\nu_{i}}=\xi_{i} \frac{d w_{e}}{w_{e}}
$$

for $e \in\{u, s\}$ and where $\frac{d w_{e}}{w_{e}}$ is defined as in Lemma 4 .

We now combine Lemma 2, Lemma 4 , and these equilibrium labor supply changes to rewrite the expression in Lemma 3 and obtain our main result.

Proposition 3. The indirect fiscal effect of a low-skilled immigrant of type $i$ is given by:

$$
d \mathscr{R}_{i n d}(i)=\frac{y_{i} \times\left|\gamma_{u, o w n}\right|}{1+\bar{\xi}^{u}\left|\gamma_{u, o w n}\right|+\bar{\xi}^{s}\left|\gamma_{s, o w n}\right|}\left(\bar{T}_{s}^{\prime}-\bar{T}_{u}^{\prime}+\overline{\varepsilon_{s} T_{s}^{\prime}}-\overline{\varepsilon_{u} T^{\prime}{ }_{u}}+\overline{\eta_{s} T_{\text {part }, s}}-\overline{\eta_{u} T_{\text {part }, u}}\right)
$$

where

$$
\overline{\eta_{e} T_{\text {part }, e}}=\frac{\int_{\mathcal{I}_{e}} T_{\text {part }}\left(y_{i}, i\right) y_{i} \eta_{i} \nu_{i} m_{i} d i}{Y_{e}}
$$

is the income-weighted average of the product of the participation tax rate and the participation elasticity of education group $e$ and

$$
\overline{\varepsilon_{e} T_{e}^{\prime}}=\frac{\int_{\mathcal{I}_{e}} T^{\prime}\left(y_{i}, i\right) y_{i} \varepsilon_{i} \nu_{i} m_{i} d i}{Y_{e}}
$$

is the income-weighted average of the product of of the marginal tax rate and the hours elasticity of education group e.

Proof. See Appendix A.2.4.

How does this formula differ from that in Proposition 2? First of all the indirect fiscal effect is scaled down by $\frac{1}{1+\bar{\xi}^{u}\left|\gamma_{u, o w n}\right|+\bar{\xi}^{s}\left|\gamma_{s, \text { own }}\right|}$ since the wage effects are mitigated. Second, in addition to the difference of the income-weighted marginal tax rates $\bar{T}_{s}^{\prime}-\bar{T}_{u}^{\prime}$, the formula accounts for the fiscal effects caused by native labor supply responses, which can be thought of as fiscal externalities. The term $\overline{\varepsilon_{s} T_{s}^{\prime}}$ captures that high-skilled natives increase their hours worked and pay more taxes while $\overline{\varepsilon_{u} T^{\prime}}{ }_{u}$ captures that low-skilled natives decrease their hours worked 
and pay less taxes. The term $\overline{\eta_{s} T_{\text {part }, s}}\left(\overline{\eta_{u} T_{\text {part }, u}}\right)$ captures the increase (decrease) in labor force participation of high-skilled (low-skilled).

We can decompose the indirect fiscal effect into the effect arising from differences in relative wages and the fiscal externalities as

$$
d \mathscr{R}_{\text {ind }}(i)=\text { RelWages }(i)+\text { FiscExternalities }(i)
$$

where

$$
\operatorname{RelWages}(i)=\frac{y_{i} \times\left|\gamma_{u, \text { own }}\right|}{1+\bar{\xi}^{u}\left|\gamma_{u, \text { own }}\right|+\bar{\xi}^{s}\left|\gamma_{s, \text { own }}\right|}\left(\overline{T^{\prime}}-\overline{T_{u}^{\prime}}\right)
$$

and

$$
\operatorname{FiscExternalities}(i)=\frac{y_{i} \times\left|\gamma_{u, \text { own }}\right|}{1+\bar{\xi}^{u}\left|\gamma_{u, \text { own }}\right|+\bar{\xi}^{s}\left|\gamma_{s, \text { own }}\right|}\left(\overline{\varepsilon_{s} T_{s}^{\prime}}-\overline{\varepsilon_{u} T_{u}^{\prime}}+\overline{\eta_{s} T_{\text {part }, s}}-\overline{\eta_{u} T_{\text {part }, u}}\right)
$$

These fiscal externalities have different welfare implications than the indirect fiscal effects that come from changes in relative wages holding labor supply fixed in that they capture efficiency gains for the natives. We now describe this in greater detail.

\subsection{Welfare Effects and Immigration Surplus}

While the focus of this paper lies on enriching the estimation of fiscal effects of low-skilled immigration, we now briefly describe how the indirect fiscal effect affects the overall picture of welfare.

Immigration Surplus - Kaldor-Hicks compensation test We first consider the concept of the immigration surplus which is an application of the Kaldor-Hicks compensation test (Kaldor, 1939; Hicks, 1939, 1940) and is a leading approach to study welfare in the immigration literature (see e.g. Borjas (2014)). The immigration surplus measures whether the natives hurt by immigration could hypothetically be compensated by those who benefit and is given by the sum of government revenue and the monetized gains and losses of all the natives in the economy. ${ }^{20}$ The following proposition shows how this concept extends to our setting.

Proposition 4. The Kaldor-Hicks surplus accruing to natives for one low-skilled immigrant of type $i$ is given by:

$$
\operatorname{Surplus}_{\text {Kaldor-Hicks }}(i)=d \mathscr{R}_{\text {dir }}(i)+\text { FiscExternalities }(i),
$$

\footnotetext{
${ }^{20}$ Importantly, these welfare calculation do not account for the welfare gains of the immigrants themselves. The welfare gains of low-skilled immigrants are likely to be very large, given that low-skilled immigrants experience massive income gains after moving to the United States (Hendricks and Schoellman, 2018).
} 
where $d \mathscr{R}_{\text {dir }}(i)$ is the direct fiscal effect and FiscExternalities $(i)$ is the fiscal externality as defined by (11).

Proof. See Appendix A.2.5.

The Kaldor-Hicks immigration surplus is simply given by the direct fiscal effect plus the fiscal externality. The fact that this surplus is non-zero beyond the direct fiscal effect is novel. Note that the fiscal externality term would be zero if (i) labor supply of natives were exogenous or (ii) the tax system were proportional and labor supply elasticities were common between low- and high-skilled workers. The endogeneity of labor supply combined with the progressivity of the tax system jointly imply a non-zero surplus beyond the direct fiscal effect: while the labor supply responses do not directly affect native welfare due to the envelope theorem, they affect native welfare through their implied indirect fiscal effects.

Inverse Optimum Weights as in Hendren (2020) Given that compensation may entail efficiency costs, the Kaldor-Hicks surplus gives an incomplete picture. Hendren (2020) extends the Kaldor-Hicks surplus to account for distortionary costs of compensation. He shows that this can be achieved by weighting the gains and losses of individuals with so-called inverse optimum weights from the optimal tax literature. ${ }^{21}$ Concretely, the gain (or loss) of an individual with income $y$ has to be weighted by $g(y)$ in the surplus calculation, where $g(y)$ is the weight that the government has implicitly used when designing the tax schedule. These weights are normalized such that on average they are equal to one and one is the weight on government revenue. We apply his extension here to the immigration surplus.

Proposition 5. The weighted surplus accruing to natives for one low-skilled immigrant is given by:

$$
\operatorname{Surplus}_{\text {weighted }}(i)=\operatorname{Surplus}_{\text {Kaldor-Hicks }}(i)+\operatorname{Distributional}(i),
$$

where

$$
\operatorname{Distributional}(i)=\frac{y_{i} \times\left|\gamma_{u, \text { own }}\right|}{1+\bar{\xi}^{u}\left|\gamma_{u, \text { own }}\right|+\bar{\xi}^{s}\left|\gamma_{s, \text { own }}\right|} \times\left(\overline{g_{s}\left(1-T_{s}^{\prime}\right)}-\overline{g_{u}\left(1-T_{u}^{\prime}\right)}+\bar{T}_{s}^{\prime}-\bar{T}_{u}^{\prime}\right)
$$

and where $\overline{g_{e}\left(1-T_{e}^{\prime}\right)}$ is the income-weighted average of the product of the welfare weights and $\left(1-T^{\prime}\right)$ conditional on skill $e$.

Proof. See Appendix A.2.5.

The terms $\overline{g_{s}\left(1-T_{s}^{\prime}\right)}-\overline{g_{u}\left(1-T_{u}^{\prime}\right)}+\bar{T}_{s}^{\prime}-\bar{T}_{u}^{\prime}$ capture the mechanical distributional effects between natives and the government. If $g(y)=1$ for all $y$, these terms sum to zero because each

\footnotetext{
${ }^{21}$ Going one step further, Tsyvinski and Werquin (2019) generalize the compensation principle to a setting where distortive taxes also imply general equilibrium effects on wages, which creates a complicated fixed-point problem. The authors analytically describe the tax reform that achieves compensation in such a setting.
} 
dollar would be valued equally regardless of whether it accrues to high-skilled natives, lowskilled natives or to the government. However, if the government cannot costlessly redistribute income between individuals, these weights may not be constant. For the U.S., Hendren (2020) calibrates a weight function $g(y)$ which is generally decreasing in income and thus gives higher weight to low-skilled than high-skilled individuals. For such weights, even if we ignore taxes and endogenous labor supply, the immigration surplus beyond the direct fiscal effect is not equal to zero because the income losses of low-skilled receive a higher weight than the income gains of high-skilled thus capturing that the compensation of the low-skilled would imply efficiency costs. ${ }^{22}$

\section{Empirical Quantification}

To quantify the formula of Proposition 3, we need earnings distributions conditional on education. Further, we need to know marginal and participation tax rates as well as labor supply elasticities along the earnings distributions. Note that even conditional on education and income, there is a distribution of tax rates and elasticities since family status, age, location, etc. are also determinants of an individual's tax burden and labor supply elasticity. Finally, we need a value for the own-wage elasticity of low-skilled wages. ${ }^{23}$

In Section 4.1, we make assumptions on parameters such as labor supply elasticities for different groups and wage elasticities. The calibrated values are based on existing empirical evidence.

Regarding the values of marginal and participation tax rates, we conduct our own empirical analysis. ${ }^{24}$ To obtain our sample of natives, we use data from the American Community Survey (ACS). To assign effective marginal and participation tax rates to all individuals in the sample, we make use of NBER's TAXSIM. However, TAXSIM does not account for the effective tax rates that are implied by welfare-transfer programs. Programs like the Supplementary Nutrition Assistance Program (SNAP) or Temporary Assistance for Needy Families (TANF) imply an increase in effective marginal tax rates since transfers are phased out as income increases. To account for this, we use data from the Survey of Income and Program Participation (SIPP). With the SIPP, we estimate effective transfer phase-out rates conditional on household size and income. Another important detail that is not captured in TAXSIM is

\footnotetext{
${ }^{22}$ This also captures the point that (Borjas, 2016b, p.191) makes: "Although the mythical average person may be unaffected, immigration creates many winners and losers. [...] immigration turns out to be just another government redistribution program."

${ }^{23}$ The raw data and code necessary to calculate effective marginal tax rates for all individuals in the ACS, calculate the income-weight effective tax rates, and calculate the main results in Table 3 are available for download at https://sites.google.com/site/markyaucolas/research.

${ }^{24}$ The Congressional Budget Office estimates effective marginal tax rates for low- and medium- income workers in the U.S. (Congressional Budget Office, 2015). We cannot use their estimates directly as they only provide the median, 10th and 90th percentile of marginal tax rates for different income groups. Further their calculations do not include workers with income over $450 \%$ of the Federal Poverty Line and do not account for TANF of SSI payments.
} 
that the payroll tax is not a pure tax because higher earnings imply not only higher taxes but also higher benefits when retired (see e.g. Feldstein and Samwick (1992)). Accounting for this requires estimates of individuals' life-cycle earnings, which determine how current income affects future social security benefits. To predict the life-cycle earnings paths of the individuals in our sample, we make use of panel data from the NLSY79. We describe all the sample selection in Section 4.2 and the effective tax rate calibration in Section 4.3. ${ }^{25}$

\subsection{Calibrated Parameters}

Wage Elasticities The own-wage elasticity of low-skilled labor can also be written as

$$
\gamma_{u, \text { own }}=-\frac{1}{\sigma} \kappa_{s}
$$

where $\sigma$ is the elasticity of substitution between high-skilled and low-skilled individuals and $\kappa_{s}$ is the income share of high-skilled labor, which we estimate as $\kappa_{s}=.79$, using our ACS sample (see description in the next section). For $\sigma$, Card (2009) concludes that values are likely to be between 1.5 and 2.5, which implies own-wage elasticities ranging from -.51 ( $\sigma=1.5)$ to -.31 $(\sigma=2.5)$ for these two polar cases. ${ }^{26}$ The own-wage elasticity of high-skilled labor is given by

$$
\gamma_{s, \text { own }}=-\frac{1}{\sigma} \kappa_{u}
$$

where $\kappa_{u}$ is the income share of low-skilled labor. For our range of values for $\sigma$, this implies own-wage elasticity for high-skilled workers ranging from -.14 $(\sigma=1.5)$ to -.08 $(\sigma=2.5)$.

Labor Supply Elasticities A number of papers emphasize that labor supply elasticities differ across genders, marital statuses, and income levels but few papers have actually estimated these elasticities across the income distribution for both genders. We therefore employ three different approaches to calibrate our labor supply elasticities. As a first pass, we assume all individuals have common intensive and extensive labor supply elasticities. Specifically, we set the intensive margin elasticity of $\varepsilon_{i}=.33$ and an extensive margin elasticity of $\eta_{i}=.25$, for all individuals $i$, based on the pooled estimates in Chetty (2012). ${ }^{27}$ Next, we allow labor supply elasticities to vary by gender and marital status. We use estimates of gender and

\footnotetext{
${ }^{25}$ Our quantification could be extended to account for the taxation of interest and pension income, estate taxes and government sponsored healthcare for natives. Accounting for income and pension income and estate taxes would likely lead to larger indirect fiscal effects, given higher savings rates of high-skilled individuals and the progressivity of estate taxes. Accounting for government sponsored heathcare for natives would lead to smaller indirect fiscal effects as Medicaid and the Affordable Care Act subsidies are means tested.

${ }^{26}$ Katz and Murphy (1992), for example, find an elasticity of substitution of 1.4. Card and Lemieux (2001) estimate an elasticity of substitution between 1.15 and 1.6 in their pooled sample of men and women.

${ }^{27}$ In fact, these numbers of Chetty (2012) refer to compensated, Hicksian elasticities while the elasticities in our formulas are uncompensated elasticities. As argued e.g. by Chetty et al. (2013), uncompensated elasticities are likely to be only slightly smaller than compensated elastiticies as microeconometric evidence shows income effects are small. Accounting for this would push our results below in Table 3 with endogenous labor supply closer to the values with exogenous labor supply in the same table.
} 
marital status specific intensive and extensive labor supply elasticities from Bargain, Orsini, and Peichl (2014), who estimate a discrete choice model to estimate elasticities. Finally, we consider the scenario in which labor supply elasticities can vary by gender, age, and income. For this we use estimates of intensive and extensive labor supply elasticities by gender, marital status and quintile of the income distribution from Bargain, Orsini, and Peichl (2014). ${ }^{28}$

Other parameters. We assume that agents start receiving social security at age 66 . We assume the real discount rate for the government to be $1 \% .{ }^{29}$ Finally, the formula in Proposition 3 shows that the income of the immigrants also plays a role beyond the education status. Since the exact income of an immigrant is not foreseeable before an immigrant has entered the country, we consider the case of taking expected immigrant income as reasonable. Using again data from the ACS, we find that the average annual gross income of an low-skilled immigrant worker in our sample is $\$ 30,317$. We also consider the indirect fiscal effects of high school dropout immigrants and high school graduate immigrants, who have average incomes of $\$ 25,861$ and $\$ 33,442$, respectively.

\subsection{Data and Sample}

ACS Our main data source is the 2017 ACS, which includes information on income and demographics for a nationally representative sample of $1 \%$ of the U.S. population. As is standard, we focus on individuals between 18 and 65 years old and eliminate individuals living in group quarters. In order to ensure that we can accurately determine an individual's tax-filing status, we limit our sample to heads of households and their spouses. This leaves us with a sample of over 1.2 million individuals. ${ }^{30}$ We utilize data on each individual's earnings, income from other sources, marital status, age, location, number and ages of children, and age and income of the individual's spouse, all of which determine an individual's tax liability and eligibility for various tax credits and deductions. ${ }^{31}$ We also utilize data on each individual's education, which we use to determine an individual's skill group. An important choice is how to define these skill groups. For this, we follow Borjas (2003), Peri and Sparber (2009),

\footnotetext{
${ }^{28}$ The intensive and extensive labor supply elasticities from Bargain, Orsini, and Peichl (2014) are reported in Appendix B.4. We choose to utilize the labor supply estimates from Bargain, Orsini, and Peichl (2014) because they estimate gender and income specific intensive and extensive margin elasticities using a common estimation procedure. Our results are robust to using estimates on extensive labor supply elasticities by wage percentile from Juhn, Murphy, and Topel (2002), who estimate extensive margin elasticities using a sample of U.S. men.

${ }^{29}$ The real interest rate on 30 year bonds was on average 0.99 (0.81) in the last ten (five) years. See https: // home.treasury.gov/policy-issues/financing-the-government/interest-rate-statistics. We show our main results under the assumption of a $2 \%$ interest rate in Appendix C.1

${ }^{30}$ Additional details on sample selection in the ACS are included in Appendix B.1.

${ }^{31}$ Top wage incomes are underrepresented in most survey data sets. We therefore append Pareto tails to the wage income distribution, starting at the highest wage income value that is not top-coded in each state, as is relatively common practice in the optimal tax literature (Piketty and Saez, 2013). We assume a shape parameter of $\alpha=1.5$.
} 
and Ottaviano and Peri (2012), and define low-skilled workers as those without any college experience and define high-skilled workers as workers with at least some college experience. ${ }^{32}$

Figure 1 shows the density of individual earnings for high-skilled and low-skilled workers given our baseline definition of skills. Overall, low-skilled individuals have average earnings of $\$ 35,600$ while high-skilled individuals have average earnings of $\$ 65,800$.

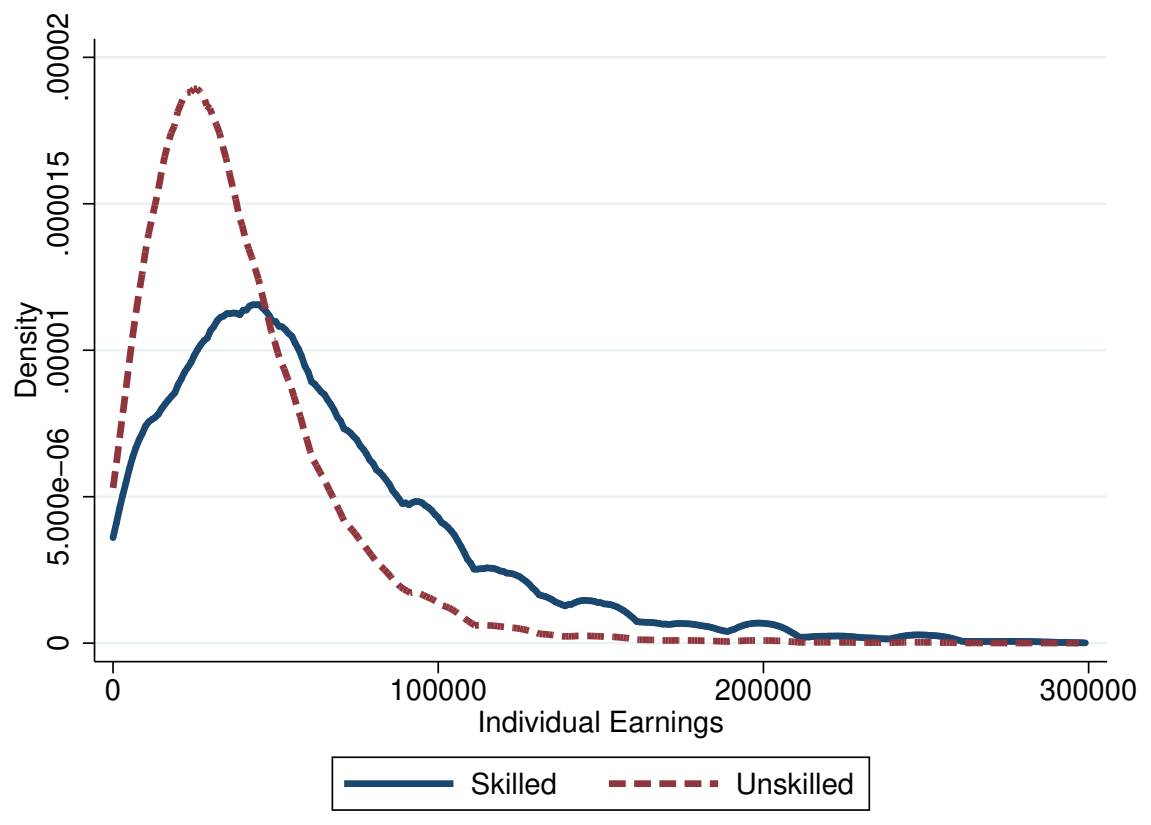

Figure 1: Kernel density plot of individual earnings for low-skilled and high-skilled individuals in our sample conditional on having positive earnings. We truncate the graph at income of $\$ 300,000$. We define low-skilled individuals as those without any college experience and define high-skilled individuals as workers with at least some college experience.

SIPP We also incorporate data from the SIPP, a nationally representative sample with detailed data on respondents' participation in income transfer programs, thereby allowing us to understand how benefits receipt varies across the earnings distribution. In particular, we utilize data from waves 1-4 of the 2014 SIPP, which includes monthly data on approximately 53,000 households from 2013 to 2016. From this dataset, we utilize data on household size, household earnings, and receipt of TANF and SNAP benefits over the year. We convert all monetary values to 2017 dollars.

One issue is that benefit receipts are generally underreported in household surveys, including the SIPP (Meyer, Mok, and Sullivan, 2015). To deal with this, we utilize data from the U.S. Bureau of Economic Analysis' National Income and Product Accounts (NIPA) tables, which report annual government spending on various U.S. programs. We multiply benefit receipt

\footnotetext{
${ }^{32}$ An alternative approach to defining skills, employed by Katz and Murphy (1992) and Card (2009), is to divide workers with some college between the two skill groups. We consider this skill classification in Appendix C.2.
} 
amounts in the SIPP by a multiplicative constant such that the total population-weighted benefit receipts in the SIPP are consistent with the aggregates from the NIPA tables. ${ }^{33}$

NLSY79 Our final data source is the NLSY79, a nationally representative panel dataset with data on over 12,000 individuals. Respondents were first interviewed in the year 1979, when respondents were between ages 14 and 22. The panel structure of the NLSY79 allows us to observe an individual's earnings over their life cycle, which determines an individual's social security benefit after retirement. Since we need data on as much of an individual's work history as possible, we drop from our sample individuals who drop out of the survey before age $50 .{ }^{34}$ In addition to data on earnings, we utilize data on education, gender, marital status, age, and number of children over the life cycle. We use these variables to map estimates of earnings over the life cycle to individuals in the ACS.

\subsection{Tax-Transfer System}

Income Taxes and the EITC. To calculate marginal income and payroll tax rates, we use NBER's TAXSIM, a tax calculator that replicates the federal and state tax codes in a given year, accounting for differential tax schedules and tax deductions and credits afforded by various demographic groups, e.g. by marital status or number of dependents. Specifically, we begin by calculating the total income for each household head and their spouse for all households in the ACS. We then use TAXSIM to calculate the marginal income and payroll taxes for each individual, taking into account the individual's marital status (which determines filing status), number of children (a determinant in personal exemptions), age of children (a determinant in eligibility of the Dependent Care Credit, the Child Credit, and the Earned Income Tax Credit), location (which determines state income tax schedules), and age of the household head and spouse (which determine eligibility for various deductions and exemptions).

The solid blue line in Panel (a) of Figure 2 shows the average marginal tax rate arising from federal and state income taxes as a function of individual labor income. Panel (b) shows the same relationship for participation tax rates. As can be seen both are increasing in income, reflecting the progressivity of federal income tax schedule.

Rows 1-2 of Table 2 give the income-weighted average marginal federal and state income taxes for high-skilled and low-skilled workers. Consistent with the progressivity of these taxes,

\footnotetext{
${ }^{33}$ Specifically, we utilize data from NIPA Table 3.12. We multiply SNAP benefits in the SIPP by a constant such they are consistent with SNAP benefits from this table and multiple TANF benefits in the SIPP by a constant such they are consistent with "Family assistance" benefits from this table multiplied by the fraction of TANF benefits which are spend on basic assistance.

${ }^{34}$ There are two complications in the NLSY that we need to deal with. First, we must deal with the fact that individuals are only interviewed on even numbered years after 1994. We therefore assume that data in odd numbered years post 1994 is the same as in the previous year. Further, in 2016, the last year from which data are available, respondents are between age 53 and 60 . We therefore do not have income information for the last few years of individual's working lives. We therefore assume that income for the remainder of the working life is equal to a respondent's last observed income.
} 


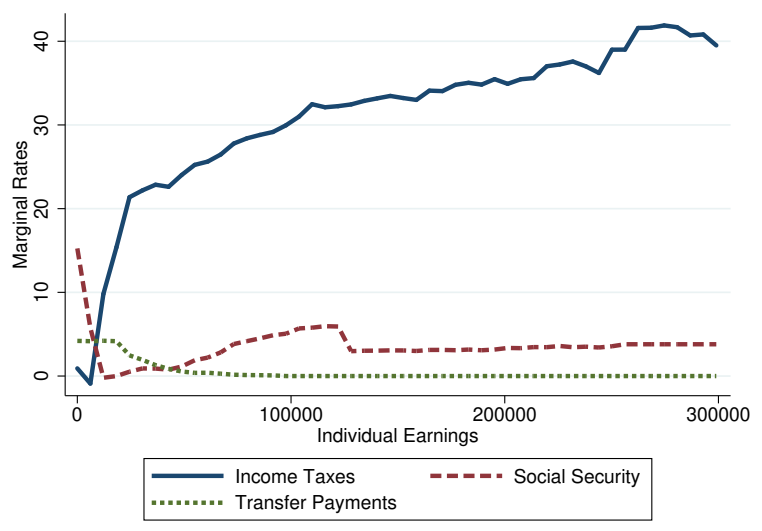

(a) Marginal Taxes

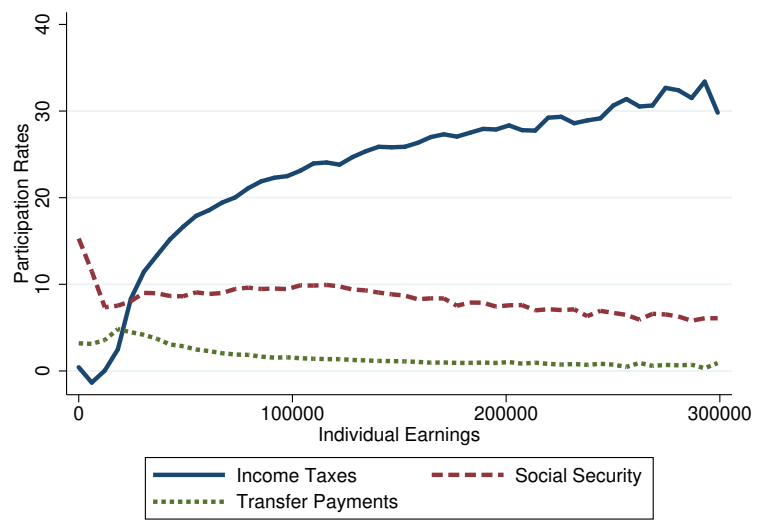

(b) Participation Taxes

Figure 2: Marginal and participation tax rates by individual earnings. Panel (a) gives the marginal effective tax rates implied by income taxes, the social security system, and transfer programs. Panel (b) reports the participation tax rates implied by income taxes, the social security system, and transfer programs. Income taxes here are the sum of state and federal income taxes, social security is defined as payroll taxes minus the discounted sum of future social security benefits, and transfer payments are the sum of TANF and SNAP phase outs.

\begin{tabular}{lrr}
\hline Object & Skilled & Unskilled \\
\hline Taxes & & \\
$\quad$ Federal Income Tax & 27.3 & 20.4 \\
$\quad$ State Income Tax & 4.9 & 4.1 \\
Transfers & & \\
$\quad$ Food stamps (SNAP) & 0.3 & 1.1 \\
$\quad$ Welfare (TANF) & 0.0 & 0.1 \\
Social Security & & \\
$\quad$ Payroll Tax & 10.4 & 13.9 \\
$\quad$ SSI Payments & -7.0 & -11.9 \\
\hline Total & 35.9 & 27.7 \\
\hline
\end{tabular}

Table 2: Estimates of income weighted effective marginal tax rates. Each entry shows the income weighted average marginal tax rates arising from each source of effective tax rates in our sample of ACS data. See text for details.

we find marginal federal income tax rates of $27.3 \%$ for high-skilled workers and $20.4 \%$ for lowskilled workers. State income tax systems are less progressive. We find marginal state income tax rates of $4.9 \%$ and $4.1 \%$ for high- and low-skilled workers, respectively.

Welfare Programs. SNAP benefits are declining in income; in the phase-out region of the SNAP benefit schedule, a dollar increase in monthly income is associated with a 24 cent reduction in monthly SNAP benefits. Similarly, TANF benefits are determined as a function of income, though the formula differs by state. However, take-up of these programs are far from 100\% (Currie, 2006), and therefore the implied changes in the effective tax rates are less than these statutory values suggest. Therefore, in order to estimate SNAP and TANF benefits as a function income, while taking into account differences in eligibility and take-up across 
households, we estimate realized benefits as a function of income and household characteristics using data from the SIPP. Details on the procedure can be found in Appendix B.2.

The dashed green line in the left of Figure 2 gives the marginal phase-out rate of social transfers, where social transfers are given by the sum of TANF and SNAP benefits. We can see that the marginal phase-out rate of transfer payments is positive but small for low levels of income before approaching 0 for higher income levels. ${ }^{35}$ The dashed green line in the right panel of Figure 2 gives the social transfer phase-out associated with labor force participation, which is also small and mostly decreasing as a function of income.

The income-weighted average marginal SNAP and TANF phase-out rates are shown in rows 3 and 4 in Table 2. The estimates of the average marginal phase-out rates of SNAP are small, at $0.3 \%$ for high-skilled workers and $1.1 \%$ for low-skilled workers. This might seem surprising, given that the phase out rate of SNAP for those who receive SNAP as a function of income is quite large. However, the relevant statistic for the marginal effect of immigration is the average income-weighted marginal benefit. To better see this, consider the average income weighted phase-out rate of SNAP for households with four members. As with other demographic groups, the phase-out rate for those on SNAP is $24 \%$. However, given that take-up is less than $100 \%$, we estimate an average phase-out rate of only $15 \%$ for households whose income places them in the phase-out region of the SNAP formula. Among four-member households, only households with gross monthly income below $\$ 2,633$ were eligible for SNAP. Therefore, only a fraction of households are eligible for SNAP and these households therefore receive little weight when calculating the income weighted marginal phase-out rates. ${ }^{36}$

The estimates for TANF are even smaller - the average income weighted TANF benefits $0.1 \%$ for low-skilled workers and less than that for high-skilled workers. As with SNAP, TANF recipients have low incomes and therefore receive little weight in the average marginal phaseout calculations. Furthermore, only 2.5 million individuals received TANF in the average month in 2017. ${ }^{37}$ Therefore, while the marginal phase-out rates of TANF and SNAP for a given individual can potentially be large, the income-weighted averages are quite small.

Social Security. Finally, our calculation of effective marginal tax rates includes social security benefits and payroll taxes. Payroll taxes are mostly decreasing with income; payroll taxes

\footnotetext{
${ }^{35}$ The fact that the phase-out rate is so low reflects the facts that 1) take-up of TANF and SNAP is less than $100 \%$ and 2) the plot shows the phase-out as a function of individual's earnings, holding spouses earnings constant. Regarding 1), one reason could be that individuals "bank" their eligibility for the future since there are are time limits in most states (Low, Meghir, Pistaferri, and Voena, 2018). Regarding 2): as TANF and SNAP eligibility are generally determined by household income, many individuals would not be eligible for these benefits even if their individual income dropped to 0 .

${ }^{36}$ To get a better sense of the magnitude, note that $21.5 \%$ of individuals belonging to four-member households have an average monthly income less than $\$ 2,633$. Further, the average household income conditional on being above this threshold is over 7 times higher than the average household income conditional on being below this threshold. This implies that the average income weighted phase-out rate of households with four members is well under $1 \%$. A back of the envelope calculation yields an income weighted average of $15 \% \times 0.215 \times \frac{1}{8}+0 \% \times 0.785 \times \frac{7}{8} \approx .40 \%$

${ }^{37}$ Source: https://www.acf.hhs.gov/sites/default/files/ofa/2017_recipient_tan.pdf
} 
have a constant marginal tax rate of $15.3 \%$ until the maximum taxable earnings threshold after which the marginal rate drops to $2.9 \% .^{38}$

However, payroll taxes are not a pure tax because higher earnings are also associated with higher social security benefits after retirement. More specifically, an individual's social security benefits are calculated as an increasing function of the individual's average indexed monthly earnings (AIME), the average monthly earnings over the individual's 35 highest earnings years of their career, adjusted for overall growth in the economy over time. Therefore, if current year earnings are one of the individuals 35 highest earning years, an increase in current earnings can increase an individual's AIME and lead to a larger benefits payment after the individual retires. As these social security payments will be received in the future, the relevant calculation for our purposes is the discounted sum of the benefits.

In order to calculate how current income affects an individual's social security benefits, we need to know their AIME and their 35th highest year of earnings, which determines whether current income enters the AIME calculation. These cannot be observed directly in the ACS, which only contains data on an individual's current income. We therefore first compute these objects for each individual in our NLSY79 sample. We then impute an AIME and 35th highest earning year for individuals in the ACS using similar individuals in the NLSY79. ${ }^{39}$ The AIME is then used to determine the marginal rate of benefits associated with earnings and the 35th highest year of earnings is used to determine if current earnings will affect the individual's AIME. Details on this procedure can be found in Appendix B.3. Finally, a crucial element of this calculation is an individual's life expectancy, which determines how many years the individual receives benefits. To calculate life expectancy, we use estimates of life expectancy conditional on income from Chetty et al. (2016), who estimate life expectancy for household income percentiles using data from 1.4 billion tax and social security death records. ${ }^{40}$

The dotted green line in the two panels of Figure 2 display the marginal tax rates and participation tax rates associated with the social security system, which we define as payroll taxes minus the marginal replacement rates. ${ }^{41}$ At very low incomes, both marginal and participation tax rates are very high. This occurs because very low income levels are unlikely to be one of an individual's 35 highest earning years, and therefore do not increase their future social security benefits. Eventually, the social security tax begins to increase with income, as higher earnings imply higher social security benefits post-retirement. At the maximum taxable earnings threshold of $\$ 127,200$, the payroll tax drops precipitously, leading to a drop in the

\footnotetext{
${ }^{38}$ The maximum taxable earnings threshold was $\$ 127,200$ in the year 2017 . At higher income levels, individuals must pay an Additional Medicare Tax, which increases the marginal tax rate by an additional $0.9 \%$.

${ }^{39}$ More specifically, we calculate the mean AIME and 35th highest year of the earnings by gender, marital status, education, age, and position in the income distribution for individuals in the NLSY79. We assign individuals in the ACS their corresponding group mean of AIME and 35th highest earning year.

${ }^{40}$ We calculate each individuals household's income percentile within their age. We then use the gender specific life expectancy associated with this income percentile.

${ }^{41}$ Note that payroll taxes also fund other programs, such as Medicare, in addition to Social Security.
} 
marginal effective tax associated with social security. ${ }^{42}$ The social security participation tax rate exhibits a kink, rather than a drop, at the maximum taxable earnings threshold, because individuals still pay payroll taxes on earnings up to this threshold.

The 5th and 6th rows of Table 2 give the income weighted average payroll tax rates and marginal discounted replacement rates. We find a higher marginal rate for low-skilled workers than high-skilled workers, at $13.9 \%$ for low-skilled workers and $10.4 \%$ for high-skilled workers, reflecting that payroll taxes drop dramatically at the maximum taxable earnings threshold. We estimate an income weighted marginal social security replacement rate of $11.9 \%$ for lowskilled workers and $7.0 \%$ for high-skilled workers, reflecting that marginal benefits rates are decreasing in AIME. Taken together, this implies an income weighted average effective social security tax of $2.0 \%$ for low-skilled and $3.4 \%$ for high-skilled workers.

The final row of Table 2 displays $\bar{T}_{s}^{\prime}$ and $\bar{T}_{u}^{\prime}$, the income-weighted effective marginal tax rates, as the sum of these elements. We obtain $\bar{T}_{u}^{\prime}=27.7 \%$ for low-skilled workers and $\bar{T}_{s}^{\prime}=35.9 \%$ for high-skilled workers, implying a difference in marginal tax rates of $8.2 \%$.

\section{Results}

Table 3 displays estimates for the indirect fiscal effect of the average low-skilled immigrant under different assumptions on the elasticity of substitution between workers and labor supply elasticities. The three columns show the indirect fiscal effect under different assumptions of the elasticity of substitution, ranging from $\sigma=1.5$ to $\sigma=2.5$. Each row displays the results for different assumptions about the labor supply elasticity.

In Panel I, we display the indirect fiscal effect with exogenous labor supply, based on Proposition 2. We find indirect fiscal benefits of $\$ 1,299(\sigma=1.5), \$ 975(\sigma=2)$, and $\$ 780$ $(\sigma=2.5) .43$

Next, in Panel II, we calculate the indirect fiscal effects when we allow for intensive, but not extensive, margin adjustments. In all three scenarios, allowing for intensive margin adjustments increases the indirect fiscal effect of low-skilled immigration. Panel III calculates the indirect fiscal effects with extensive, but without intensive margin labor supply adjustments. When elasticities are common or only vary by gender and marital status, the indirect fiscal effect is larger than the case with no labor supply responses. However, when extensive margin elasticities can vary by income, gender and marital status, the indirect effect decreases slightly because extensive margin elasticities are generally decreasing in income.

Finally, Panel IV displays the results with both intensive and extensive labor supply adjustments. When labor supply elasticities are common across gender, marital status and income, we find indirect fiscal benefits of $\$ 1,471(\sigma=1.5), \$ 1,186(\sigma=2)$, and $\$ 993(\sigma=2.5)$.

\footnotetext{
${ }^{42}$ After this threshold, the marginal tax rate is mostly flat, reflecting that further income increases do not count for social security purposes.

${ }^{43}$ These results are slightly smaller than those in Section 2 because the model in that section multiplies tax differences by the income of the average low-skilled worker, not the average low-skilled immigrant.
} 


\begin{tabular}{lrrr}
\hline & \multicolumn{3}{c}{ Elasticity of Substitution } \\
\cline { 2 - 4 } & 1.5 & 2.0 & 2.5 \\
\hline I. No Labor Supply Responses & 1,299 & 975 & 780 \\
II. Intensive Only & & \\
$\quad$ Common Elasticity & 1,417 & 1,113 & 916 \\
$\quad$ By Gender and Marital Status & 1,303 & 979 & 784 \\
$\quad$ By Income, Gender and Marital Status & 1,347 & 1,015 & 815 \\
III. Extensive Only & & & \\
$\quad$ Common Elasticity & 1,380 & 1,074 & 878 \\
$\quad$ By Gender and Marital Status & 1,335 & 1,020 & 826 \\
$\quad$ By Income, Gender and Marital Status & 1,268 & 965 & 779 \\
IV. Intensive and Extensive & & & \\
$\quad$ Common Elasticity & 1,471 & 1,186 & 993 \\
$\quad$ By Gender and Marital Status & 1,339 & 1,025 & 830 \\
By Income, Gender and Marital Status & 1,313 & 1,004 & 813 \\
\hline
\end{tabular}

Table 3: Indirect Fiscal Effects of low-skilled immigrants with intensive and extensive margin labor supply responses. The three columns show the indirect fiscal effect under different assumptions of the elasticity of substitution, ranging from $\sigma=1.5$ to $\sigma=2.5$. Each row displays the indirect fiscal effect for different assumptions about the labor supply elasticity.

Tables 13 and 14 in Appendix C.3 repeat the analysis for the average high school dropout immigrant and the average high school graduate immigrant. From (3) we can see that the income of the immigrant only enters as a multiplicative constant, therefore, the indirect fiscal effects associated with high school dropouts (graduates) can easily be calculated by multiplying the effects in Table 3 by the ratio of income of the immigrant high school dropouts (graduates) over the income of all low-skilled immigrants. As such, the indirect fiscal effects for high school dropouts are roughly 15\% smaller than those for all low-skilled immigrants and range from $\$ 660$ to $\$ 1,220$ while the indirect fiscal effects for high school graduates are roughly $10 \%$ larger than those for all low-skilled immigrants and range from $\$ 860$ to $\$ 1,620$.

Relation to Direct Fiscal Effects We now relate our results about the indirect fiscal effects to the direct fiscal effects of the report by the National Academy of Sciences (2017).

Our approach is as follows: we first consider the lifetime direct fiscal effect of a low-skilled immigrant who arrives at age 23 and lives until the age of 79 . We choose 23 since this is the median age of arrival for low-skilled immigrants in the ACS and we chose 79 years because the life expectancy at age 23 in the U.S. is roughly $79 .{ }^{44}$ We make use of Figure 8-21 of the NAS report, which provides us with the net direct fiscal impact by age for both high school graduates and high school dropouts. These calculations account for the immigrant's federal, state and local taxes, incarceration costs, veteran's benefits, refugee support costs, government healthcare costs, and a variety of federal and state level transfer programs over

\footnotetext{
${ }^{44}$ In 2017, the life expectancy at age 23 was 77.06 for men and 81.72 for women. This yields a simple average of 79.39. Source: https://www.ssa.gov/oact/STATS/table4c6.html
} 
an individual's life-cycle. ${ }^{45}$ Further, we need to make an assumption about how immigrants affect government spending on public goods. ${ }^{46}$ We consider four different scenarios, similar to the NAS report: (i) there are zero marginal costs of public goods and hence no costs are assigned to immigrants, (ii) marginal costs are equal to $25 \%$ the average costs of public goods, (iii) marginal costs are equal to $50 \%$ of average costs, and (iv) marginal costs equal average costs. ${ }^{47}$ For all of these four scenarios, we can calculate the net present value (NPV) direct fiscal effect of low-skilled immigrants. To make this number comparable to our annual indirect fiscal effect, we calculate the annuity value for the period of 23 until 65 (labor market period) that corresponds to the NPV of the lifetime direct fiscal effect.

Table 4 contains these annuitized values for the four different scenarios. The first column gives the results for a high school dropout immigrant, the next column gives the results for high school graduates, and the last column gives the results for the average low-skilled immigrant. We can clearly see that low-skilled immigrants imply a direct fiscal burden in nearly every scenario - only high school graduates are a small fiscal surplus for the first scenario. Recall that we calculate indirect fiscal effects of $\$ 660$ to $\$ 1220$ for high school dropouts and $\$ 860$ to $\$ 1620$ for high school graduates. Accounting for these indirect effects in scenarios (ii) and (iii) can turn high school graduates from a fiscal burden into a small fiscal surplus. More generally, comparing the numbers in Table 4 with the numbers in Table 3, one can see that indirect fiscal effects are economically meaningful in comparison to the direct fiscal effects and should therefore be taken into account.

\begin{tabular}{lrrr}
\hline Public Goods & $\begin{array}{r}\text { High School } \\
\text { Dropout }\end{array}$ & $\begin{array}{r}\text { High School } \\
\text { Graduate }\end{array}$ & Average \\
\hline Scenario & $-4,151$ & 695 & $-1,388$ \\
Zero Marginal Costs & $-4,922$ & -86 & $-2,165$ \\
$\mathrm{MC}=0.25 \times \mathrm{AC}$ & $-5,693$ & -867 & $-2,942$ \\
$\mathrm{MC}=0.5 \times \mathrm{AC}$ & $-7,235$ & $-2,429$ & $-4,496$ \\
$\mathrm{MC}=\mathrm{AC}$ & &
\end{tabular}

Table 4: Annuitized direct fiscal effect of an immigrant that arrives at age 23 and dies at age 79 . We use a discount rate of $1 \%$. Only direct fiscal contributions are accounted for and rely on Figure 8-21 of National Academy of Sciences (2017). We calculate the annuity value for the period of 23 until 65 (age of retirement).

Welfare Effects - Immigration Surplus. We can use (11) to calculate the indirect fiscal effects arising from fiscal externalities associated with changes in native labor supply. For the case of $\sigma=2$ and with common labor supply elasticities, the fiscal externality is $\$ 430$.

\footnotetext{
${ }^{45}$ National Academy of Sciences (2017) also accounts for schooling costs, but these are less relevant here given that we consider low-skilled immigrants from age 23 onwards.

${ }^{46}$ Dustmann and Frattini (2014) give a detailed discussion about this for the UK and point out that the exact specification matters significantly. Referring to assumptions on the marginal cost of public goods, the NAS report states "In fact, such assumptions are likely to swamp the impact of most of the other assumptions and data issues that arise in fiscal impact analyses." (National Academy of Sciences, 2017, p. 266).

${ }^{47}$ Case (i) relates to scenario 6 and case (iv) relates to scenario 2 of Box 8-1 of National Academy of Sciences (2017). Cases (ii) and (iii) are intermediate cases of those two.
} 
This is more than a third of the whole effect. In light of Proposition 4 this implies a - so far neglected - surplus effect of $\$ 430 .{ }^{48}$ How does this relate to the welfare loss due to the increase in inequality? Quantification of the formula in Proposition 5 reveals a distributional effect of -\$783. Hence, the novel fiscal externality of $\$ 430$ more than halves this distributional loss in the surplus calculation. An implication is that low-skilled immigration could be implemented in a Pareto-improving manner if immigrants had a positive direct fiscal effect above $\$ 353$ which could for example be achieved by accordingly set visa fees.

\section{Extensions and Robustness}

We now examine the sensitivity of our results to several alternative model specifications. Sections 6.1 through Section 6.3 consider alternative production functions utilized in the immigration literature. As we focus on differences in production functions, we consider the case with exogenous native labor supply. Section 6.4 considers the case when workers can endogenously choose their supply of communication- and manual-intensive tasks. Section 6.5 considers the case with decreasing returns to scale and Section 6.6 discusses additional extensions.

\subsection{Imperfectly Substitutable Education and Experience}

So far we assumed that all workers within a given a skill group are perfectly substitutable. We now change these assumptions and follow Borjas (2003), who considers a nested-CES production function in which narrower education groups and experience levels are imperfect substitutes. In particular, we assume that production takes the form of a two-level nested CES function. ${ }^{49}$ The top level of the production function combines labor supplies of four education groups: high school dropouts, high school graduates, some college, and college graduates. Letting $e$ index education groups, output $Y$ is given by

$$
Y=\left(\sum_{e} \theta_{e} \mathscr{L}_{e}^{\frac{\sigma_{E}-1}{\sigma_{E}}}\right)^{\frac{\sigma_{E}}{\sigma_{E}-1}}
$$

where $\mathscr{L}_{e}$ is the labor aggregate of labor of education group $e, \sigma_{E}$ is the elasticity of substitution between education groups, and $\theta_{e}$ is a factor-intensity parameter. Due to this finer stratification of skill groups, an increase in the number of high school dropouts, for example, affects the relative wages of dropouts to high school graduates, in addition to the relative wages of high-skilled versus low-skilled workers.

\footnotetext{
${ }^{48}$ Note that holding labor supply elasticities constant, the fiscal externality is the same fraction of the indirect fiscal effect for any value of the elasticity of substitution, $\sigma$. Therefore, the result that the fiscal externality is over one third of the fiscal surplus is true for any value of the elasticity of substitution.

${ }^{49}$ We abstract away from physical capital (or alternatively assume that capital supply is perfectly elastic) in Sections 6.1 through 6.5. We discuss the role of capital in Section 7.1.
} 
In turn, each education-specific labor aggregate is itself an aggregator of experience levels within a given education group. As in Borjas (2003), we divide workers into 8 experience levels consisting of 5-year experience intervals, starting with 1-5 years experience until 36-40 years of experience. Letting $a$ index these experience levels, we can write

$$
\mathscr{L}_{e}=\left(\sum_{a} \theta_{a e} \mathscr{L}_{a e}^{\frac{\sigma_{X}-1}{\sigma_{X}}}\right)^{\frac{\sigma_{X}}{\sigma_{X}-1}}
$$

where $\mathscr{L}_{a e}$ gives the labor supply of a given experience-education group and is given by $\mathscr{L}_{a e}=\int_{\mathcal{I}_{a e}} L_{i} \omega_{i} d i$, and where $\mathcal{I}_{a e}$ is the set of types within a given experience-education group. The parameter $\sigma_{X}$ is equal to the elasticity of substitution of experience levels within the same education group and $\theta_{a e}$ is a factor-intensity parameter. Therefore, within the same education level, workers of different experience levels are imperfectly substitutable in production. Immigrant inflows therefore change the relative wages of different experience groups within the same education level.

As we show in Appendix A.3, if labor supply is inelastic, the indirect fiscal benefit of an immigrant of type $i$ in experience group $a$ and education group $e$ is given by

$$
d \mathscr{R}_{\text {ind }}^{\text {Borjas }}(a, e, i)=y_{i}[\underbrace{\left(\bar{T}_{a^{\prime} \neq a, e}^{\prime}-\bar{T}_{a e}^{\prime}\right)\left|\tilde{\gamma}_{a e, \text { own }}\right|}_{\text {Experience Effect }}+\underbrace{\left(\bar{T}_{e^{\prime} \neq e}^{\prime}-\bar{T}_{e}^{\prime}\right)\left|\gamma_{e, o w n}\right|}_{\text {Education Effect }}],
$$

where $\tilde{\gamma}_{a e, \text { own }}$ is the own-wage elasticity of experience group $a$ and education group $e$, holding the overall ratio of education groups constant, $\bar{T}_{a^{\prime} \neq a, e}^{\prime}$ is the income weighted average tax rate of all other experience groups in education group $e, \bar{T}_{e^{\prime} \neq e}^{\prime}$ is the income weighted tax rate of all other education groups, $\gamma_{e, \text { own }}$ is the own-wage elasticity of education group $e$, where the wage of an education group is defined as $\frac{\partial Y}{\partial \mathscr{L}_{e}}$. Therefore, we can decompose the indirect fiscal effect into two separate effects. The first effect, which we label the "experience effect" comes from the fact that an immigrant inflow of experience group $a$ increases the supply of experience group $a$ relative to all other experience groups within education group $e$. The "education effect" captures that the immigrant inflow also increases the ratio of labor from education group $e$ relative to all other education groups.

Results Following Borjas (2003), we set $\sigma_{X}=3.5$ and set $\sigma_{E}=1.3$. The indirect fiscal effect associated with a worker in each of the experience groups for both high school dropouts and high school graduates are given in Table 5 . The first column gives the indirect fiscal effect associated with high school dropouts and the second column gives the effect associated with high school graduates. The fiscal effect of both education levels is increasing in experience level, reflecting that incomes are increasing in experience. Across all experience groups, the average high school dropout is associated with a $\$ 1,932$ indirect fiscal benefit and the high 


\begin{tabular}{|c|c|c|}
\hline Experience Group & HS Dropout & HS Graduate \\
\hline $1-5$ & 1,595 & 1,368 \\
\hline $6-10$ & 1,803 & 1,597 \\
\hline $11-15$ & 1,720 & 1,650 \\
\hline $16-20$ & 1,844 & 1,732 \\
\hline $21-25$ & 1,825 & 1,786 \\
\hline $26-30$ & 1,948 & 1,926 \\
\hline $31-35$ & 2,043 & 2,016 \\
\hline $36-40$ & 2,172 & 2,056 \\
\hline Education Average & 1,932 & 1,834 \\
\hline Overall Average & \multicolumn{2}{|c|}{1,873} \\
\hline
\end{tabular}

Table 5: Indirect Fiscal Effects using model from Borjas (2003). Each entry gives the indirect fiscal effect associated with a worker in each narrow education and experience group. The "Education Average" gives the weighted average indirect fiscal effect within each education group and the "Overall Average" is the weighted average across all groups.

school graduate with a $\$ 1,834$ indirect fiscal benefit. The average low-skilled immigrant across education groups leads to a fiscal benefit of $\$ 1,873$.

To better understand why the indirect fiscal effect here is larger than in the previous sections, we now perform several alternative calculations. First, to understand the role of the "experience effect", we calculate the indirect fiscal benefit when experience groups are perfect substitutes within education, by setting $\frac{1}{\sigma_{X}}=0$. This has only a slight effect on the indirect fiscal effect: the average indirect fiscal effect increases from $\$ 1,873$ in the baseline case to $\$ 1,892$ in the case when experience groups are perfect substitutes within education group. Next, to understand the role of the elasticity of substitution parameter, we calculate the indirect fiscal benefit under the assumption that the elasticity of substitution is equal to 2 by setting $\sigma_{E}=2$. This reduces the average fiscal benefit to $\$ 1,230$, similar in magnitude to the effect we found in Section 3. Therefore, despite the key differences between the production function here and that presented in Section 3, both production functions lead to similar estimates of the indirect fiscal effect of low-skilled immigration, once we use comparable parameter estimates.

\subsection{Domestic-Born and Foreign-Born Complementarity}

Ottaviano and Peri (2012) consider a model in which domestic- and foreign-born workers are imperfect substitutes within education and experience groups. The production function takes a similar structure to that in the previous section but has two important differences. First, instead of assuming all four education groups aggregate within a single CES aggregator, we now follow Ottaviano and Peri (2012) and instead use a two level nested structure to model complementarity between education groups. High school dropouts and high school graduates aggregate to low-skilled labor and individuals with some college and college graduates aggregate to high-skilled labor. This specification allows for one elasticity of substitution between high-skilled and low-skilled workers and a second elasticity of substitution between 


\begin{tabular}{|c|c|c|}
\hline Experience Group & HS Dropout & HS Graduate \\
\hline $1-5$ & 796 & 888 \\
\hline $6-10$ & 945 & 1,014 \\
\hline $11-15$ & 876 & 1,026 \\
\hline $16-20$ & 868 & 1,112 \\
\hline $21-25$ & 838 & 1,111 \\
\hline $26-30$ & 915 & 1,206 \\
\hline $31-35$ & 996 & 1,289 \\
\hline $36-40$ & 1,014 & 1,321 \\
\hline \multirow{2}{*}{$\begin{array}{c}\text { Education Average } \\
\text { Overall Average }\end{array}$} & 920 & 1,161 \\
\hline & \multicolumn{2}{|c|}{1,065} \\
\hline
\end{tabular}

Table 6: Indirect Fiscal Effects using model from Ottaviano and Peri (2012). Each entry gives the indirect fiscal effect associated with a worker in each narrow education and experience group. The "Education Average" gives the weighted average indirect fiscal effect within each education group and the "Overall Average" is the weighted average across all groups. We focus on "Model B" from Ottaviano and Peri (2012), which the authors show is the most consistent with the data. We use estimates from column 7 of Table 6 , which gives an elasticity of substitution between skill levels of 1.85 .

narrow education groups. Second, within each skill-education-experience group, we allow for the possibility that domestic- and foreign-born workers may be imperfectly substitutable in production. Ultimately the production function takes the form of a four-level nested CES labor aggregate function, with a top nest corresponding to skill groups (high skill and low skill), a second nest corresponding with education groups within these two skill groups (high school graduate and dropout within low-skilled workers, some college and college graduate within high-skilled), a third nest corresponding with 8 experience groups within each education group, and a final nest aggregating domestic- and foreign-born workers. ${ }^{50}$ We show the formula for the indirect fiscal effect in this setting in Appendix A.4.

Results We quantify the model using parameters estimates from Ottaviano and Peri (2012). Table 6 gives the indirect fiscal effect associated with an immigrant with average income in each experience group for both high school dropouts and high school graduates. The average high school dropout immigrant leads to an indirect fiscal benefit of $\$ 920$ while the average high school graduate immigrant leads to an indirect fiscal benefit of $\$ 1,161$. Taken together, this implies the average low-skilled immigrant leads to an average indirect fiscal effect of $\$ 1,065$.

To better understand the implications of the nesting structure on the indirect fiscal effects, we sequentially recalculate the indirect fiscal effects under the assumptions that labor supplies in each of the CES nests are perfectly substitutable. First, we assume domestic- and foreignborn workers within experience-education-skill groups are perfect substitutes. This leads to a fiscal benefit of $\$ 1,057$. Next, we additionally assume workers of difference experience groups within the same education level are perfect substitutes. This implies a fiscal benefit of $\$ 1,065$.

\footnotetext{
${ }^{50}$ We focus on "Model B" from Ottaviano and Peri (2012), which the authors show is the most consistent with the data. We use their estimates from column 7 of Table 6.
} 
Finally, we remove imperfect substitutability between narrow education groups. This model now shares the same structure as the model presented in Section 3, as all workers within the two skill groups are perfectly substitutable. In this case the indirect fiscal benefit is $\$ 1,059$.

As emphasized by Dustmann, Schönberg, and Stuhler (2016) and Ottaviano and Peri (2012), the inclusion of domestic-foreign complementarity in the production function has strong implications for which workers bear the incidence of low-skilled immigrant inflows. ${ }^{51}$ However, domestic-foreign born complementary does not play a first-order role in determining the indirect fiscal effect of immigration. Further, imperfect substitablility between experience and education groups play almost no role in the indirect fiscal benefit. In fact, the indirect fiscal benefits calculated using the production function in Ottaviano and Peri (2012) and the production function in Borjas (2003) are quite similar if we use comparable estimates of the elasticity of substitution between education groups.

\subsection{Skills Defined by Position in Wage Distribution}

Dustmann, Frattini, and Preston (2013) argue than an immigrant's education level might give an inaccurate approximation of a worker's skills, given that skills are often not transferable. They propose a skill classification in which a worker's skill is given by her position in the wage distribution. Therefore, immigrants at a given position in the wage distribution compete with natives at the same position of the wage distribution, regardless of their education levels. ${ }^{52}$

To formalize this, let total output be given by the CES aggregator

$$
Y=\left(\sum_{j} \theta_{j} \mathscr{L}_{j}^{\frac{\sigma-1}{\sigma}}\right)^{\frac{\sigma}{\sigma-1}}
$$

where $\mathscr{L}_{j}$ gives the labor supply of a given skill group, and skill groups are defined by position in the wage distribution (for example percentiles or deciles). Formally, $\mathscr{L}_{j}$ is given by $\mathscr{L}_{j}=$ $\int_{\mathcal{I}_{j}} L_{i} \omega_{i} d i$, where $\mathcal{I}_{j}$ is the set of workers types within skill group $j$. The parameter $\sigma$ gives the elasticity of substitution between skill groups and each $\theta_{j}$ parameter measures the factor intensity of skill type $j$. As we show in Appendix A.5, the indirect fiscal benefit associated with an immigrant of type $i$ in skill group $j$ is given by

$$
d \mathscr{R}_{\text {ind }}^{\mathrm{DFP}}(j, i)=y_{i} \times\left|\gamma_{j, \text { own }}\right| \times\left(\bar{T}_{k \neq j}^{\prime}-\bar{T}_{j}\right)
$$

where $y_{i}$ is the income level of workers of type $i, \bar{T}_{k \neq j}^{\prime}$ is the income weighted average marginal tax rate of all other groups $k \neq j$, and $\bar{T}_{j}^{\prime}$ is the income weighted average marginal tax rate

\footnotetext{
${ }^{51}$ Allowing for domestic-foreign complementarity implies that low-skilled foreign born workers who immigrated in the past experience the largest wages decreases as a result of new low-skilled immigrant inflows, while low-skilled domestic-born workers only experience small wage decreases or even wage increases.

${ }^{52}$ This is similar to the production function utilized in Heathcote, Storesletten, and Violante (2017), which combines labor from a continuum of skill types.
} 


\begin{tabular}{|c|c|c|}
\hline $\begin{array}{c}\text { Decile of } \\
\text { Wage Distribution }\end{array}$ & $\begin{array}{r}\text { Indirect } \\
\text { Fiscal Effect }\end{array}$ & $\begin{array}{r}\% \text { of LS } \\
\text { Immigrants }\end{array}$ \\
\hline 1 & 970 & 20 \\
\hline 2 & 1,182 & 22 \\
\hline 3 & 1,366 & 17 \\
\hline 4 & 1,625 & 10 \\
\hline 5 & 1,825 & 9 \\
\hline 6 & 1,768 & 7 \\
\hline 7 & 1,460 & 5 \\
\hline 8 & 643 & 4 \\
\hline 9 & -588 & 3 \\
\hline 10 & $-10,924$ & 2 \\
\hline Overall Average & & \\
\hline
\end{tabular}

Table 7: Indirect Fiscal Effects using model from Dustmann, Frattini, and Preston (2013). The second columns gives the indirect fiscal effect for an immigrant in each decile of the wage distribution. The right column gives the percent of total low-skilled immigrants in each wage decile. The bottom row gives the weighted average of the indirect fiscal effects across the wage distribution.

income group $j$. Given the CES production function, the own-wage elasticity has the simple expression $\frac{1-\kappa_{j}}{\sigma}$, where $\kappa_{j}$ is the income share of workers in skill group $j$.

Results We define skill groups using deciles of the wage distribution. ${ }^{53}$ The results are not sensitive to the grouping of $j$. We use our central value for the elasticity of substitution between skill groups and set $\sigma=2 .{ }^{54}$ Table 7 gives the indirect fiscal effect associated with the average immigrant of each decile of the wage distribution. The indirect fiscal effect is increasing in wage decile up until the 5 th decile, reflecting the fact that income is increasing in the wage decile. Starting with the 6th decile, the indirect fiscal benefit decreases as the average marginal tax rates increase relative to the average marginal tax rates of other groups. The weighted average indirect fiscal effect is $\$ 1,017$, similar to the fiscal effect found in Section 3 when we set $\sigma=2$.

\subsection{Endogenous Occupational Choice of Natives}

We consider the model of immigration and the labor market developed by Peri and Sparber (2009). In this framework, low-skilled domestic-born workers differ from low-skilled foreignborn workers in that they choose different occupations due to different comparative advantages. Low-skilled foreign-born workers tend to choose occupations with a high manual task and lower communication task intensity than low-skilled natives. Since manual tasks and

\footnotetext{
${ }^{53}$ We calculate wages as total wage and self-employment income divided by weeks worked and average hours worked. In the 2017 ACS, weeks worked are intervalled, we use the midpoint of the interval.

${ }^{54}$ Using data from the UK, Dustmann, Frattini, and Preston (2013) find that an elasticity of substitution between skill group of 0.6 fits their reduced form evidence best. Using this value as the elasticity of substitution yields and an average indirect fiscal benefit of low-skilled immigrants of $\$ 2,766$. We believe the value of $\sigma=2$ to be more appropriate for the US context.
} 
communication tasks are complementary in production, low-skilled domestic-born workers and low-skilled foreign-born workers are now imperfect substitutes. ${ }^{55}$ Additionally, occupation choices are endogenous and therefore low-skilled workers may respond to low-skilled immigration by changing to more communication-intensive occupations.

Perfectly competitive firms produce a numeraire output good using cognitive, communication and manual tasks. Cognitive tasks are supplied by high-skilled individuals. Communication and manual tasks are performed by low-skilled individuals. Denote by $M$ total manual task supply and by $C$ total communication task supply. In the bottom nest of the production function, these tasks combine to form the aggregate of low-skilled labor, $\mathscr{L}_{u}$, as

$$
\mathscr{L}_{u}=\left(\theta_{u} M^{\frac{\sigma_{u}-1}{\theta_{u}}}+\left(1-\theta_{u}\right) C^{\frac{\sigma_{u}-1}{\sigma_{u}}}\right)^{\frac{\sigma_{u}}{\sigma_{u}-1}}
$$

The parameter $\sigma_{u}$ measures the elasticity of substitution between communication and manual tasks and $\theta_{u}$ measures the factor intensity of manual tasks. The task supplies $M$ and $C$ are given by the sum of each task supplied by both low-skilled domestic-born and foreign-born workers. Letting $d$ index low-skilled domestic-born workers, and $f$ index low-skilled foreignborn workers, we can write the total manual task supply as $M=N_{f} m_{f}+N_{d} m_{d}$ where $N_{f}$ and $N_{d}$ are the total number of low-skilled foreign-born and domestic-born workers in the economy and $m_{f}$ and $m_{d}$ are the amounts of manual tasks supplied by each low-skilled foreign- and domestic-born worker, respectively. Similarly, we can write the supply of communication tasks as $C=N_{f} c_{f}+N_{d} c_{d}$ where $c_{f}$ and $c_{d}$ are the endogenous amounts of communication tasks supplied by each low-skilled foreign- and domestic-born worker, respectively.

Each high-skilled worker inelastically supplies one unit of the cognitive task; aggregate high-skilled labor $\mathscr{L}_{s}$ is simply the total cognitive task supplied in the economy. High-skilled labor $\mathscr{L}_{s}$ and the aggregate of low-skilled labor, $\mathscr{L}_{u}$, are aggregated according to:

$$
Y=A\left(\theta \mathscr{L}_{u}^{\frac{\sigma-1}{\sigma}}+(1-\theta) \mathscr{L}_{s}^{\frac{\sigma-1}{\sigma}}\right)^{\frac{\sigma}{\sigma-1}}
$$

where $Y$ is the produced amount of the numeraire output good. The parameter $\sigma$ corresponds with the elasticity of substitution between high-skilled labor and the low-skilled aggregate. Total factor productivity is given by $A$ and $\theta$ gives the factor intensity of low-skilled labor.

Let $w_{c}, w_{m}$ and $w_{s}$ denote the compensation for one unit of communication, manual and cognitive tasks. As firms are perfectly competitive, these task prices are given by the marginal products of each task. Since high-skilled workers supply exactly one unit of the cognitive task, their income equals the task wage, hence we have $y_{s}=w_{s}$. For low-skilled workers, income is given by the sum of the worker's task supplies multiplied by the appropriate task prices. Letting $j \in\{f, d\}$ index low-skilled worker types (foreign-born or domestic-born), we can write the agent's income as $y_{j}=c_{j} w_{c}+m_{j} w_{m}$.

\footnotetext{
${ }^{55}$ In essence, the differences in task concentration between domestic- and foreign-born workers provide a microfoundation for the domestic- and foreign-born complementarity in Ottaviano and Peri (2012).
} 
The indirect fiscal benefit resulting from an inflow of $d N_{f}$ workers is given by

$$
d \mathscr{R}_{i n d}^{\mathrm{PS}}=T_{s}^{\prime} N_{s} \frac{d y_{s}}{d N_{f}} d N_{f}+T_{f}^{\prime} N_{f} \frac{d y_{f}}{d N_{f}} d N_{f}+T_{d}^{\prime} N_{d} \frac{d y_{d}}{d N_{f}} d N_{f} .
$$

That is, the total indirect fiscal effect is given by the change in income of each type of worker multiplied by the number of workers of that type and the marginal tax rate. It's important to note that changes in income for low-skilled workers, $\frac{d y_{f}}{d N_{f}}$ and $\frac{d y_{d}}{d N_{f}}$, arise for two reasons. First, low-skilled immigrant inflows change task prices $w_{c}$ and $w_{m}$, and therefore the incomes of foreign- and domestic-born workers. Second, income will change as a result of changes in task supplies in response to these inflows. For example, if low-skilled domestic-born workers respond to immigrant inflows by increasing the amount of communication task they supply (perhaps by moving into managerial occupations), this will lead to an additional change in native income in response to immigrant inflows. We show in Appendix A.6 how this formula can be written as a function of structural parameters and task supply elasticities.

Quantification We quantify the indirect fiscal effects by utilizing estimates of task intensities from ONET and selected parameter estimates from Peri and Sparber (2009). The procedure we use for estimating income and marginal tax rates are similar to those in other sections. Details can be found in Appendix B.5. Here we focus on the parameter estimates we take from Peri and Sparber (2009).

Peri and Sparber (2009) estimate the elasticity of substitution between manual and communication tasks, $\sigma_{u}$, using state level variation in immigrant inflows. We set $\sigma_{u}=1$ and set the elasticity of substitution between low- and high-skilled workers as $\sigma=1.75$, based on their estimates. Peri and Sparber (2009) also use this variation to estimate the elasticities of task supplies with respect to the immigrant share of low-skilled workers. We directly use these estimates of task supply elasticities. Most notably, they find that domestic-born workers respond to low-skilled immigrant inflows by increasing their communication task supply and that foreign-born workers do not change their task supplies in response to immigrant inflows.

Results First of all, we calculate the indirect fiscal effect which would result if workers did not adjust their occupation. We find this number to be $\$ 1,115$, which is in a similar ballpark as the numbers we found in Section 5. ${ }^{56}$ However, once we allow for endogenous occupation choice, low-skilled domestic-born workers respond by switching into higher-paying communication-intensive occupations. This increases their incomes and thus their tax payments. Holding task prices constant, this occupation upgrading leads to an additional fiscal effect of $\$ 899 .{ }^{57}$ Finally, these occupation changes lead to additional changes in the equilib-

\footnotetext{
${ }^{56}$ This is not surprising since the elasticity of substitution between high and low-skilled labor $\sigma$ is chosen to be 1.75 in this calculation which is in the range of values considered Section 5 .

${ }^{57}$ Note that this effect constitutes a fiscal externality. This fiscal externality is much larger than the externality resulting from hours worked and participation responses in the canonical model.
} 
rium task prices leading to an additional fiscal effect of $\$ 117.58$ Ultimately, the indirect fiscal effect is equal to $d \mathscr{R}_{\text {ind }}^{P S}=\$ 2,131$ with endogenous occupation choice.

\subsection{Decreasing Returns to Scale}

Throughout the paper, we have considered production functions that exhibit constant returns to scale. We now calculate the indirect fiscal effect of immigration with decreasing returns to scale. Consider a homogeneous production function with two inputs,

$$
Y=F\left(\mathscr{L}_{u}, \mathscr{L}_{s}\right)
$$

where, as before, $\mathscr{L}_{u}=\int_{\mathcal{I}_{u}} L_{i} \omega_{i} d i$ and $\mathscr{L}_{s}=\int_{\mathcal{I}_{s}} L_{i} \omega_{i} d i$. Let $\lambda$ be the degree of homogeneity: $F\left(t \mathscr{L}_{u}, t \mathscr{L}_{s}\right)=t^{\lambda} F\left(\mathscr{L}_{u}, \mathscr{L}_{s}\right)$. With decreasing returns to scale $(\lambda<1)$, an immigrant inflow can also lead to changes in firm profits in addition to changes in wages. Therefore, holding labor supply constant, the indirect fiscal effects of immigration with decreasing returns are given by:

$$
d \mathscr{R}_{\text {ind }}^{\mathrm{DRS}}(i)=h_{i} \omega_{i}\left[\tau_{p} \frac{\partial \pi}{\partial \mathscr{L}_{u}}+\int_{\mathcal{I}_{s}} T^{\prime}\left(y_{i}, i\right) \frac{\partial w_{s}}{\partial \mathscr{L}_{u}} h_{i} \omega_{i} m_{i} d i+\int_{\mathcal{I}_{u}} T^{\prime}\left(y_{i}, i\right) \frac{\partial w_{u}}{\partial \mathscr{L}_{u}} h_{i} \omega_{i} m_{i} d i\right],
$$

where $\pi$ represents total firm profits and $\tau_{p}$ is the tax rate on firm profits.

In the case of constant returns to scale, the indirect fiscal effects arose because of a change in relative incomes of high-skilled and low-skilled workers. With decreasing returns to scale, there is a second effect arising from an increase in firm profits relative to worker income. As we show in Appendix A.7 the indirect fiscal effect of an immigrant of type $i$ with decreasing returns to scale is given by

$$
d \mathscr{R}_{\text {ind }}^{\text {DRS }}(i)=y_{i}[\underbrace{\left(\bar{T}_{s}^{\prime}-\bar{T}_{u}^{\prime}\right)\left|\tilde{\gamma}_{u, \text { own }}\right|}_{\text {Factor Ratio Effect }}+\underbrace{(1-\lambda)\left(\tau_{p}-\bar{T}_{I}^{\prime}\right)}_{\text {Scale Effect }}] .
$$

Consider the first term of (16), which we refer to as the "factor ratio effect". The term $\tilde{\gamma}_{u, \text { own }}$ gives the own-wage elasticity for low-skilled workers, holding total labor income constant. Specifically, this term is given by $\tilde{\gamma}_{u, \text { own }}=\gamma_{u, \text { own }}+\kappa_{u}(1-\lambda)$, where $\kappa_{u}=\frac{\mathscr{L}_{u} w_{u}}{\mathscr{L}_{s} w_{s}+\mathscr{L}_{u} w_{u}}$ is the labor income share of low-skilled labor. ${ }^{59}$ This factor ratio effect gives the indirect fiscal effect as a result of changing the relative wages of high-skilled relative to low-skilled workers.

\footnotetext{
${ }^{58}$ This term is positive because the increase in supply of communication tasks by low-skilled workers implies an increase in cognitive wages, an increase in manual wages but a decrease in communication wages.

${ }^{59}$ Note that $-\kappa_{u}(1-\lambda)$ is the effect of immigration on low-skilled income that occurs through the scale effect - if total income changes but the share going to low-skilled workers stays constant. Therefore, we can think of $\tilde{\gamma}_{u, \text { own }}$ as as the change in low-skilled income from immigration minus the scale effect. Note that if the production function exhibits constant returns to scale, then this elasticity is independent of scale and we have $\tilde{\gamma}_{u, o w n}=\gamma_{u, o w n}$.
} 
In addition to changing the factor ratio, an influx of low-skilled labor also increases the scale of production and therefore increases profits at the cost of worker income. We refer to the resulting fiscal effect as the "scale effect", which is the second term in (16). The term $\bar{T}_{I}^{\prime}$ gives the income-weighted average marginal tax of all workers. A smaller value of $\lambda$ implies lower returns to scale and therefore a greater redistribution of surplus from workers to firms. The fiscal effects of the redistribution are scaled by the differences in the average tax rates between firms and workers, $\left(\tau_{p}-\bar{T}_{I}^{\prime}\right)$.

Results To calculate the fiscal effects with decreasing returns to scale, we need estimates of the profit tax $\tau_{p}$, income weighted marginal tax rates, the returns to scale, $\lambda$, and $\tilde{\gamma}_{u, o w n}$, the own-wage elasticity of low-skilled labor, holding labor income constant. For the profit tax, we use the weighted average of the state and federal corporate tax rates and the business income weighted average income tax rate, which is the tax rate that applies for pass-through businesses. ${ }^{60}$ This gives us an estimate of $\tau_{p}=36.8 \%$. We estimate a marginal tax rate for all workers as $\bar{T}_{I}^{\prime}=34.2 \%$. Finally, we take our value of $\lambda=.9$ from Burnside (1996), who estimates returns to scale for US industries. ${ }^{61}$ Finally, $\tilde{\gamma}_{u, \text { own }}=-\frac{1}{\sigma} \kappa_{s}$, where again $\sigma$ is the elasticity of substitution between low- and high-skilled labor. ${ }^{62}$ Therefore, $\tilde{\gamma}_{u, \text { own }}$ is the same as the own-wage elasticity with constant returns to scale, given the same value for $\sigma$.

Putting this together, we estimate that if production exhibits decreasing returns to scale, the indirect fiscal effect associated with the average low-skilled immigrant is equal to $\$ 1,057$ given an elasticity of substitution of $\sigma=2$. Recall that with constant returns to scale and $\sigma=2$, we calculated an indirect fiscal effect with exogenous labor supply of $\$ 975$. The small increase in the fiscal effect with decreasing returns is due to the scale effect: profits increase relative to labor income and profits face a higher marginal tax rate than labor income. ${ }^{63}$

\subsection{Further Potential Extensions}

Endogenous Education Low-skilled natives may respond to low-skilled immigrant inflows by further investing in their education (Llull, 2018). This would likely increase the indirect fiscal effects of immigration as increased education leads to increased lifetime income and

\footnotetext{
${ }^{60}$ Corporations account for $60 \%$ of total net income from business. We calculate $\tau_{p}$ as .6 times federal and average state corporate tax rate plus .4 times the business income weighted average effective tax rate arising from income taxes and transfers using our ACS data. In 2017, the federal corporate tax rate plus the average of the state income tax rates was 38.9\%. Source: https://taxfoundation.org/ us-corporate-income-tax-more-competitive/. We find a business income weighted effective tax rate of $33.9 \%$.

${ }^{61}$ Burnside (1996) estimates a weighted average of industry specific returns to scale of .9.

${ }^{62}$ As we show in Appendix A.7, the own-wage elasticity with decreasing returns to scale is given by $\gamma_{u, o w n}=$ $(\lambda-1) \kappa_{u}-\frac{1}{\sigma} \kappa_{s}$. Therefore, the own-wage elasticity holding labor income constant is simply given by $\tilde{\gamma}_{u, o w n}=$ $-\frac{1}{\sigma} \kappa_{s}$.

${ }^{63}$ It's worth noting that corporate tax rates dropped substantially in 2018 to a weighted average of $25.7 \%$. Performing this calculating with 2018 corporate tax rates implies an indirect fiscal effect of $\$ 817$.
} 
therefore increased tax payments. As shown in Colas, Findeisen, and Sachs (2018), this fiscal externality associated with attending college is quantitatively important. ${ }^{64}$

Monopsonistic Labor Markets Amior and Manning (2020) emphasize that most of the immigration literature rests on the assumption of perfectly competitive labor markets. They argue that this assumption is problematic because markdowns on wages in a setting with monopsony power are likely to be endogenous to immigration since labor supply of immigrants tends to be relatively inelastic. ${ }^{65}$ In this case, low-skilled immigration would not only imply redistribution from low- to high-skilled workers but also from workers to firms, similar to the decreasing-returns to scale extension in Section 6.5. An important difference to Section 6.5 is that immigrants are not paid their marginal product in such a setting. This implies that the economic pie accruing to natives would increase thereby reinforcing the indirect fiscal benefit.

Search Frictions We have abstracted from search frictions in the labor market. As as been pointed out by Battisti, Felbermayr, Peri, and Poutvaara (2018) immigration can attenuate search frictions on the labor market, which also implies indirect fiscal benefits.

Native Migration Responses Low-skilled immigrant inflows into a given city can induce migration responses by natives (Borjas, Freeman, and Katz, 1997; Piyapromdee, 2020; Monras, 2020). These native migration responses, either in the form of outflows of low-skilled or inflows of high-skilled natives, would mitigate the effect of immigration on local wage inequality and therefore reduce the indirect fiscal effect generated locally, but would increase wage inequality and therefore generate indirect fiscal effects in other cities. Concretely, if the economy consists of $J$ cities with different population sizes but that are otherwise identical, the total indirect fiscal effect generated across all cities would be independent of the distribution of the lowskilled immigrants across cities and of any native migration responses. ${ }^{66}$ However, if cities differ in their wage levels, a native's income and tax payments will depend on their location and therefore native migration will imply a fiscal externality. These effects could be jointly analyzed using a spatial equilibrium model with taxes, such as in Colas and Hutchinson (2020).

\section{Discussion}

In this section we discuss additional issues and address limitations of our analysis. First, in Section 7.1 we discuss the role of physical capital. In Section 7.2, we discuss some critical issues about the assumptions we made when estimating the indirect fiscal effect.

\footnotetext{
${ }^{64}$ Colas, Findeisen, and Sachs (2018) estimate average lifetime fiscal externalities of attending college ranging roughly $\$ 60,000$ to $\$ 90,000$, conditional on parental income.

${ }^{65}$ For the US, the authors show that the assumption that markdowns are exogenous is rejected by the data.

${ }^{66}$ This is because the indirect fiscal effect is independent of the size of the native population. See also the discussion in Foonote 14.
} 


\subsection{The Role of Physical Capital}

We have abstracted away from the role of capital in production. Here we show how physical capital can be accommodated into our formulas. This does not significantly change our results.

Elastically Supplied Physical Capital Consider a constant returns production function $Y=F\left(\mathscr{L}_{u}, \mathscr{L}_{s}, K\right)$ that uses physical capital, $K$, as an input in addition to low- and highskilled labor. Since the supply of capital is perfectly elastic and since $F(\cdot)$ exhibits constant returns to scale, the optimal capital level can be written as a function of the ratio of high- to low-skill labor, $K^{\star}\left(\frac{\mathscr{L}_{s}}{\mathscr{L}_{u}}\right)$. Therefore, one can redefine production in terms of labor quantities given optimal capital levels as

$$
\tilde{F}\left(\mathscr{L}_{u}, \mathscr{L}_{s}\right)=F\left(\mathscr{L}_{u}, \mathscr{L}_{s}, K^{\star}\left(\frac{\mathscr{L}_{s}}{\mathscr{L}_{u}}\right)\right)
$$

Note that $\tilde{F}$ is a function of only labor quantities and exhibits constant returns to scale. Therefore, Proposition 3 can still be applied if we interpret the own-wage elasticity $\gamma_{\text {own }}$ as the wage elasticity given optimal capital adjustments. ${ }^{67}$ As a simple example, consider the case with the Cobb-Douglas production function $F\left(\mathscr{L}_{u}, \mathscr{L}_{s}, K\right)=K^{\alpha}\left(G\left(\mathscr{L}_{u}, \mathscr{L}_{s}\right)\right)^{1-\alpha}$, where $G(\cdot)$ is a CRS labor aggregate. With elastic capital supply, the ratio of capital to the labor aggregate is constant. Therefore, we can rewrite the production function as $\tilde{F}\left(\mathscr{L}_{u}, \mathscr{L}_{s}\right)=\bar{A} G\left(\mathscr{L}_{u}, \mathscr{L}_{s}\right)$ where $\bar{A}$ is a positive multiplicative constant, see Appendix A.8.

Inelastically Supplied Physical Capital Lewis (2011) argues that capital stocks adjust quickly to immigrant inflows, and therefore the case with elastic capital supply is appropriate for most settings. Yet, it is interesting to get a sense of how our results would change if capital supply is inelastic. Consider again the Cobb-Douglas production function that combines physical capital, $K$, with a labor aggregate $G$

$$
Y=K^{\alpha} G\left(\mathscr{L}_{u}, \mathscr{L}_{s}\right)^{1-\alpha}
$$

where $\alpha \in(0,1)$ is a parameter and $G$ is a constant returns to scale function. We assume capital is supplied inelastically and capital payments are taxed at rate $\tau_{k}$.

As we show in Appendix A.8, the indirect fiscal benefit with inelastic labor supply for an immigrant of type $i$ is given by

$$
d \mathscr{R}_{\text {ind }}^{\text {inelast }}(i)=y_{i}[\underbrace{\left(\bar{T}_{s}^{\prime}-\bar{T}_{u}^{\prime}\right)\left|\gamma_{u, \text { ewn }}^{\text {elast }}\right|}_{\text {Skill Ratio Effect }}+\underbrace{\alpha\left(\tau_{k}-\bar{T}_{I}^{\prime}\right)}_{\text {Capital Labor Ratio Effect }}],
$$

\footnotetext{
${ }^{67}$ Note that the above does not rely on a particular production function (such as Cobb-Douglas) or separability of capital in the production function more generally. The above arguments also apply to cases with non-separable capital and capital-skill complementarity, as in the models in Lewis (2011) and Lewis (2013).
} 
where $\gamma_{u, o w n}^{\text {elast }}=\frac{\partial \log \frac{\partial G}{\partial \mathscr{L}_{u}}}{\partial \log \mathscr{L}_{u}}$ is the own-wage elasticity of low-skilled labor when capital supply is perfectly elastic. ${ }^{68}$ Therefore, the indirect fiscal effect generated by the "skill ratio effect" is simply equal to the indirect fiscal effect with elastic capital supply. One reasonable assumption is that when physical capital supply is inelastic, returns to physical capital have a similar tax rate as firm profits. Therefore using the marginal tax rate for profit we calculated of $36.8 \%$ in the previous section, and capital share parameter of $\alpha=.33$, we find that the indirect fiscal effect of an average low-skilled immigrant with inelastic capital supply will increase by $y_{i} \alpha\left(\tau_{k}-\bar{T}_{I}^{\prime}\right)=\$ 273$ compared to the case with elastic capital supply.

\subsection{Further Issues}

Steady State versus Dynamics In all our specifications, we have focused on a steady state interpretation and have abstracted from the fact that it may take some time until the economy reaches the new steady state after the arrival of the immigrants. ${ }^{69}$ It would certainly be possible to extend our approach numerically to such more dynamic settings and discuss how the indirect fiscal effects differ in the short run.

More structural approaches have been taken in the literature more recently, e.g. by Llull (2018) who considers endogenous responses of workers along the occupation and education margin, by Bound, Braga, Golden, and Khanna (2015) who consider major and occupation choice responses of skilled natives, by Monras (2020) who considers a dynamic spatial equilibrium model, and by Colas (2019) who also considers sectoral choices of natives.

Documented versus Undocumented Immigration In our analysis we have not explicitly made the distinction between authorized and undocumented immigrants. This distinction would matter for the calculation of the indirect fiscal effect because undocumented immigrants differ in their eligibility status for welfare programs and their likelihood to pay income or payroll taxes. However, we focus on the indirect fiscal effect, which operates through a low-skilled immigrant's effect on native wages, independent of the taxes paid and benefits received by the immigrant themselves. As such, an immigrant's documentation status is unlikely to have a first-order effect on their indirect fiscal effect conditional on their income level $y_{i}{ }^{70}$

Other Indirect Effects Immigrants may have indirect fiscal effects on top of those described in this paper. We have focused on a single consumption good and therefore abstracted from how immigrants may affect tax revenue by changing relative consumption prices. For example, it has been shown that low-skilled immigration lowers prices for low-skilled services such as gardening or housekeeping (Cortes, 2008). Such effects would only matter if the goods

\footnotetext{
${ }^{68}$ This is also equal to the own-wage elasticity when $\alpha=0$.

${ }^{69}$ See, for example, Card (1990), Cohen-Goldner and Paserman (2011), Llull (2017), Monras (2020), Borjas (2015) and Edo (2017) for reduced-form evidence comparing the short- and long-run wage impacts.

${ }^{70}$ As undocumented immigrants on average have lower income than authorized immigrants, they will have on average a lower indirect fiscal effect because the indirect fiscal effect is increasing in the immigrant's income.
} 
or services whose relative prices increase is taxed at a different rate then the goods for which the relative prices decrease. An effect that probably matters more is the interaction between the prices for these services and native labor supply. Cortes and Tessada (2011) show that high-skilled female native labor supply increased due low-skilled immigration and, consistently with that, these women have reduced their time spent on household work. Additionally, immigration may increase local housing prices and rents (Saiz, 2003, 2007) and therefore lead to additional fiscal effects arising from property taxes and taxes on rental income.

Local Taxes versus Federal Taxes We have accounted in detail for how taxes paid and transfers received vary with income to obtain reliable estimates for income-weighted averages of marginal tax rates for the different income groups. We have not accounted for the fact that some taxes are raised at the state level and some at the federal level. Similarly, some transfers are paid by the states and some by the federal government. We have therefore taken a national perspective on public finances. We leave the issue of how the fiscal effect is distributed between different levels of government for future research.

Larger Immigrant Inflows We have focused on small inflows of immigrants and therefore considered first-order approximations throughout, thus allowing for a transparent analytical approach. For larger inflows of immigrants, these first-order approximations would become less appropriate. It would be straightforward to consider larger immigration inflows numerically and thereby go beyond first-order approximations.

\section{Conclusion}

In this paper, we explore the indirect fiscal effect of immigration that works through the impact on the native wages and labor supply. Applying these formulas to the U.S., we find that the indirect fiscal effects of low-skilled immigration are sizable and positive. For some plausible scenario they turn low-skilled immigration from a fiscal burden to a fiscal surplus.

Future work could extend our analysis to other countries, where the tax system, labor supply responses and wage effects of immigration may differ from the U.S. case. Our approach could also be extended to calculate the indirect fiscal effects of high-skilled immigrants. In thinking about the indirect effects of high-skilled immigration, it would seem natural to allow for highskilled immigrants to affect factor productivity, in addition to factor ratios (Kerr and Lincoln, 2010; Peri, Shih, and Sparber, 2015; Bound, Khanna, and Morales, 2017; Khanna and Lee, 2018). We leave these extensions for future research. 


\section{References}

Acemoglu, D. And D. Autor (2011): "Skills, Tasks and Technologies: Implications for Employment and Earnings," Handbook of Labor Economics, 4, 1043-1171.

Alesina, A., A. Miano, And S. Stantcheva (2018): "Immigration and redistribution," Tech. rep., National Bureau of Economic Research.

Amior, M. And A. Manning (2020): "Monopsony and the Wage Effects of Migration," CEP LSE Discussion Paper. Centre for Economic Performance, London School of Economics.

Bargain, O., K. Orsini, And A. Peichl (2014): "Comparing labor supply elasticities in europe and the united states new results," Journal of Human Resources, 49, 723-838.

Battisti, M., G. Felbermayr, G. Peri, and P. Poutvaara (2018): "Immigration, search and redistribution: A quantitative assessment of native welfare," Journal of the European Economic Association, 16, 1137-1188.

Bodvarsson, Ö. And H. VAn Den Berg (2009): "The economics of immigration," Theory and.

Boeri, T. (2010): "Immigration to the Land of Redistribution," Economica, 77, 651-687.

Borjas, G. J. (2003): "The Labor Demand Curve Is Downward Sloping: Reexamining the Impact of Immigration on the Labor Market," The Quarterly Journal of Economics, 118, $1335-1374$.

(2014): Immigration economics, Harvard University Press.

(2015): "The wage impact of the Marielitos: A reappraisal," ILR Review.

(2016a): "A User's Guide to the 2016 National Academy Report on "The Economic and Fiscal Consequences of Immigration"," https://sites.hks.harvard.edu/fs/gborjas/publications/working\%20papers/NAS2016.pdf.

(2016b): We wanted workers: Unraveling the immigration narrative, WW Norton \& Company.

Borjas, G. J., R. B. Freeman, And L. F. Katz (1997): "How much do immigration and trade affect labor market outcomes?" Brookings papers on economic activity, 1997, 1-90.

Borjas, G. J. And L. Hilton (1996): "Immigration and the Welfare State: Immigrant Participation in Means-Tested Entitlement Programs*," The Quarterly journal of economics, $111,575-604$.

Bound, J., B. Braga, J. M. Golden, and G. Khanna (2015): "Recruitment of foreigners in the market for computer scientists in the United States," Journal of labor economics, 33, S187-S223.

Bound, J., G. Khanna, And N. Morales (2017): "Understanding the Economic Impact of the H-1B Program on the US," Tech. rep., National Bureau of Economic Research.

Burnside, C. (1996): "Production function regressions, returns to scale, and externalities," Journal of monetary Economics, 37, 177-201. 
Busch, C., D. Krueger, A. Ludwig, I. Popova, And Z. Iftikhar (2020): "Should Germany Have Built a New Wall? Macroeconomic Lessons from the 2015-18 Refugee Wave," Journal of Monetary Economics.

CARD, D. (1990): "The impact of the Mariel boatlift on the Miami labor market," ILR Review, $43,245-257$.

(2009): "Immigration and Inequality," American Economic Review, 99, 1-21.

Card, D. And T. Lemieux (2001): "Can falling supply explain the rising return to college for younger men? A cohort-based analysis," The Quarterly Journal of Economics, 116, 705-746.

Chetty, R. (2012): "Bounds on Elasticities with Optimization Frictions: A Synthesis of Micro and Macro Evidence on Labor Supply," Econometrica, 80, 969-1018.

Chetty, R., A. Guren, D. Manoli, and A. Weber (2013): "Does indivisible labor explain the difference between micro and macro elasticities? A meta-analysis of extensive margin elasticities," NBER macroeconomics Annual, 27, 1-56.

Chetty, R., M. Stepner, S. Abraham, S. Lin, B. Scuderi, N. Turner, A. BergERON, AND D. Cutler (2016): "The association between income and life expectancy in the United States, 2001-2014," Jama, 315, 1750-1766.

Coen-Pirani, D. (2011): "Immigration and spending on public education: California, 19702000," Journal of Public Economics, 95, 1386-1396.

Cohen-Goldner, S. And M. D. Paserman (2011): "The dynamic impact of immigration on natives' labor market outcomes: Evidence from Israel," European Economic Review, 55, $1027-1045$.

Colas, M. (2019): "Dynamic responses to immigration," Opportunity and Inclusive Growth Institute.

Colas, M., S. Findeisen, And D. Sachs (2018): "Optimal Need-Based Financial Aid," .

Colas, M. And K. Hutchinson (2020): "Heterogeneous workers and federal income taxes in a spatial equilibrium," .

Congressional Budget Office, U. S. (2015): "Effective Marginal Tax Rates for Lowand Moderate-Income Workers in 2016." Tech. rep., Washington: U.S. Congress.

Cortes, P. (2008): "The effect of low-skilled immigration on US prices: evidence from CPI data," Journal of political Economy, 116, 381-422.

Cortes, P. And J. Tessada (2011): "Low-skilled immigration and the labor supply of highly skilled women," American Economic Journal: Applied Economics, 3, 88-123.

Currie, J. (2006): "The Take-Up of Social Benefits," Public Policy and the Income Distribution, 80.

Dustmann, C. And T. Frattini (2014): "The fiscal effects of immigration to the UK," The economic journal, 124, F593-F643.

Dustmann, C., T. Frattini, And I. P. Preston (2013): "The effect of immigration along the distribution of wages," The Review of Economic Studies, 80, 145-173. 
Dustmann, C. And I. P. Preston (2007): "Racial and economic factors in attitudes to immigration," The BE Journal of Economic Analysis \& Policy, 7.

Dustmann, C., U. SchönberG, And J. Stuhler (2016): "The impact of immigration: Why do studies reach such different results?" Journal of Economic Perspectives, 30, 31-56.

(2017): "Labor supply shocks, native wages, and the adjustment of local employment," The Quarterly Journal of Economics, 132, 435-483.

EDO, A. (2017): "The Impact of immigration on wage dynamics: Evidence from the Algerian independence war," Journal of the European Economic Association.

Feldstein, M. And A. SAmwick (1992): "Social security rules and marginal tax rates," NBER Working Paper No. 3962.

Foged, M. AND G. Peri (2016): "Immigrants' effect on native workers: New analysis on longitudinal data," American Economic Journal: Applied Economics, 8, 1-34.

Heathcote, J., K. Storesletten, And G. L. Violante (2017): "Optimal tax progressivity: An analytical framework," The Quarterly Journal of Economics, 132, 1693-1754.

Hendren, N. (2015): "The Policy Elasticity," in Tax Policy and the Economy, Volume 30, University of Chicago Press.

(2020): "Measuring economic efficiency using inverse-optimum weights," Journal of Public Economics, 187, 104198.

Hendricks, L. AND T. SCHOELlman (2018): "Human capital and development accounting: New evidence from wage gains at migration," The Quarterly Journal of Economics, 133, $665-700$.

Hicks, J. R. (1939): "The foundations of welfare economics," The Economic Journal, 49, 696-712.

(1940): "The valuation of the social income," Economica, 7, 105-124.

Juhn, C., K. M. Murphy, And R. H. Topel (2002): "Current unemployment, historically contemplated," Brookings Papers on Economic Activity, 2002, 79-116.

KALDOR, N. (1939): "Welfare propositions of economics and interpersonal comparisons of utility," The Economic Journal, 549-552.

Katz, L. F. And K. M. Murphy (1992): "Changes in Relative Wages, 1963-1987: Supply and Demand Factors," The Quarterly Journal of Economics, 107, 35-78.

KerR, W. R. And W. F. LinCOLn (2010): "The supply side of innovation: H-1B visa reforms and US ethnic invention," Journal of Labor Economics, 28, 473-508.

Khanna, G. And M. Lee (2018): "High-skill immigration, innovation, and creative destruction," Tech. rep., National Bureau of Economic Research.

Krugman, P. (2006): "Notes on Immigration," New York Times, op-ed: https://krugman. blogs . nytimes. com/2006/03/27/notes-on-immigration/.

LEWIS, E. (2011): "Immigration, skill mix, and capital skill complementarity," The Quarterly Journal of Economics, 126, 1029-1069. 
(2013): "Immigration and production technology," Annu. Rev. Econ., 5, 165-191.

LLULL, J. (2017): "The effect of immigration on wages: exploiting exogenous variation at the national level," Journal of Human Resources, 0315-7032R2.

(2018): "Immigration, wages, and education: A labour market equilibrium structural model," The Review of Economic Studies, 85, 1852-1896.

Low, H., C. Meghir, L. Pistaferri, And A. Voena (2018): "Marriage, labor supply and the dynamics of the social safety net," NBER Working Paper No. 24356.

Manacorda, M., A. Manning, And J. WAdsworth (2012): "The impact of immigration on the structure of wages: Theory and evidence from Britain," Journal of the European Economic Association, 10, 120-151.

Meyer, B. D., W. K. Mok, And J. X. Sullivan (2015): "Household surveys in crisis," Journal of Economic Perspectives, 29, 199-226.

Monras, J. (2020): "Immigration and wage dynamics: Evidence from the mexican peso crisis," Journal of Political Economy, 128.

Monras, J., J. VÁzquez-Grenno, And F. Elias (2018): "Understanding the Effects of Legalizing Undocumented Immigrants," .

National Academy of Sciences, U. S. (2017): The economic and fiscal consequences of immigration, National Academies Press.

Ottaviano, G. I. And G. Peri (2012): "Rethinking the effect of immigration on wages," Journal of the European Economic Association, 10, 152-197.

Patt, A., J. Ruhose, S. Wiederhold, And M. Flores (2020): "International emigrant selection on occupational skills," Journal of the European Economic Association.

Peri, G., K. Shin, And C. Sparber (2015): "STEM workers, H-1B visas, and productivity in US cities," Journal of Labor Economics, 33, S225-S255.

Peri, G. And C. Sparber (2009): "Task Specialization, Immigration, and Wages," American Economic Journal: Applied Economics, 1, 135-69.

Piketty, T. And E. SAez (2013): "Optimal labor income taxation," Handbook of Public Economics, Vol 5.

PIYAPROMdEE, S. (2020): "The impact of immigration on wages, internal migration and welfare," Tech. rep., Working paper.

Preston, I. (2014): "The effect of immigration on public finances," The Economic Journal, 124, F569-F592.

Ruggles, S., J. T. Alexander, K. Genadek, R. Goeken, M. B. Schroeder, and M. Sobek (2010): "Integrated Public Use Microdata Series: Version 5.0 [Machine-readable database]," Minneapolis: University of Minnesota.

Sachs, D., A. Tsyvinski, And N. Werquin (2020): "Nonlinear tax incidence and optimal taxation in general equilibrium," Econometrica, 88, 469-493.

SAIZ, A. (2003): "Room in the kitchen for the melting pot: Immigration and rental prices," Review of Economics and Statistics, 85, 502-521. 
(2007): "Immigration and housing rents in American cities," Journal of urban Economics, 61, 345-371.

Storesletten, K. (2000): "Sustaining fiscal policy through immigration," Journal of political Economy, 108, 300-323.

(2003): "Fiscal implications of immigration?A net present value calculation," The Scandinavian Journal of Economics, 105, 487-506.

Tsyvinski, A. And N. Werquin (2019): "Generalized Compensation Principle," Working Paper. 


\section{A Theoretical Appendix}

\section{A.1 Relation between Own-Wage Elasticity and Elasticity of Sub- stitution}

To understand the relationship $\gamma_{u, o w n}=\frac{\frac{N_{s} y_{s}}{N_{u} y_{u}+N_{s} y_{s}}}{\sigma}$, first recall the definition of the elasticity of substitution

$$
\sigma=-\frac{\frac{\partial \mathscr{L}_{u}}{\partial \mathscr{L}_{s}} / \frac{\mathscr{L}_{u}}{\mathscr{L}_{s}}}{\frac{\partial w_{u}}{\partial w_{s}} / \frac{w_{u}}{w_{s}}}
$$

Now consider an increase of low skilled labor by $1 \%$. This increases the ratio of low-skilled over high-skilled labor by $1 \%$ (since the high skilled labor stays constant). This directly implies that the relative wage ratio $\frac{\partial w_{u}}{\partial w_{s}} / \frac{w_{u}}{w_{s}}$ decreases by $\frac{1}{\sigma}$.

Next, derive the percentage change of $\frac{w_{u}}{w_{s}}$ by using the cross- and own-wage elasticity. The numerator changes by $\gamma_{u, \text { own }} \%$. The denominator changes by $\gamma_{s, \text { cross }} \%$. Hence, $\frac{\partial w_{u}}{\partial w_{s}} / \frac{w_{u}}{w_{s}}=$ $\gamma_{u, \text { own }}-\gamma_{s, \text { cross }}$. Using Lemma 1 , this can be written as: $\gamma_{u, \text { own }}+\gamma_{u, \text { own }} \frac{w_{u} \mathscr{L}_{u}}{w_{s} \mathscr{L}_{s}}$.

As a consequence, we have to have

$$
-\frac{1}{\sigma}=\gamma_{u, \text { own }}+\gamma_{u, \text { own }} \frac{w_{u} \mathscr{L}_{u}}{w_{s} \mathscr{L}_{s}}
$$

which yields the result: $\gamma_{u, o w n}=-\frac{\frac{N_{s} y_{s}}{N_{u} y_{u}+N_{s} y_{s}}}{\sigma}$.

\section{A.2 Canonical Model with Labor Supply}

\section{A.2.1 Proof of Proposition 2}

Note that tax revenue in this economy provided by natives is given by:

$$
\mathscr{R}=\int_{\mathcal{I}_{u}} T\left(y_{i}, i\right) m_{i} d i+\int_{\mathcal{I}_{s}} T\left(y_{i}, i\right) m_{i} d i .
$$

The indirect fiscal effect associated with an immigrant with productivity $\omega_{j}$ and hours $h_{j}$ is given by the effect of an immigrant on tax revenue derived from natives

$$
d \mathscr{R}_{i n d}^{e x}(j)=\frac{d \mathscr{R}}{d \mathscr{L}_{u}} \omega_{j} h_{j}
$$

Taking derivatives yields

$$
d \mathscr{R}_{i n d}^{e x}(j)=\frac{\partial w_{u}}{\partial \mathscr{L}_{u}} \omega_{j} h_{j} \int_{\mathcal{I}_{u}} \frac{\partial T\left(y_{i}, i\right)}{\partial y_{i}} h_{i} \omega_{i} m_{i} d i+\frac{\partial w_{s}}{\partial \mathscr{L}_{u}} \omega_{j} h_{j} \int_{\mathcal{I}_{s}} \frac{\partial T\left(y_{i}, i\right)}{\partial y_{i}} h_{i} \omega_{i} m_{i} d i .
$$


Next, we can use the definitions of own- and cross-wage elasticities to write

$$
d \mathscr{R}_{\text {ind }}^{\text {ex }}(j)=\gamma_{u, \text { own }} \frac{\omega_{j} h_{j}}{\mathscr{L}_{u}} \int_{\mathcal{I}_{u}} \frac{\partial T\left(y_{i}, i\right)}{\partial y_{i}} h_{i} \omega_{i} w_{u} m_{i} d i+\gamma_{s, \text { cross }} \frac{\omega_{j} h_{j}}{\mathscr{L}_{u}} \int_{\mathcal{I}_{s}} \frac{\partial T\left(y_{i}, i\right)}{\partial y_{i}} h_{i} \omega_{i} w_{s} m_{i} d i
$$

Applying the relationship between cross- and own-wage elasticities in Lemma 2 yields $d \mathscr{R}_{\text {ind }}^{e x}(j)=\left|\gamma_{u, \text { own }}\right|\left(-\frac{\omega_{j} h_{j} w_{u}}{\mathscr{L}_{u} w_{u}} \int_{\mathcal{I}_{u}} \frac{\partial T\left(y_{i}, i\right)}{\partial y_{i}} h_{i} \omega_{i} w_{u} m_{i} d i+\frac{w_{u} \mathscr{L}_{u}}{w_{s} \mathscr{L}_{s}} \frac{\omega_{j} h_{j}}{\mathscr{L}_{u}} \int_{\mathcal{I}_{s}} \frac{\partial T\left(y_{i}, i\right)}{\partial y_{i}} h_{i} \omega_{i} w_{s} m_{i} d i\right)$

Finally, defining income-weighted marginal tax rates as $\bar{T}_{e}^{\prime}=\frac{\int_{i \in \mathcal{I}_{e}} \frac{\partial T\left(y_{i}, i\right)}{\partial y_{i}} y_{i} m_{i} d i}{Y_{e}}$, we can rewrite the above equation as

$$
d \mathscr{R}_{i n d}^{e x}(j)=\left|\gamma_{u, \text { own }}\right| \times y_{j} \times\left(\bar{T}_{s}^{\prime}-\bar{T}_{u}^{\prime}\right) .
$$

\section{A.2.2 Proof of Lemma 3}

Tax revenue is given by

$$
\mathscr{R}=\int_{\mathcal{I}_{u}}\left(T\left(y_{i}, i\right) \nu_{i}+T(0, i)\left(1-\nu_{i}\right)\right) m_{i} d i+\int_{\mathcal{I}_{s}}\left(T\left(y_{i}, i\right) \nu_{i}+T(0, i)\left(1-\nu_{i}\right)\right) m_{i} d i
$$

Denote by $\frac{d w_{u}}{w_{u}}$ and $\frac{d w_{s}}{w_{s}}$ the equilibrium changes in wages that occur due to the immigrant and the implied endogenous responses of the natives along both the intensive and the extensive margins. Then, it follows from the definitions of the labor supply elasticities that tax revenue changes according to:

$$
\begin{aligned}
d \mathscr{R}_{\text {ind }}= & \int_{\mathcal{I}_{u}} T^{\prime}\left(y_{i}, i\right) y_{i} \frac{d w_{u}}{w_{u}}\left(1+\varepsilon_{i}\right) \nu_{i} m_{i} d i+\int_{\mathcal{I}_{s}} T^{\prime}\left(y_{i}, i\right) y_{i} \frac{d w_{s}}{w_{s}}\left(1+\varepsilon_{i}\right) \nu_{i} m_{i} d i \\
& +\int_{\mathcal{I}_{u}} T_{\text {part }}\left(y_{i}, i\right) y_{i} \frac{d w_{u}}{w_{u}} \eta_{i} \nu_{i} m_{i} d i+\int_{\mathcal{I}_{s}} T_{\text {part }}\left(y_{i}, i\right) y_{i} \frac{d w_{s}}{w_{s}} \eta_{i} \nu_{i} m_{i} d i .
\end{aligned}
$$

\section{A.2.3 Proof of Lemma 4}

The set of integral equations is given by

$$
\forall i \in \mathcal{I}_{u}: \frac{d L_{i}}{L_{i}}=\xi_{i}\left(\gamma_{u, \text { own }} \frac{L^{I m}}{\mathscr{L}_{u}}+\gamma_{u, \text { own }} \int_{\mathcal{I}_{u}} \frac{d L_{j}}{L_{j}} \frac{L_{j} \omega_{j}}{\mathscr{L}_{u}} d j+\gamma_{u, \text { cross }} \int_{\mathcal{I}_{s}} \frac{d L_{j}}{L_{j}} \frac{L_{j} \omega_{j}}{\mathscr{L}_{s}} d j\right)
$$

and

$$
\forall i \in \mathcal{I}_{s}: \frac{d L_{i}}{L_{i}}=\xi_{i}\left(\gamma_{s, \text { cross }} \frac{L^{I m}}{\mathscr{L}_{u}}+\gamma_{s, \text { cross }} \int_{\mathcal{I}_{u}} \frac{d L_{j}}{L_{j}} \frac{L_{j} \omega_{j}}{\mathscr{L}_{u}} d j+\gamma_{s, \text { own }} \int_{\mathcal{I}_{s}} \frac{d L_{j}}{L_{j}} \frac{L_{j} \omega_{j}}{\mathscr{L}_{s}} d j\right)
$$


This is a system of integral equations with a simple solution because the kernels of the integral equations are separable. Let's first consider the integral equation for low-skilled workers. Multiplying both sides by $\frac{\omega_{i} L_{i}}{\mathscr{L}_{u}}$ and integrating over $\mathcal{I}_{u}$ gives

$$
\begin{aligned}
\int_{\mathcal{I}_{u}} \frac{d L_{i}}{L_{i}} \frac{\omega_{i} L_{i}}{\mathscr{L}_{u}} d i= & \int_{\mathcal{I}_{u}} \xi_{i}\left(\gamma_{u, \text { own }} \frac{L^{I m}}{\mathscr{L}_{u}}\right. \\
& \left.+\gamma_{u, \text { own }} \int_{\mathcal{I}_{u}} \frac{d L_{j}}{L_{j}} \frac{L_{j} \omega_{j}}{\mathscr{L}_{u}} d j+\gamma_{u, \text { cross }} \int_{\mathcal{I}_{s}} \frac{d L_{j}}{L_{j}} \frac{L_{j} \omega_{j}}{\mathscr{L}_{s}} d j\right) \frac{\omega_{i} L_{i}}{\mathscr{L}_{u}} m_{i} d i
\end{aligned}
$$

which can be written as

$$
\frac{d \mathscr{L}_{u}}{\mathscr{L}_{u}}=\bar{\xi}^{u} \gamma_{u, \text { own }} \frac{L^{I m}}{\mathscr{L}_{u}}+\bar{\xi}^{u} \gamma_{u, \text { own }} \frac{d \mathscr{L}_{u}}{\mathscr{L}_{u}}+\bar{\xi}^{u} \gamma_{u, \text { cross }} \frac{d \mathscr{L}_{s}}{\mathscr{L}_{s}}
$$

where $d \mathscr{L}_{u}=\int_{\mathcal{I}_{u}} d L_{i} \omega_{i} d i$ and $\bar{\xi}^{u}=\frac{\int_{\mathcal{I}_{i}} \xi_{i} \omega_{i} L_{i} d i}{\mathscr{L}_{u}}=\frac{\int_{\mathcal{I}_{u}} \xi_{i} y_{i} m_{i} \nu_{i} d i}{Y_{u}}$ is the income-weighted average of the total hours elasticity of low-skilled labor.

Equivalently, we obtain

$$
\frac{d \mathscr{L}_{s}}{\mathscr{L}_{s}}=\bar{\xi}^{s} \gamma_{s, \text { cross }} \frac{L^{I m}}{\mathscr{L}_{u}}+\bar{\xi}^{s} \gamma_{s, \text { cross }} \frac{d \mathscr{L}_{u}}{\mathscr{L}_{u}}+\bar{\xi}^{s} \gamma_{s, \text { own }} \frac{d \mathscr{L}_{s}}{\mathscr{L}_{s}}
$$

This is just a simple system of two linear equations and it is easy to show that it has the following solution:

$$
\frac{d \mathscr{L}_{u}}{\mathscr{L}_{u}}=\frac{\bar{\xi}^{u} \gamma_{u, \text { own }}}{1-\bar{\xi}^{u} \gamma_{u, \text { own }}-\bar{\xi}^{s} \gamma_{s, \text { own }}} \frac{L^{\text {Im }}}{\mathscr{L}_{u}}
$$

and

$$
\frac{d \mathscr{L}_{s}}{\mathscr{L}_{s}}=\frac{\bar{\xi}^{s} \gamma_{s, \text { cross }}}{1-\bar{\xi}^{u} \gamma_{u, \text { own }}-\bar{\xi}^{s} \gamma_{s, \text { own }}} \frac{L^{I m}}{\mathscr{L}_{u}} .
$$

Next, we obtain the wage changes for $e=s, u$. We can rewrite the definition of the total hours elasticity as

$$
\frac{d L_{i}}{L_{i}}=\xi_{i} \frac{d w_{e}}{w_{e}}
$$

Again multiplying both sides by $\frac{\omega_{i} L_{i}}{\mathscr{L}_{e}}$ and integrating over $\mathcal{I}_{e}$ yields

$$
\int_{\mathcal{I}_{e}} \frac{d L_{i}}{L_{i}} \frac{\omega_{i} L_{i}}{\mathscr{L}_{e}} d i=\frac{d w_{e}}{w_{e}} \int_{\mathcal{I}_{e}} \xi_{i} \frac{\omega_{i} L_{i}}{\mathscr{L}_{e}} d i
$$

Using $d \mathscr{L}_{e}=\int_{\mathcal{I}_{e}} d L_{i} \omega_{i} d i$ and $\bar{\xi}^{e}=\frac{\int_{\mathcal{I}_{i}} \xi_{i} \omega_{i} L_{i} d i}{\mathscr{L}_{e}}$ gives us

$$
\frac{d w_{e}}{w_{e}}=\frac{d \mathscr{L}_{e}}{\mathscr{L}_{e}} \frac{1}{\bar{\xi}}
$$


Therefore, we have

$$
\begin{aligned}
\frac{d w_{u}}{w_{u}} & =\frac{\gamma_{u, \text { own }}}{1+\bar{\xi}^{u}\left|\gamma_{u, \text { own }}\right|+\bar{\xi}^{s}\left|\gamma_{s, \text { own }}\right|} \frac{L^{I m}}{\mathscr{L}_{u}} \\
\frac{d w_{s}}{w_{s}} & =\frac{\gamma_{s, \text { cross }}}{1+\bar{\xi}^{u}\left|\gamma_{u, \text { own }}\right|+\bar{\xi}^{s}\left|\gamma_{s, \text { own }}\right|} \frac{L^{\text {Im }}}{\mathscr{L}_{u}} .
\end{aligned}
$$

\section{A.2.4 Proof of Proposition 3}

Now we have described the equilibrium changes of labor supply. We can now turn to the indirect fiscal effect, which is given by:

$$
\begin{aligned}
d \mathscr{R}_{\text {ind }}= & \int_{\mathcal{I}_{u}} T^{\prime}\left(y_{i}, i\right) y_{i} \frac{d w_{u}}{w_{u}}\left(1+\varepsilon_{i}\right) \nu_{i} m_{i} d i+\int_{\mathcal{I}_{s}} T^{\prime}\left(y_{i}, i\right) y_{i} \frac{d w_{s}}{w_{s}}\left(1+\varepsilon_{i}\right) \nu_{i} m_{i} d i \\
& +\int_{\mathcal{I}_{u}} T_{\text {part }}\left(y_{i}, i\right) y_{i} \frac{d w_{u}}{w_{u}} \eta_{i} \nu_{i} m_{i} d i+\int_{\mathcal{I}_{s}} T_{\text {part }}\left(y_{i}, i\right) y_{i} \frac{d w_{s}}{w_{s}} \eta_{i} \nu_{i} m_{i} d i .
\end{aligned}
$$

Now using the equilibrium wage changes:

$$
\frac{d w_{u}}{w_{u}}=\frac{\gamma_{u, \text { own }}}{1-\bar{\xi}^{u} \gamma_{u, \text { own }}-\bar{\xi}^{s} \gamma_{s, \text { own }}} \frac{L^{I m}}{\mathscr{L}_{u}}
$$

and

$$
\frac{d w_{s}}{w_{s}}=\frac{\gamma_{s, \text { cross }}}{1-\bar{\xi}^{u} \gamma_{u, \text { own }}-\bar{\xi}^{s} \gamma_{s, \text { own }}} \frac{L^{I m}}{\mathscr{L}_{u}}
$$

as well as

$$
\gamma_{s, \text { cross }}=\left|\gamma_{u, \text { own }}\right| \times \frac{w_{u} \mathscr{L}_{u}}{w_{s} \mathscr{L}_{s}}
$$

implies the following:

$$
\begin{aligned}
d \mathscr{R}_{\text {ind }}= & \frac{\frac{L^{I m}}{\mathscr{L}_{u}}\left|\gamma_{u, \text { own }}\right| Y_{u}}{1-\bar{\xi}^{u} \gamma_{u, \text { own }}-\bar{\xi}^{s} \gamma_{s, \text { own }}}\left(-\frac{\int_{\mathcal{I}_{u}} T^{\prime}\left(y_{i}, i\right) y_{i}\left(1+\varepsilon_{i}\right) \nu_{i} m_{i} d i}{Y_{u}}+\frac{\int_{\mathcal{I}_{s}} T^{\prime}\left(y_{i}, i\right) y_{i}\left(1+\varepsilon_{i}\right) \nu_{i} m_{i} d i}{Y_{s}}\right. \\
& \left.-\frac{\int_{\mathcal{I}_{u}} T_{\text {part }}\left(y_{i}, i\right) y_{i} \eta_{i} \nu_{i} m_{i} d i}{Y_{u}}+\frac{\int_{\mathcal{I}_{s}} T_{\text {part }}\left(y_{i}, i\right) y_{i} \eta_{i} \nu_{i} m_{i} d i}{Y_{s}}\right)
\end{aligned}
$$

and hence

$$
d \mathscr{R}_{\text {ind }}(i)=\frac{y_{i}\left|\gamma_{u, o w n}\right|}{1+\bar{\xi}^{u}\left|\gamma_{u, \text { own }}\right|+\bar{\xi}^{s}\left|\gamma_{s, \text { own }}\right|}\left(\bar{T}_{s}^{\prime}-\bar{T}_{u}^{\prime}+\overline{\varepsilon_{s} T_{s}^{\prime}}-\overline{\varepsilon_{u} T^{\prime}{ }_{u}}+\overline{\eta_{s} T_{\text {part }, s}}-\overline{\eta_{u} T_{\text {part }, u}}\right) .
$$

\section{A.2.5 Kaldor-Hicks Surplus}

To obtain the Kaldor-Hicks surplus, one has to add up the monetized gains and losses of all citizens and the fiscal effects. Denote the direct fiscal effect by $d \mathscr{R}_{d i r}$. The indirect fiscal effect is given by (see Proposition 3): 


$$
d \mathscr{R}_{i n d}(i)=\frac{y_{i}\left|\gamma_{u, o w n}\right|}{1+\bar{\xi}^{u}\left|\gamma_{u, o w n}\right|+\bar{\xi}^{s}\left|\gamma_{s, o w n}\right|}\left(\bar{T}_{s}^{\prime}-\bar{T}_{u}^{\prime}+\overline{\varepsilon_{s} T_{s}^{\prime}}-\overline{\varepsilon_{u} T_{u}^{\prime}}+\overline{\eta_{s} T_{\text {part }, s}}-\overline{\eta_{u} T_{\text {part }, u}}\right)
$$

The monetized utility effect of native individuals is simply given by the change in income that arises due to the change in wages. The changes in income due to changes in labor supply do not matter for utility due to the envelope theorem. Hence, an individual of type $i$ with $e_{i}=e$ has a utility change of

$$
\left(1-T^{\prime}\left(y_{i}, i\right)\right) y_{i} \frac{d w_{e}}{w_{e}}
$$

where $\frac{d w_{e}}{w_{e}}$ is given in Lemma 4. Integrating over all natives and adding the monetized gains and losses to the tax revenue effects gives the immigration surplus:

$\operatorname{Surplus}_{\text {Kaldor-Hicks }}(i)=d \mathscr{R}_{\text {dir }}+\frac{y_{i}\left|\gamma_{u, o w n}\right|}{1+\bar{\xi}^{u}\left|\gamma_{u, \text { own }}\right|+\bar{\xi}^{s}\left|\gamma_{s, \text { own }}\right|}\left(\overline{\varepsilon_{s} T_{s}^{\prime}}-\overline{\varepsilon_{u} T^{\prime}}+\overline{\eta_{s} T_{\text {part }, s}}-\overline{\eta_{u} T_{\text {part }, u}}\right)$.

The indirect fiscal effects that were not caused by fiscal externalities and the monetized gains and losses from natives add up to zero. What the government gains is what native taxpayers in aggregate lose.

Note that this only holds because all gains and losses are given equal weight. If we follow Hendren (2020) and weight the monetized utility gains and losses by the inverse optimum weights $g(y)$, then we obtain:

$$
\begin{aligned}
\text { Surplus }_{\text {weighted }}(i)= & d \mathscr{R}_{\text {dir }}+\frac{y_{i}\left|\gamma_{u, \text { own }}\right|}{1+\bar{\xi}^{u}\left|\gamma_{u, \text { own }}\right|+\bar{\xi}^{s}\left|\gamma_{s, \text { own }}\right|} \times \\
& \left(\overline{g_{s}\left(1-T_{s}^{\prime}\right)}-\overline{g_{u}\left(1-T_{u}^{\prime}\right)}+\overline{T_{s}^{\prime}}-\overline{T_{u}^{\prime}}+\overline{\varepsilon_{s} T_{s}^{\prime}}-\overline{\varepsilon_{u} T_{u}^{\prime}}+\overline{\eta_{s} T_{\text {part }, s}}-\overline{\eta_{u} T_{\text {part }, u}}\right) .
\end{aligned}
$$

\section{A.3 Indirect Fiscal Effect with Four Education Groups and Imper- fectly Substitutable Experience Groups}

We consider an immigrant $i$ with experience $a$ and education $e$. The indirect fiscal effect is given by:

$d \mathscr{R}_{i n d}(a, e, i)=h_{i} \omega_{i}\left[\sum_{e^{\prime} \neq e} \sum_{a^{\prime}}\left(\bar{T}_{a^{\prime} e^{\prime}}^{\prime} \mathscr{L}_{a^{\prime} e^{\prime}} \frac{\partial w_{a^{\prime} e^{\prime}}}{\partial \mathscr{L}_{a e}}\right)+\sum_{a^{\prime} \neq a}\left(\bar{T}_{a^{\prime} e^{\prime}}^{\prime} \mathscr{L}_{a^{\prime} e} \frac{\partial w_{a^{\prime} e}}{\partial \mathscr{L}_{a e}}\right)+\left(\bar{T}_{a e}^{\prime} \mathscr{L}_{a e} \frac{\partial w_{a e}}{\partial \mathscr{L}_{a e}}\right)\right]$

The first term captures the wage changes of individuals with different education levels, whose wage unambiguously increases. The second term captures the wage change of those 
with the same education but different experience, whose wage may increase or decrease. The third term captures the wage change of those with the same education and experience, whose wage unambiguously decreases.

Now we rewrite it in terms of elasticities

$d \mathscr{R}_{i n d}(a, e, i)=h_{i} \omega_{i}\left[\sum_{e^{\prime} \neq e} \sum_{a^{\prime}}\left(\bar{T}_{a^{\prime} e^{\prime}}^{\prime} \frac{\mathscr{L}_{a^{\prime} e^{\prime}} w_{a^{\prime} e^{\prime}}}{\mathscr{L}_{a e}} \gamma_{a^{\prime} e^{\prime}, a e}\right)+\sum_{a^{\prime} \neq a}\left(\bar{T}_{a^{\prime} e}^{\prime} \frac{\mathscr{L}_{a^{\prime} e} w_{a^{\prime} e}}{\mathscr{L}_{a e}} \gamma_{a^{\prime} e, a e}\right)+\left(\bar{T}_{a e}^{\prime} w_{a e} \gamma_{a e, a e}\right)\right]$.

Let $Y_{a e}=w_{a e} \mathscr{L}_{a e}$ give aggregate income for a given education-experience group and let $Y_{e}=$ $\sum_{a} Y_{a e}$ give aggregate income of a given education group. Further, let $\kappa_{e}=\frac{Y_{e}}{Y}$ give the income share of education group $e$ and let $\kappa_{a, e}=\frac{Y_{a e}}{Y_{e}}$ give the income share of experience group $a$ within education group $e$. Some standard algebra shows, that the wage elasticities read as follows for this nested CES production function:

$$
\gamma_{e, e}=-\frac{1-\kappa_{e}}{\sigma_{E}}
$$

and

$$
\gamma_{e^{\prime}, e}=\frac{\kappa_{e}}{\sigma_{E}}
$$

Further, for $e^{\prime} \neq e$, we have:

$$
\gamma_{a^{\prime} e^{\prime}, a e}=\frac{\kappa_{e}}{\sigma_{E}} \kappa_{a, e}=\gamma_{e^{\prime}, e} \kappa_{a, e} .
$$

For $e^{\prime}=e$, this becomes:

$$
\gamma_{a^{\prime} e, a e}=-\frac{1-\kappa_{e}}{\sigma_{E}} \kappa_{a, e}+\underbrace{\frac{\kappa_{a, e}}{\sigma_{X}}}_{:=\tilde{\gamma}_{a^{\prime} e, a e}}=\gamma_{e, e} \kappa_{a, e}+\tilde{\gamma}_{a^{\prime} e, a e} .
$$

Finally, for $e^{\prime}=e$ and $a^{\prime}=a$, this becomes

$$
\gamma_{a e, a e}=-\frac{1-\kappa_{e}}{\sigma_{E}} \kappa_{a, e} \underbrace{-\frac{1-\kappa_{a, e}}{\sigma_{X}}}_{:=\tilde{\gamma}_{a e, a e}}=\gamma_{e, e} \kappa_{a, e}+\tilde{\gamma}_{a e, a e} .
$$

Plugging this into the indirect fiscal effect formulas gives:

$$
\begin{aligned}
d \mathscr{R}_{\text {ind }}^{\text {Borjas }}(a, e, i)= & h_{i} \omega_{i}\left[\frac { \kappa _ { a , e } } { \mathscr { L } _ { a e } \sigma _ { E } } \left(\kappa_{e} \sum_{e^{\prime} \neq e} \sum_{a^{\prime}}\left(\bar{T}_{a^{\prime} e^{\prime}}^{\prime} \mathscr{L}_{a^{\prime} e^{\prime}} w_{a^{\prime} e^{\prime}}\right)\right.\right. \\
& \left.-\left(1-\kappa_{e}\right)\left(\sum_{a^{\prime}} \bar{T}_{a^{\prime} e}^{\prime} \mathscr{L}_{a^{\prime} e} w_{a^{\prime} e}\right)\right) \\
& \left.+\frac{1}{\mathscr{L}_{a e} \sigma_{X}}\left(\kappa_{a, e} \sum_{a^{\prime} \neq a}\left(\bar{T}_{a^{\prime} e}^{\prime} \mathscr{L}_{a^{\prime} e} w_{a^{\prime} e}\right)-\left(1-\kappa_{a, e}\right)\left(\bar{T}_{a e}^{\prime} \mathscr{L}_{a e} w_{a e}\right)\right)\right] .
\end{aligned}
$$


This can be rewritten as

$$
\begin{aligned}
d \mathscr{R}_{\text {ind }}^{\text {Borjas }}(a, e, i)= & \underbrace{h_{i} \omega_{i} w_{a e}}_{y_{i}}\left[\frac{\kappa_{a, e}}{Y_{a e} \sigma_{E}}\left(\kappa_{e} \sum_{e^{\prime} \neq e}\left(Y_{e}^{\prime}\right) \times \bar{T}_{e^{\prime} \neq e}^{\prime}-\left(1-\kappa_{e}\right) Y_{e} \bar{T}_{e}^{\prime}\right)\right. \\
& \left.+\frac{1}{Y_{a e} \sigma_{X}}\left(\kappa_{a, e} \sum_{a^{\prime} \neq a}\left(Y_{a^{\prime} e}\right) \times \bar{T}_{a^{\prime} \neq a, e}^{\prime}-\left(1-\kappa_{a, e}\right) Y_{a e} \bar{T}_{a e}^{\prime}\right)\right] .
\end{aligned}
$$

Now use the definition of the income shares to write this as:

$$
\begin{aligned}
d \mathscr{R}_{\text {ind }}^{\text {Borjas }}(a, e, i)= & y_{i}\left[\frac{\kappa_{a, e}\left(1-\kappa_{e}\right) Y_{e}}{Y_{a e} \sigma_{E}}\left(\bar{T}_{e^{\prime} \neq e}^{\prime}-\bar{T}_{e}^{\prime}\right)\right. \\
& \left.+\frac{\left(1-\kappa_{a, e}\right) Y_{a e}}{Y_{a e} \sigma_{X}}\left(\bar{T}_{a^{\prime} \neq a, e}^{\prime}-\bar{T}_{a e}^{\prime}\right)\right] .
\end{aligned}
$$

and hence

$$
d \mathscr{R}_{\text {ind }}^{\text {Borjas }}(a, e, i)=y_{i}\left[\left(\bar{T}_{a^{\prime} \neq a, e}^{\prime}-\bar{T}_{a e}^{\prime}\right)\left|\tilde{\gamma}_{a e, o w n}\right|+\left(\bar{T}_{e^{\prime} \neq e}^{\prime}-\bar{T}_{e}^{\prime}\right)\left|\gamma_{e, o w n}\right|\right]
$$

\section{A.4 Indirect Fiscal Effects with Domestic- and Foreign-Born Com- plementarity}

The top nest of the production functions combines a high-skilled labor aggregate $\mathscr{L}_{s}$ and a low-skilled labor aggregate $\mathscr{L}_{u}$ using the following production function

$$
Y=\left(\theta_{s} \mathscr{L}_{s}^{\frac{\sigma-1}{\sigma}}+\theta_{u} \mathscr{L}_{u}^{\frac{\sigma-1}{\sigma}}\right)^{\frac{\sigma}{\sigma-1}}
$$

$\mathscr{L}_{s}$ aggregates some college and college graduate labor while $\mathscr{L}_{u}$ aggregates high school dropout and high school graduate labor. Let $e_{1}, e_{2}, e_{3}$, and $e_{4}$ denote high school dropout, high school graduate, some college and college graduate labor, respectively. Then we can write

$$
\mathscr{L}_{s}=\left(\theta_{e_{3}} \mathscr{L}_{e_{3}}{ }^{\frac{\sigma_{S}-1}{\sigma_{S}}}+\theta_{e_{4}} \mathscr{L}_{e_{4}}{ }^{\frac{\sigma_{S}-1}{\sigma_{S}}}\right)^{\frac{\sigma_{S}}{\sigma_{S}-1}}
$$

and

$$
\mathscr{L}_{u}=\left(\theta_{e_{1}} \mathscr{L}_{e_{1}}^{\frac{\sigma_{U}-1}{\sigma_{U}}}+\theta_{e_{2}} \mathscr{L}_{e_{2}}^{\frac{\sigma_{U}-1}{\sigma_{U}}}\right)^{\frac{\sigma_{U}}{\sigma_{U}-1}} .
$$

Each of these education aggregates combine labor from 8 experience groups, indexed by $a$, as

$$
\mathscr{L}_{e}=\left(\sum_{a} \theta_{a e} \mathscr{L}_{a e^{\frac{\sigma_{E X P}-1}{\sigma_{E X P}}}}\right)^{\frac{\sigma_{E X P}}{\sigma_{E X P}-1}} .
$$


for $e \in\left\{e_{1}, e_{2}, e_{3}, e_{4}\right\}$. Finally, each of the education, experience labor aggregates, $\mathscr{L}_{a e}$ combines nativity groups (domestic-born and foreign-born) labor using

$$
\mathscr{L}_{a e}=\left(\theta_{\text {aef }} \mathscr{L}_{\text {aef }}^{\frac{\sigma_{N, U}-1}{\sigma_{N, U}}}+\theta_{\text {aed }} \mathscr{L}_{\text {aed }}^{\frac{\sigma_{N, U}-1}{\sigma_{N, U}}}\right)^{\frac{\sigma_{N, U}}{\sigma_{N, U}-1}}
$$

and low-skilled labor $\left(e \in\left\{e_{1}, e_{2}\right\}\right)$ and

$$
\mathscr{L}_{a e}=\left(\theta_{a e f} \mathscr{L}_{a e f}^{\frac{\sigma_{N, S}-1}{\sigma_{N, S}}}+\theta_{\text {aed }} \mathscr{L}_{\text {aed }}^{\frac{\sigma_{N, S}-1}{\sigma_{N, S}}}\right)^{\frac{\sigma_{N, S}}{\sigma_{N, S}-1}}
$$

for high-skilled labor $\left(e \in\left\{e_{3}, e_{4}\right\}\right)$. $\mathscr{L}_{\text {aen }}$ gives the labor supply of a given educationexperience-nativity group $(n \in\{d, f\})$ and is given by $\mathscr{L}_{\text {aen }}=\int_{\mathcal{I}_{\text {aen }}} L_{i} \omega_{i} d i$, and where $\mathcal{I}_{\text {aen }}$ is the set of types $i$ within a given education-experience-nativity group.

The indirect fiscal benefit of an immigrant of type $i$ in experience group $a^{\prime}$ and education group $e^{\prime}$ is given by

$$
d \mathscr{R}_{i n d}\left(a^{\prime}, e^{\prime}, i\right)=\frac{y_{i}}{\bar{y}_{a^{\prime} e^{\prime} f}} \sum_{a} \sum_{e} \sum_{n} \bar{T}_{a e n}^{\prime} \frac{N_{a e n}}{N_{a^{\prime} e^{\prime} f}} \bar{y}_{a e n} \gamma_{a e n, a^{\prime} e^{\prime} f}
$$

where $\bar{y}_{a e n}$ is the average income of workers of experience group $a$, education group $e$, and nativity $n, \bar{T}_{a e n}^{\prime}$ is the income-weighted average marginal tax of workers in this group, and $\gamma_{a e n, a^{\prime} e^{\prime} f}=\frac{\partial w_{a e n}}{\partial L_{a^{\prime} e^{\prime} f}} \frac{L_{a^{\prime} e^{\prime} f}}{w_{a e n}}$ is the elasticity of wages of workers of experience group $a$ and education $e$ and nativity $n$ with respect to labor supply of foreign-born workers of experience group $a^{\prime}$ and education $e^{\prime}$. We refrain from further simplifying the formula in this case.

\section{A.5 Indirect Fiscal Effects in Dustmann, Frattini, and Preston (2013)}

The indirect fiscal effect for an immigrant of skill group $j$ is given by

$$
d \mathscr{R}_{i n d}(j, i)=h_{i} \omega_{i} \sum_{k} \int_{\mathcal{I}_{k}} T^{\prime}\left(y_{i}\left(\omega^{\prime}\right)\right) L_{i} \frac{\partial w_{j}}{\partial \mathscr{L}_{i}} d i=h_{i} \omega_{i} \sum_{k} \bar{T}_{k}^{\prime} \mathscr{L}_{j} \frac{\partial w_{k}}{\partial \mathscr{L}_{j}}
$$

Since the production function is CRS, we know by Euler's equation that

$$
\mathscr{L}_{j} \frac{\partial w_{j}}{\partial L_{j}}=-\sum_{k \neq j} \mathscr{L}_{k} \frac{\partial w_{k}}{\partial \mathscr{L}_{j}}
$$

Plugging this into the indirect fiscal effect and rearranging yields:

$$
d \mathscr{R}_{i n d}(j, i)=h_{i} \omega_{i} \sum_{k \neq j}\left(\bar{T}_{k}^{\prime}-\bar{T}_{j}^{\prime}\right) \mathscr{L}_{k} \frac{\partial w_{k}}{\partial \mathscr{L}_{j}}
$$


which can be rewritten in terms of elasticities as

$$
d \mathscr{R}_{i n d}(j, i)=h_{i} \omega_{i} \sum_{k \neq j}\left(\bar{T}_{k}^{\prime}-\bar{T}_{j}^{\prime}\right) \frac{w_{k} \mathscr{L}_{k}}{\mathscr{L}_{j}} \gamma_{k, j}
$$

where $\gamma_{k, j}=\frac{\partial w_{k}}{\partial \mathscr{L}_{j}} \frac{\mathscr{L}_{j}}{w_{k}}$ gives the cross-wage elasticity of $k$ 's wages with respect to $\mathscr{L}_{j}$.

Given the CES production function, these cross-wage elasticities are all given by $\gamma_{k, j}=\frac{1}{\sigma} \kappa_{j}$, where $\kappa_{j}=\frac{w_{j} L_{j}}{Y}$. Plugging in and rearranging yields

$$
d \mathscr{R}_{i n d}(j, i)=\frac{y_{i}}{\sigma}\left[\left(\sum_{k \neq j}\left(\bar{T}_{k}^{\prime} \kappa_{k}\right)\right)-\bar{T}_{j}^{\prime} \sum_{k \neq j} \kappa_{k}\right] .
$$

Dividing and multiplying by $\sum_{k \neq j} \kappa_{k}=1-\kappa_{j}$ yields

$$
d \mathscr{R}_{i n d}(j, i)=\frac{y_{i}}{\sigma}\left[\bar{T}_{k \neq j}^{\prime}-\bar{T}_{j}^{\prime}\right]\left(1-\kappa_{j}\right)
$$

where $\bar{T}_{k \neq j}^{\prime}=\frac{\sum_{k \neq j} T^{\prime}\left(y_{k}\right) \omega_{k}}{\sum_{k \neq j} \omega_{k}}$ is the income weighted tax of all other group $k \neq j$.

$$
d \mathscr{R}_{\text {ind }}^{D F P}(j, i)=y_{i} \times\left(\bar{T}_{k \neq j}^{\prime}-\bar{T}_{j}\right) \times\left|\gamma_{j, \text { own }}\right|=y_{i} \times\left(\bar{T}_{k \neq j}^{\prime}-\bar{T}_{j}\right) \frac{1-\kappa_{j}}{\sigma}
$$

where we used $\frac{1-\kappa_{j}}{\sigma}=\left|\gamma_{j, \text { own }}\right|$.

\section{A.6 Indirect Fiscal Effect in Peri and Sparber (2009)}

The starting point is equation (15)

$$
d \mathscr{R}_{i n d}^{P S}=T_{s}^{\prime} N_{s} \frac{d y_{s}}{d N_{f}} d N_{f}+T_{f}^{\prime} N_{f} \frac{d y_{f}}{d N_{f}} d N_{f}+T_{d}^{\prime} N_{d} \frac{d y_{d}}{d N_{f}} d N_{f}
$$

We now show how this can be decomposed into three terms:

$$
d \mathscr{R}_{\text {ind }}=\underbrace{d \mathscr{R}_{\text {ind }}^{S R}}_{\text {short run effect }}+\underbrace{d \mathscr{R}_{\text {ind }}^{S O R T}}_{\text {sorting effect }}+\underbrace{d \mathscr{R}_{\text {ind }}^{P R}}_{\text {secondary price effect }}
$$

The first term captures the indirect fiscal effect that would arise if task choices were exogenous. The second term gives the change in tax revenue that is due to the change in task supplies - holding task wages constant. The third term is similar to the first term again in that it captures changes in wages for given task supplies. It captures the changes in tax payment due to wage changes that are due to the changes in task supply of low-skilled natives and low-skilled (previous) immigrants.

To arrive at this decomposition, first note that the effect of immigration $N_{f}$ on task supplies can be written (note that cognitive task supply is by assumption exogenous): 


$$
\frac{d M}{d N_{f}}=m_{f}+N_{d} \frac{d m_{d}}{d N_{f}}+N_{f} \frac{d m_{f}}{d N_{f}}=m_{f}+\left(\frac{d M}{d N_{f}}\right)_{i n d}
$$

and

$$
\frac{d C}{d N_{f}}=c_{f}+N_{d} \frac{d c_{d}}{d N_{f}}+N_{f} \frac{d c_{f}}{d N_{f}}=c_{f}+\left(\frac{d C}{d N_{f}}\right)_{i n d},
$$

where $(\cdot)_{\text {ind }}$ captures the indirect effect through changes in task supply. These indirect effect are given by

$$
\left(\frac{d C}{d N_{f}}\right)_{i n d}=c_{d} \eta_{d}^{c}(1-f)^{2}+c_{f} \eta_{c}^{f} f^{2}
$$

and

$$
\left(\frac{d M}{d N_{f}}\right)_{i n d}=m_{d} \eta_{d}^{m}(1-f)^{2}+m_{f} \eta_{f}^{m} f^{2}
$$

where

$$
\eta_{j}^{c}=\frac{d c^{j}}{d f} \frac{1}{c^{j}} \text { and } \eta_{j}^{m}=\frac{d m^{j}}{d f} \frac{1}{m^{j}} \forall j=f, d \text { and } f=\frac{N_{f}}{N_{f}+N_{d}}
$$

Note that $\eta_{j}$ and $\eta_{j}^{m}$ are general equilibrium elasticities that captures all adjustments and higher order wage effects. The reason why we express - in contrast to our analysis in the main model - the formula in terms of such general equilibrium elasticities is that Peri and Sparber (2009) provide estimates for these general equilibrium elasticities.

As a next step, note that the wage changes of high-skilled, foreign and domestic low-skilled workers can be written as (recall that for high skilled we have $y_{s}=w_{s}$ - wage equals income since the high-skilled exogenously supply one unit of cognitive taks):

$$
\begin{gathered}
\frac{d y_{s}}{d N_{f}}=\frac{\partial y_{s}}{\partial M} \frac{d M}{d N_{f}}+\frac{\partial y_{s}}{\partial C} \frac{d C}{d N_{f}} \\
=\underbrace{\frac{\partial y_{s}}{\partial M} m_{f}+\frac{\partial y_{s}}{\partial C} c_{f}}_{\text {direct effect }}+\underbrace{\frac{\partial y_{s}}{\partial M}\left(\frac{d M}{d N_{f}}\right)_{\text {ind }}+\frac{\partial y_{s}}{\partial C}\left(\frac{d C}{d N_{f}}\right)_{\text {ind }}}_{\text {indirect price effect }},
\end{gathered}
$$

for high skilled natives,

$$
\frac{d y_{f}}{d N_{f}}=\frac{d w_{m}}{d N_{f}} m_{f}+\frac{d w_{c}}{d N_{f}} c_{f}+\underbrace{w_{m} \frac{d m_{f}}{d N_{f}}+w_{c} \frac{d c_{f}}{d N_{f}}}_{\text {sorting effect }},
$$

for low-skilled foreigners and

$$
\frac{d y_{d}}{d N_{f}}=\frac{d w_{m}}{d N_{f}} m_{d}+\frac{d w_{c}}{d N_{f}} c_{d}+\underbrace{w_{m} \frac{d m_{d}}{d N_{f}}+w_{c} \frac{d c_{d}}{d N_{f}}}_{\text {sorting effect }},
$$

for low-skilled natives. For the latter two, the changes in wages of the manual and communication tasks can be written as: 


$$
\frac{d w_{m}}{d N_{f}}=\underbrace{\frac{\partial w_{m}}{\partial M} m_{f}+\frac{\partial w_{m}}{\partial C} c_{f}}_{\text {direct effect }}+\underbrace{\frac{\partial w_{m}}{\partial M}\left(\frac{d M}{d N_{f}}\right)_{\text {ind }}+\frac{\partial w_{m}}{\partial C}\left(\frac{d C}{d N_{f}}\right)_{i n d}}_{\text {indirect price effect }},
$$

and

$$
\frac{d w_{c}}{d N_{f}}=\underbrace{\frac{\partial w_{c}}{\partial M} m_{f}+\frac{\partial w_{c}}{\partial C} c_{f}}_{\text {direct effect }}+\underbrace{\frac{\partial w_{c}}{\partial M}\left(\frac{d M}{d N_{f}}\right)_{i n d}+\frac{\partial w_{c}}{\partial C}\left(\frac{d C}{d N_{f}}\right)_{i n d}}_{\text {indirect price effect }}
$$

Rearranging terms, we can now obtain (21). We describe the three terms one after another. All the terms are expressed in terms of empirical objects. For the quantification, see Appendix B.5.

Short Run Effect: Collecting the terms that do not involve endogenous task responses yields:

$$
\begin{aligned}
& d \mathscr{R}_{i n d}^{S R}=\left.T_{s}^{\prime} N_{s} \frac{d y_{s}}{d N_{f}}\right|_{d c_{j}=d m_{j}=0} d N_{f}+ \\
& \left.T_{f}^{\prime} N_{f} \frac{d y_{f}}{d N_{f}}\right|_{d c_{j}=d m_{j}=0} d N_{f}+\left.T_{d}^{\prime} N_{d} \frac{d y_{d}}{d N_{f}}\right|_{d c_{j}=d m_{j}=0} d N_{f},
\end{aligned}
$$

where

$$
\begin{gathered}
\left.\frac{d y_{s}}{d N_{f}}\right|_{d c_{j}=d m_{j}=0}=\frac{\partial y_{s}}{\partial M} m_{f}+\frac{\partial y_{s}}{\partial C} c_{f} \\
\left.\frac{d y_{f}}{d N_{f}}\right|_{d c_{j}=d m_{j}=0}=m_{f}\left(\frac{\partial w_{m}}{\partial M} m_{f}+\frac{\partial w_{m}}{\partial C} c_{f}\right)+c_{f}\left(\frac{\partial w_{c}}{\partial M} m_{f}+\frac{\partial w_{c}}{\partial C} c_{f}\right)
\end{gathered}
$$

and

$$
\left.\frac{d y_{d}}{d N_{f}}\right|_{d c_{j}=d m_{j}=0}=m_{d}\left(\frac{\partial w_{m}}{\partial M} m_{f}+\frac{\partial w_{m}}{\partial C} c_{f}\right)+c_{d}\left(\frac{\partial w_{c}}{\partial M} m_{f}+\frac{\partial w_{c}}{\partial C} c_{f}\right)
$$

give the income elasticities of the three worker groups, holding all task supplies of a given worker constant.

Holding task supplies constant, the production function exhibits constant returns to scale in labor from the three worker types. Therefore, using Euler's theorem, we know that

$$
\left.\frac{d y_{d}}{d N_{f}}\right|_{d c_{j}=d m_{j}=0}+\left.\frac{d y_{s}}{d N_{f}}\right|_{d c_{j}=d m_{j}=0}=-\left.\frac{d y_{f}}{d N_{f}}\right|_{d c_{j}=d m_{j}=0}
$$

Plugging this in and writing in terms of elasticities yields:

$$
\begin{aligned}
\mathscr{R}_{i n d}^{S R} & =\frac{N_{d}}{N_{f}}\left(T_{d}^{\prime}-T_{f}^{\prime}\right) y_{d} \times\left.\gamma_{y_{d}, M}\right|_{d c_{j}=d m_{j}=0} m_{f} d N_{f} \\
& +\frac{N_{d}}{N_{f}}\left(T_{d}^{\prime}-T_{f}^{\prime}\right) y_{d} \times\left.\gamma_{y_{d}, C}\right|_{d c_{j}=d m_{j}=0} c_{f} d N_{f} \\
& +\frac{N_{s}}{N_{f}}\left(T_{s}^{\prime}-T_{f}^{\prime}\right) y_{s} \times\left.\gamma_{y_{s}, M}\right|_{d c_{j}=d m_{j}=0} m_{f} d N_{f} \\
& +\frac{N_{s}}{N_{f}}\left(T_{s}^{\prime}-T_{f}^{\prime}\right) y_{s} \times\left.\gamma_{y_{s}, C}\right|_{d c_{j}=d m_{j}=0} c_{f} d N_{f}
\end{aligned}
$$


where $\left.\gamma_{y_{d}, M}\right|_{d c_{j}=d m_{j}=0},\left.\gamma_{y_{d}, C}\right|_{d c_{j}=d m_{j}=0},\left.\gamma_{y_{s}, M}\right|_{d c_{j}=d m_{j}=0}$, and $\left.\gamma_{y_{s}, C}\right|_{d c_{j}=d m_{j}=0}$ are 'short run' elasticities that capture how the incomes of low- and high-skilled natives change in response to changes in task supplies under the assumption that past immigrants and low-skilled natives do not react. $\left.\gamma_{y_{d}, M}\right|_{d c_{j}=d m_{j}=0}$ and $\left.\gamma_{y_{d}, C}\right|_{d c_{j}=d m_{j}=0}$ can be written in terms of native task elasticities as

$$
\left.\gamma_{y_{d}, C}\right|_{d c_{j}=d m_{j}=0}=\gamma_{w_{c}, C} \frac{w_{c} c_{d}}{y_{d}}+\gamma_{w_{m}, C} \frac{w_{m} m_{d}}{y_{d}}
$$

and

$$
\left.\gamma_{y_{d}, M}\right|_{d c_{j}=d m_{j}=0}=\gamma_{w_{c}, M} \frac{w_{c} c_{d}}{y_{d}}+\gamma_{w_{m}, M} \frac{w_{m} m_{d}}{y_{d}} .
$$

Finally, the task price elasticities can be solved for via CES algebra as

$$
\begin{gathered}
\left.\gamma_{y_{s}, M}\right|_{d c_{j}=d m_{j}=0}=\gamma_{w_{s}, M}=\frac{\kappa_{m}}{\sigma}, \\
\left.\gamma_{y_{s}, C}\right|_{d c_{j}=d m_{j}=0}=\gamma_{w_{s}, C}=\frac{\kappa_{c}}{\sigma}, \\
\gamma_{w_{c}, C}=\left(\frac{1}{\sigma}\right) \kappa_{c}+\left(\frac{1}{\sigma_{u}}-\frac{1}{\sigma}\right) \kappa_{c}^{u}-\frac{1}{\sigma_{u}}, \\
\gamma_{w_{m}, M}=\left(\frac{1}{\sigma}\right) \kappa_{m}+\left(\frac{1}{\sigma_{u}}-\frac{1}{\sigma}\right) \kappa_{m}^{u}-\frac{1}{\sigma_{u}}, \\
\gamma_{w_{c}, M}=\left(\frac{1}{\sigma}\right) \kappa_{m}+\left(\frac{1}{\sigma_{u}}-\frac{1}{\sigma}\right) \kappa_{m}^{u},
\end{gathered}
$$

and

$$
\gamma_{w_{m}, C}=\left(\frac{1}{\sigma}\right) \kappa_{c}+\left(\frac{1}{\sigma_{u}}-\frac{1}{\sigma}\right) \kappa_{c}^{u}
$$

where $\kappa_{j}$ for $j \in\{c, m\}$ is the fraction of total income paid to factor $j$, and $\kappa_{j}^{u}$ is the fraction of total low-skilled income paid to factor $j$.

Sorting Effect: The fiscal effect of sorting is given by

$$
\underbrace{T_{f}^{\prime} N_{f}\left(w_{m} \frac{d m_{f}}{d N_{f}}+w_{c} \frac{d c_{f}}{d N_{f}}\right) d N_{f}}_{\text {Immigrant Sorting Effect }}+\underbrace{T_{d}^{\prime} N_{d}\left(w_{m} \frac{d m_{d}}{d N_{f}}+w_{c} \frac{d c_{d}}{d N_{f}}\right) d N_{f}}_{\text {Native Sorting Effect }} .
$$

The terms in brackets multiplied by $d N_{f}$ give the change in income per past immigrant and native. Multiplying this with their amount and the marginal tax rate gives the implied tax effects.

We can rewrite this formula in terms of task supply elasticities $\eta_{j}^{c}$ and $\eta_{j}^{m}$, for $j=f, d$ as

$$
\underbrace{T_{f}^{\prime} N_{f}\left(w_{m} m_{f} \eta_{f}^{m} \frac{d f}{d N_{f}}+w_{c} c_{f} \eta_{f}^{c} \frac{d f}{d N_{f}}\right) d N_{f}}_{\text {Immigrant Sorting Effect }}+\underbrace{T_{d}^{\prime} N_{d}\left(w_{m} m_{d} \eta_{d}^{m} \frac{d f}{d N_{f}}+w_{c} c_{d} \eta_{d}^{c} \frac{d f}{d N_{f}}\right) d N_{f}}_{\text {Native Sorting Effect }}
$$


Using $\frac{d f}{d N_{f}}=\frac{N_{d}}{\left(N_{d}+N_{f}\right)^{2}}$, we can rewrite this term again solely in terms of shares and independent of population size:

$$
d \mathscr{R}_{\text {ind }}^{S O R T}=\underbrace{T_{f}^{\prime} f(1-f)\left(w_{m} m_{f} \eta_{f}^{m}+w_{c} c_{f} \eta_{f}^{c}\right) d N_{f}}_{\text {Immigrant Sorting Effect }}+\underbrace{T_{d}^{\prime}(1-f)^{2}\left(w_{m} m_{d} \eta_{d}^{m}+w_{c} c_{d} \eta_{d}^{c}\right) d N_{f}}_{\text {Native Sorting Effect }} .
$$

Secondary Price Effect: Collecting the remaining terms yields the indirect price effect:

$$
\begin{aligned}
& d \mathscr{R}_{i n d}^{P R}= \\
& T_{s}^{\prime} N_{s}\left[\frac{\partial y_{s}}{\partial M}\left(\frac{d M}{d N_{f}}\right)_{i n d}+\frac{\partial y_{s}}{\partial C}\left(\frac{d C}{d N_{f}}\right)_{i n d}\right]+ \\
& T_{f}^{\prime} N_{f}\left[m_{f}\left(\frac{\partial w_{m}}{\partial M}\left(\frac{d M}{d N_{f}}\right)_{i n d}+\frac{\partial w_{m}}{\partial C}\left(\frac{d C}{d N_{f}}\right)_{i n d}\right)+c_{f}\left(\frac{\partial w_{c}}{\partial M}\left(\frac{d M}{d N_{f}}\right)_{i n d}+\frac{\partial w_{c}}{\partial C}\left(\frac{d C}{d N_{f}}\right)_{i n d}\right)\right]+ \\
& T_{d}^{\prime} N_{d}\left[m_{d}\left(\frac{\partial w_{m}}{\partial M}\left(\frac{d M}{d N_{f}}\right)_{i n d}+\frac{\partial w_{m}}{\partial C}\left(\frac{d C}{d N_{f}}\right)_{i n d}\right)+c_{d}\left(\frac{\partial w_{c}}{\partial M}\left(\frac{d M}{d N_{f}}\right)_{i n d}+\frac{\partial w_{c}}{\partial C}\left(\frac{d C}{d N_{f}}\right)_{i n d}\right)\right] .
\end{aligned}
$$

We can rearrange this to yield

$$
\begin{aligned}
& d \mathscr{R}_{\text {ind }}^{P R}= \\
& \left(\frac{d M}{d N_{f}}\right)_{\text {ind }}\left[T_{s}^{\prime} N_{s} \frac{\partial y_{s}}{\partial M}+T_{f}^{\prime} N_{f} \frac{\partial y_{f}}{\partial M}+T_{d}^{\prime} N_{d} \frac{\partial y_{d}}{\partial M}\right]+ \\
& \left(\frac{d C}{d N_{f}}\right)_{\text {ind }}\left[\bar{T}_{s}^{\prime} N_{s} \frac{\partial y_{s}}{\partial C}+T_{f}^{\prime} N_{f} \frac{\partial y_{f}}{\partial C}+T_{d}^{\prime} N_{d} \frac{\partial y_{d}}{\partial C}\right]
\end{aligned}
$$

Using again Euler's theorem again, this yields:

$$
\begin{aligned}
\mathscr{R}_{i n d}^{P R} & =\frac{N_{d}}{N_{f}}\left(T_{d}^{\prime}-T_{f}^{\prime}\right) y_{d} \times\left.\gamma_{y_{d}, M}\right|_{d c_{j}=d m_{j}=0}\left(\frac{d M}{d N_{f}}\right)_{i n d} d N_{f} \\
& +\frac{N_{d}}{N_{f}}\left(T_{d}^{\prime}-T_{f}^{\prime}\right) y_{d} \times\left.\gamma_{y_{d}, C}\right|_{d c_{j}=d m_{j}=0}\left(\frac{d C}{d N_{f}}\right)_{i n d} d N_{f} \\
& +\frac{N_{s}}{N_{f}}\left(T_{s}^{\prime}-T_{f}^{\prime}\right) y_{s} \times\left.\gamma_{y_{s}, M}\right|_{d c_{j}=d m_{j}=0}\left(\frac{d M}{d N_{f}}\right)_{i n d} d N_{f} \\
& +\frac{N_{s}}{N_{f}}\left(T_{s}^{\prime}-T_{f}^{\prime}\right) y_{s} \times\left.\gamma_{y_{s}, C}\right|_{d c_{j}=d m_{j}=0}\left(\frac{d C}{d N_{f}}\right)_{i n d} d N_{f} .
\end{aligned}
$$

\section{A.7 Indirect Fiscal Effect with Decreasing Returns to Scale}

The indirect fiscal effect associated with an immigrant of type $i$ is

$$
d \mathscr{R}_{i n d}^{\mathrm{DRS}}(i)=h_{i} \omega_{i}\left[\tau_{p} \frac{\partial \pi}{\partial \mathscr{L}_{u}}+\int_{\mathcal{I}_{s}} T^{\prime}\left(y_{i}, i\right) \frac{\partial w_{s}}{\partial \mathscr{L}_{u}} h_{i} \omega_{i} m_{i} d i+\int_{\mathcal{I}_{u}} T^{\prime}\left(y_{i}, i\right) \frac{\partial w_{u}}{\partial \mathscr{L}_{u}} h_{i} \omega_{i} m_{i} d i\right]
$$


We can rewrite this as

$$
d \mathscr{R}_{i n d}^{\mathrm{DRS}}(i)=h_{i} \omega_{i}\left[\tau_{p} \frac{\partial \pi}{\partial \mathscr{L}_{u}}+\bar{T}_{s}^{\prime} \mathscr{L}_{s} \frac{\partial w_{s}}{\partial \mathscr{L}_{u}}+\bar{T}_{u}^{\prime} \mathscr{L}_{u} \frac{\partial w_{u}}{\partial \mathscr{L}_{u}}\right]
$$

where $\bar{T}_{u}^{\prime}$ and $\bar{T}_{s}^{\prime}$ are the income-weighted marginal tax rates of low and high skilled labor and $\tau_{p}$ is the tax on profits. First, we derive a relation between a change in profits and the change in labor income. Consider the effect of the inflow on profits:

$$
\frac{\partial \pi}{\partial \mathscr{L}_{u}}=\left(\frac{\partial \pi}{\partial w_{s}} \frac{\partial w_{s}}{\partial \mathscr{L}_{u}}+\frac{\partial \pi}{\partial w_{u}} \frac{\partial w_{u}}{\partial \mathscr{L}_{u}}\right)
$$

By Hotelling's lemma $\frac{\partial \pi}{\partial w_{s}}=-\mathscr{L}_{s}$ and same for low-skilled labor. Therefore we can write:

$$
\frac{\partial \pi}{\partial \mathscr{L}_{u}}=-\left(\mathscr{L}_{s} \frac{\partial w_{s}}{\partial \mathscr{L}_{u}}+\mathscr{L}_{u} \frac{\partial w_{u}}{\partial \mathscr{L}_{u}}\right)
$$

Denote by $I$ aggregate labor income. Then we of course have

$$
\frac{\partial I}{\partial \mathscr{L}_{u}}=\mathscr{L}_{s} \frac{\partial w_{s}}{\partial \mathscr{L}_{u}}+\mathscr{L}_{u} \frac{\partial w_{u}}{\partial \mathscr{L}_{u}}
$$

and we can write

$$
\frac{\partial \pi}{\partial \mathscr{L}_{u}}=-\frac{\partial I}{\partial \mathscr{L}_{u}}
$$

With constant returns to scale, we of course have that both sides are equal to zero. With decreasing returns, profits increase and labor income decreases. Aggregate native income (sum of profits and labor income) it not affected, however. We can therefore write the indirect fiscal effect as:

$$
d \mathscr{R}_{i n d}^{\mathrm{DRS}}(i)=h_{i} \omega_{i}\left[-\tau_{p} \frac{\partial I}{\partial \mathscr{L}_{u}}+\bar{T}_{s}^{\prime} \mathscr{L}_{s} \frac{\partial w_{s}}{\partial \mathscr{L}_{u}}+\bar{T}_{u}^{\prime} \mathscr{L}_{u} \frac{\partial w_{u}}{\partial \mathscr{L}_{u}}\right]
$$

Let $\kappa_{s}=\frac{\mathscr{L}_{s} w_{s}}{\mathscr{L}_{s} w_{s}+\mathscr{L}_{u} w_{u}}$ be the high-skilled fraction of labor income. Adding and subtracting $\left(\bar{T}_{s}^{\prime} \kappa_{s}+\bar{T}_{u}^{\prime} \kappa_{u}\right) \frac{\partial I}{\partial \mathscr{L}_{u}}:$

$$
\begin{aligned}
d \mathscr{R}_{i n d}^{\mathrm{DRS}}(i)= & h_{i} \omega_{i}\left[-\tau_{p} \frac{\partial I}{\partial \mathscr{L}_{u}}+\bar{T}_{s}^{\prime}\left(\mathscr{L}_{s} \frac{\partial w_{s}}{\partial \mathscr{L}_{u}}-\kappa_{s} \frac{\partial I}{\partial \mathscr{L}_{u}}\right)+\bar{T}_{u}^{\prime}\left(\mathscr{L}_{u} \frac{\partial w_{u}}{\partial \mathscr{L}_{u}}-\kappa_{u} \frac{\partial I}{\partial \mathscr{L}_{u}}\right)+\right. \\
& \left.\left(\bar{T}_{s}^{\prime} \kappa_{s}+\bar{T}_{u}^{\prime} \kappa_{u}\right) \frac{\partial I}{\partial \mathscr{L}_{u}}\right] .
\end{aligned}
$$

Rearranging the above equation yields

$$
d \mathscr{R}_{\text {ind }}^{\mathrm{DRS}}(i)=h_{i} \omega_{i}\left[\left(\bar{T}_{I}^{\prime}-\tau_{p}\right) \frac{\partial I}{\partial \mathscr{L}_{u}}+\bar{T}_{s}^{\prime}\left(\mathscr{L}_{s} \frac{\partial w_{s}}{\partial \mathscr{L}_{u}}-\kappa_{s} \frac{\partial I}{\partial \mathscr{L}_{u}}\right)+\bar{T}_{u}^{\prime}\left(\mathscr{L}_{u} \frac{\partial w_{u}}{\partial \mathscr{L}_{u}}-\kappa_{u} \frac{\partial I}{\partial \mathscr{L}_{u}}\right)\right]
$$


where $\bar{T}_{I}^{\prime}=\bar{T}_{s}^{\prime} \kappa_{s}+\bar{T}_{u}^{\prime} \kappa_{u}$ is income weighted average income tax. Note that

$$
\mathscr{L}_{s} \frac{\partial w_{s}}{\partial \mathscr{L}_{u}}+\mathscr{L}_{u} \frac{\partial w_{u}}{\partial \mathscr{L}_{u}}=\kappa_{u} \frac{\partial I}{\partial \mathscr{L}_{u}}+\kappa_{s} \frac{\partial I}{\partial \mathscr{L}_{u}}
$$

So we can plug in $\mathscr{L}_{s} \frac{\partial w_{s}}{\partial \mathscr{L}_{u}}-\kappa_{s} \frac{\partial I}{\partial \mathscr{L}_{u}}=-\left(\mathscr{L}_{u} \frac{\partial w_{u}}{\partial \mathscr{L}_{u}}-\kappa_{u} \frac{\partial I}{\partial \mathscr{L}_{u}}\right)$ which yields

$$
d \mathscr{R}_{i n d}^{\mathrm{DRS}}(i)=h_{i} \omega_{i}\left[\left(\bar{T}_{I}^{\prime}-\tau_{p}\right) \frac{\partial I}{\partial \mathscr{L}_{u}}+\left(\bar{T}_{u}^{\prime}-\bar{T}_{s}^{\prime}\right)\left(\mathscr{L}_{u} \frac{\partial w_{u}}{\partial \mathscr{L}_{u}}-\kappa_{u} \frac{\partial I}{\partial \mathscr{L}_{u}}\right)\right]
$$

The term $\kappa_{u} \frac{\partial I}{\partial \mathscr{L}_{u}}$ is the effect of immigration on low-skilled income that occurs through the scale effect that arises from changing the total income but keeping share going to low-skilled workers constant. Therefore, we can think of the whole term $N_{u} h_{u} \frac{\partial w_{u}}{\partial \mathscr{L}_{u}}-\kappa_{u} \frac{\partial I}{\partial \mathscr{L}_{u}}$ as the total change in low-skilled income from immigration minus the scale effect. Therefore, this whole term captures the effect of immigration on wages, holding total labor income constant. Define $\frac{\partial \tilde{w}_{u}}{\partial \mathscr{L}_{u}}=N_{u} h_{u} \frac{\partial w_{u}}{\partial \mathscr{L}_{u}}-\kappa_{u} \frac{\partial I}{\partial \mathscr{L}_{u}}$ as the effect of immigration on wages, holding total labor income constant. Let's further assume that the production function is homogenous of degree $\lambda$, where $\lambda<1$ if we have decreasing returns to scale. Hence, $F\left(t \mathscr{L}_{u}, t \mathscr{L}_{s}\right)=t^{\lambda} F\left(\mathscr{L}_{u}, \mathscr{L}_{s}\right)$. Taking derivatives w.r.t. to $t$ and normalizing $t=1$ yields :

$$
\mathscr{L}_{u} w_{u}+\mathscr{L}_{s} w_{s}=\lambda F
$$

Now taking derivatives of both sides w.r.t. $\mathscr{L}_{u}$ yields:

$$
w_{u}+\mathscr{L}_{u} \frac{\partial w_{u}}{\partial \mathscr{L}_{u}}+\mathscr{L}_{s} \frac{\partial w_{s}}{\partial \mathscr{L}_{u}}=\lambda w_{u}
$$

Therefore (recall $\left.\frac{\partial I}{\partial \mathscr{L}_{u}}=\mathscr{L}_{u} \frac{\partial w_{u}}{\partial \mathscr{L}_{u}}+\mathscr{L}_{s} \frac{\partial w_{s}}{\partial \mathscr{L}_{u}}\right)$

$$
\frac{\partial I}{\partial \mathscr{L}_{u}}=(\lambda-1) w_{u}
$$

Inserting this into the indirect fiscal effect yields

$$
d \mathscr{R}_{\text {ind }}^{\mathrm{DRS}}(i)=h_{i} \omega_{i} w_{u}\left[\left(\tau_{p}-\bar{T}_{I}^{\prime}\right)(1-\lambda)+\left(\bar{T}_{s}^{\prime}-\bar{T}_{u}^{\prime}\right)\left(\left|\gamma_{u, o w n}+\kappa_{u}(1-\lambda)\right|\right)\right]
$$

which yields

$$
d \mathscr{R}_{\text {ind }}^{\mathrm{DRS}}(i)=y_{i}\left[\left(\tau_{p}-\bar{T}_{I}^{\prime}\right)(1-\lambda)+\left(\bar{T}_{s}^{\prime}-\bar{T}_{u}^{\prime}\right)\left(\left|\tilde{\gamma}_{u, \text { own }}\right|\right)\right],
$$

where $\tilde{\gamma}_{u, \text { own }}=\gamma_{u, \text { own }}+\kappa_{u}(1-\lambda)$ is own-wage elasticity, holding total labor income constant.

To solve for $\tilde{\gamma}_{u, \text { own }}$ as a function of the elasticity of substitution, note that as shown in Appendix A.1, we can use the definition of the elasticity of subsitution to write:

$$
-\frac{1}{\sigma}=\gamma_{u, o w n}-\gamma_{s, c r o s s}
$$


From Euler's homogenous function theorem we know that

$$
w_{u} \mathscr{L}_{u}+w_{s} \mathscr{L}_{s}=\lambda Y
$$

Taking derivatives with respect to $\mathscr{L}_{u}$ and rearranging yields

$$
\gamma_{s, \text { cross }}=-\gamma_{u, \text { own }} \frac{w_{u} \mathscr{L}_{u}}{w_{s} \mathscr{L}_{s}}+(\lambda-1) \frac{w_{u} \mathscr{L}_{u}}{w_{s} \mathscr{L}_{s}}
$$

Plugging this into (24) yields

$$
-\frac{1}{\sigma}=\gamma_{u, \text { own }} \underbrace{\left(1+\frac{w_{u} \mathscr{L}_{u}}{w_{s} \mathscr{L}_{s}}\right)}_{=\frac{\lambda Y}{w_{s} \mathscr{L}_{s}}}-\frac{w_{u} \mathscr{L}_{u}}{w_{s} \mathscr{L}_{s}}(\lambda-1) .
$$

Solving for $\gamma_{u, \text { own }}$ yields

$$
\gamma_{u, \text { own }}=(\lambda-1) \frac{w_{u} \mathscr{L}_{u}}{\lambda Y}-\frac{1}{\sigma} \frac{w_{s} \mathscr{L}_{s}}{\lambda Y}
$$

Using $\frac{w_{u} \mathscr{L}_{u}}{\lambda Y}=\kappa_{u}$ and $\frac{w_{s} \mathscr{L}_{s}}{\lambda Y}=\kappa_{s}$ by Euler's homogenous function theorem yields

$$
\gamma_{u, o w n}=(\lambda-1) \kappa_{u}-\frac{1}{\sigma} \kappa_{s}
$$

Therefore, we can write

$$
\tilde{\gamma}_{u, o w n}=-\frac{1}{\sigma} \kappa_{s}
$$

\section{A.8 Indirect Fiscal Effect with Inelastically Supplied Capital}

We show the proof for the more general CES production function. Let production $Y$ be given by

$$
Y=\left(\theta_{k} K^{\rho}+\theta_{l} G\left(\mathscr{L}_{u}, \mathscr{L}_{s}\right)^{\rho}\right)^{1 / \rho}
$$

We begin by solving for the relationship of factor price elasticities when capital supply is elastic and capital supply is inelastic. For this, first consider the case when capital supply is perfectly elastic. In this case, the capital labor ratio is constant. In this case, we can write $K=C G\left(\mathscr{L}_{u}, \mathscr{L}_{s}\right)$ where $C$ is the constant capital labor ratio. The production function can be written as

$$
Y=\bar{A} G\left(\mathscr{L}_{u}, \mathscr{L}_{s}\right)
$$

where $\bar{A}$ is a constant. ${ }^{71}$ The elasticities of wages with respect to low-skilled labor with perfectly elastic capital supply are given by

\footnotetext{
${ }^{71}$ Concretely, note that $Y=\left(\theta_{k}(C G)^{\rho}+\theta_{l} G^{\rho}\right)^{1 / \rho}$ and hence $Y=\left(\theta_{k} C^{\rho}+\theta_{l}\right)^{\frac{1}{\rho}} G$. Hence, the constant is given by $\bar{A}=\left(\theta_{k} C^{\rho}+\theta_{l}\right)^{\frac{1}{\rho}}$.
} 


$$
\gamma_{s, u}^{\text {elast }}=\frac{\partial \log \frac{\partial G}{\partial \mathscr{L}_{s}}}{\partial \log \mathscr{L}_{u}}
$$

and

$$
\gamma_{u, u}^{\text {elast }}=\frac{\partial \log \frac{\partial G}{\partial \mathscr{L}_{u}}}{\partial \log \mathscr{L}_{u}} .
$$

Next, consider the case in which capital supply is perfectly inelastic. Let $\kappa_{L}=\frac{w_{u} \mathscr{L}_{u}+w_{s} \mathscr{L}_{s}}{Y}$ be the share of factor payments that go to labor, let $\kappa_{K}=1-\kappa_{L}$, and let $\kappa_{u}=\frac{w_{u} \mathscr{L}_{u}}{w_{u} \mathscr{L}_{u}+w_{s} \mathscr{L}_{s}}$ be the share of wage payments that go to low-skilled labor.

Let $r$ give the price of capital. Standard CES algebra yields the capital price elasticity

$$
\gamma_{r, u}=\frac{\kappa_{L}}{\sigma} \kappa_{u}
$$

Further, note that log wages for each skill group are given by

$$
\log w_{u}=\log \frac{\partial Y}{\partial G}+\log \frac{\partial G}{\partial \mathscr{L}_{u}}
$$

and

$$
\log w_{s}=\log \frac{\partial Y}{\partial G}+\log \frac{\partial G}{\partial \mathscr{L}_{s}} .
$$

Taking derivatives of these $\log$ wage functions with respect to $\log \mathscr{L}_{u}$ yields

$$
\gamma_{s, u}=\underbrace{\frac{\partial \log \frac{\partial Y}{\partial G}}{\partial \log \mathscr{L}_{u}}}_{=-\frac{\kappa_{K}}{\sigma} \kappa_{u}}+\underbrace{\frac{\partial \log \frac{\partial G}{\partial \mathscr{L}_{s}}}{\partial \log \mathscr{L}_{u}}}_{\gamma_{s, u}^{\text {elast }}}
$$

and

$$
\gamma_{u, u}=\underbrace{\frac{\partial \log \frac{\partial Y}{\partial G}}{\partial \log \mathscr{L}_{u}}}_{=-\frac{\kappa_{K}}{\sigma} \kappa_{u}}+\underbrace{\frac{\partial \log \frac{\partial G}{\partial \mathscr{L}_{u}}}{\partial \log \mathscr{L}_{u}}}_{\gamma_{u, u}^{\text {elast }}},
$$

which give the relationship between own wage elasticity with elastically supplied and inelastically supplied capital.

Now, consider the indirect fiscal effect with inelastically supply supplied capital:

$$
d \mathscr{R}_{i n d}(i)=h_{i} \omega_{i}\left[\tau_{k} K \frac{\partial r}{\partial \mathscr{L}_{u}}+\bar{T}_{s}^{\prime} \mathscr{L}_{s} \frac{\partial w_{s}}{\partial \mathscr{L}_{u}}+\bar{T}_{u}^{\prime} \mathscr{L}_{u} \frac{\partial w_{u}}{\partial \mathscr{L}_{u}}\right]
$$

We can rewrite this as

$$
d \mathscr{R}_{i n d}(i)=h_{i} \omega_{i}\left[\tau_{k} \frac{r K}{\mathscr{L}_{u}} \gamma_{r, u}+\bar{T}_{s}^{\prime} \frac{\mathscr{L}_{s} w_{s}}{\mathscr{L}_{u}} \gamma_{s, u}+\bar{T}_{u}^{\prime} w_{u} \gamma_{u, u}\right]
$$


Plugging in the factor price elasticities from above yields

$$
\begin{aligned}
d \mathscr{R}_{\text {ind }}(i)= & h_{i} \omega_{i}\left[\frac{\kappa_{u}}{\mathscr{L}_{u} \sigma}\left(\tau_{k} r K \frac{w_{u} \mathscr{L}_{u}+w_{s} \mathscr{L}_{s}}{Y}-\bar{T}_{s}^{\prime} \mathscr{L}_{s} w_{s} \frac{r K}{Y}-\bar{T}_{u}^{\prime} \mathscr{L}_{u} w_{u} \frac{r K}{Y}\right)+\right. \\
& \left.\bar{T}_{s}^{\prime} \frac{\mathscr{L}_{s} w_{s}}{\mathscr{L}_{u}} \gamma_{s, u}^{\text {elast }}+\bar{T}_{u}^{\prime} w_{u} \gamma_{u, u}^{\text {elast }}\right] .
\end{aligned}
$$

Factorizing $\kappa_{K}=\frac{r K}{Y}$ in the first line yields

$$
\begin{aligned}
d \mathscr{R}_{\text {ind }}(i)= & h_{i} \omega_{i}\left[\kappa_{K} \frac{\kappa_{u}}{\mathscr{L}_{u} \sigma}\left(\tau_{k}\left(w_{u} \mathscr{L}_{u}+w_{s} \mathscr{L}_{s}\right)-\bar{T}_{s}^{\prime} \mathscr{L}_{s} w_{s}-\bar{T}_{u}^{\prime} \mathscr{L}_{u} w_{u}\right)+\right. \\
& \left.\bar{T}_{s}^{\prime} \frac{\mathscr{L}_{s} w_{s}}{\mathscr{L}_{u}} \gamma_{s, u}^{\text {elast }}+\bar{T}_{u}^{\prime} w_{u} \gamma_{u, u}^{\text {elast }}\right] .
\end{aligned}
$$

Letting $\bar{T}_{I}^{\prime}=\frac{\bar{T}_{s}^{\prime} \mathscr{L}_{s} w_{s}+\bar{T}_{u}^{\prime} \mathscr{L}_{u} w_{u}}{w_{u} \mathscr{L}_{u}+w_{s} \mathscr{L}_{s}}$, we can rewrite this as:

$$
d \mathscr{R}_{i n d}(i)=h_{i} \omega_{i}\left[\left(w_{u} \mathscr{L}_{u}+w_{s} \mathscr{L}_{s}\right) \kappa_{K} \frac{\kappa_{u}}{\mathscr{L}_{u} \sigma}\left(\tau_{k}-\bar{T}_{I}^{\prime}\right)+\bar{T}_{s}^{\prime} \frac{\mathscr{L}_{s} w_{s}}{\mathscr{L}_{u}} \gamma_{s, u}^{\text {elast }}+\bar{T}_{u}^{\prime} w_{u} \gamma_{u, u}^{\text {elast }},\right]
$$

which can be simplified to

$$
d \mathscr{R}_{\text {ind }}(i)=h_{i} \omega_{i}\left[w_{u} \frac{\kappa_{K}}{\sigma}\left(\tau_{k}-\bar{T}_{I}^{\prime}\right)+\bar{T}_{s}^{\prime} \frac{\mathscr{L}_{s} w_{s}}{\mathscr{L}_{u}} \gamma_{s, u}^{\text {elast }}+\bar{T}_{u}^{\prime} w_{u} \gamma_{u, u}^{\text {elast }} \cdot\right]
$$

Further, we know that $F$ is constant returns to scale, which implies that $w_{u} \gamma_{u, u}^{\text {elast }}=-\frac{\mathscr{L}_{s} w_{s}}{\mathscr{L}_{u}} \gamma_{s, u}^{\text {elast }}$ (recall Lemma 2). We can therefore write

$$
d \mathscr{R}_{\text {ind }}(i)=h_{i} \omega_{i}\left[w_{u} \frac{\kappa_{K}}{\sigma}\left(\tau_{k}-\bar{T}_{I}^{\prime}\right)+\left(\bar{T}_{s}^{\prime}-\bar{T}_{u}^{\prime}\right) w_{u}\left|\gamma_{u, u}^{\text {elast }}\right|\right]
$$

Rearranging this equation yields

$$
d \mathscr{R}_{\text {ind }}(i)=y_{i}\left[\left(\bar{T}_{s}^{\prime}-\bar{T}_{u}^{\prime}\right)\left|\gamma_{u, o w n}^{\text {elast }}\right|+\frac{\kappa_{K}}{\sigma}\left(\tau_{k}-\bar{T}_{I}^{\prime}\right)\right]
$$

If the production function is Cobb-Douglas in capital and the labor aggregate, then $\frac{\kappa_{K}}{\sigma}=\alpha$.

\section{B Empirical Appendix}

\section{B.1 Data Cleaning and Sample Selection in the ACS}

We use data from the 2017 ACS. We limit the sample to individuals between ages 18 and 65 who do not live in group quarters. We limit our sample to household heads and their spouses, 
as tax filling status is less clear for other individuals. This leaves us with a sample of over 1.2 million individuals.

When calculating taxes, we account for an individual's wage income and business income as sources of taxable income. All income weighted averages are weighted by wage incomes and sample weights. When calculating the income-weighted pass-through tax rate in Section 6.5, we weight by business income.

\section{B.2 Calculation of Marginal Phase-Out Rates and TANF and SNAP}

We begin by calculating total monthly SNAP benefits and TANF benefits for each household in the SIPP. To deal with underreporting, we estimate these estimated monthly benefits such that the total benefits received match national aggregates reported from the Bureau of Economic Analysis. Next, we divide households by household size and estimate monthly TANF and SNAP benefits as a linear spline in household income. We estimate a separate spline for each household size. Next, using these function of benefits as a function of income, we can calculate the marginal average monthly benefits as a function of monthly income and household size. We aggregate these monthly estimates to yearly estimates by taking the income-weighted average across months for each household in the SIPP.

\section{B.3 Calculation of Marginal Replacement Rates of Social Security Benefits}

An individual's social security benefits are calculated as a function of their average indexed monthly earnings (AIME). If the current year's income is one of the 35 highest earning years, a $\$ 1$ increase in current year income will increase an individual's AIME by $\$ 1 / 35$. If the current year's income is not one of the 35 highest earning years, a marginal increase in current year income will have no effect on social security benefits. Further, if current year's income is above the maximum taxable earnings threshold, an increase in current income has no effect on social security benefits.

We assume an individual receives social security from age 66 until their death.

Let $M R R\left(A I M E_{i}\right)$ denote the marginal increase in yearly social security benefits as a function of an individual's AIME and let $T_{i}$ represent an individual's life expectancy. The discounted marginal replacement rate associate with current earnings of an individual of age $a_{g} e_{i}$ is given by:

$$
D R R_{i}=\operatorname{MRR}\left(A I M E_{i}\right) \frac{1}{35}\left(\frac{1+g}{1+r}\right)^{65-a g e_{i}} \sum_{t=66}^{T_{i}}\left(\frac{1}{1+r}\right)^{t-65}
$$

if current year income is one of the individual's 35 highest earning years and income is below the maximum taxable earnings threshold, and 0 otherwise, where $g$ is the aggregate growth rate 
and $r$ is the interest rate. This gives the increase in yearly social security benefits associated with a $\$ 1$ increase in AIME. An increase in the current year's income increase the average career income by $1 / 35$, which in turn increases yearly future social security benefits from the agents retirement until death.

We estimate an individual's AIME and 35th highest year of earning as a function of current income and household characteristics using data from the NLSY79. The NLSY79 is a nationally representative panel dataset which provides data on respondents from 1979 until 2016. There are a few issues with missing data that we need to resolve. First, starting in 1994, individuals are only interviewed in even numbered years. We therefore assume that data in odd numbered years post 1994 is the same as in the previous year. Further, in 2016, the last year from which data are available, respondents are between age 53 and 60 . We therefore do not have income information for the last few years of individual's working lives. We therefore assume that income for the remainder of the working life is equal to a respondent's last observed income.

After dealing with these data issues, we can calculate an individual's AIME as the average of their 35 highest income years, adjusted for inflation, and an individual's 35th highest income year. We calculate the average of these two statistics conditional the following characteristics:

1. An individual's education - high school dropout, high school graduate, some college, or college graduate

2. Whether or not an agent is married

3. 5-year age bins

4. Whether or not the agent has children living in their household

5. Quintiles of the income distribution, conditional on working and conditional on the above characteristics.

For individuals in the ACS, we impute AIME and 35th highest earning year as the average of these two statistics conditional on the characteristics above.

\section{B.4 Intensive and Extensive Labor Supply Elasticities from Bargain, Orsini, and Peichl (2014)}

Tables 8 and 9 display the extensive and intensive labor supply elasticities estimated in Bargain, Orsini, and Peichl (2014). The first column displays the income quintile. The next four columns display the labor supply elasticities for married females, single females, married males, and single males, respectively. 


\begin{tabular}{|c|c|c|c|c|}
\hline \multirow{2}{*}{$\begin{array}{l}\text { Income } \\
\text { Quintile }\end{array}$} & \multicolumn{2}{|c|}{ Females } & \multicolumn{2}{|c|}{ Males } \\
\hline & Married & Single & Married & Single \\
\hline 1 & 0.12 & 0.19 & 0.07 & 0.20 \\
\hline 2 & 0.12 & 0.31 & 0.05 & 0.25 \\
\hline 3 & 0.12 & 0.23 & 0.05 & 0.20 \\
\hline 4 & 0.12 & 0.16 & 0.04 & 0.16 \\
\hline 5 & 0.11 & 0.09 & 0.02 & 0.10 \\
\hline
\end{tabular}

Table 8: Estimates of extensive margin labor supply elasticities from Bargain, Orsini, and Peichl (2014) by income quintile, gender, and marital status.

\begin{tabular}{|c|c|c|c|c|}
\hline Income & \multicolumn{2}{|c|}{ Females } & \multicolumn{2}{|c|}{ Males } \\
\hline Quintile & Married & Single & Married & Single \\
\hline 1 & 0.02 & 0.03 & 0.02 & 0.01 \\
\hline 2 & 0.02 & 0.03 & 0.03 & 0.02 \\
\hline 3 & 0.02 & 0.04 & 0.03 & 0.02 \\
\hline 4 & 0.02 & 0.05 & 0.03 & 0.02 \\
\hline 5 & 0.04 & 0.06 & 0.05 & 0.04 \\
\hline
\end{tabular}

Table 9: Estimates of intensive margin labor supply elasticities from Bargain, Orsini, and Peichl (2014) by income quintile, gender, and marital status.

\section{B.5 Quantifying the Fiscal Effect in Peri and Sparber (2009)}

We now calculate the indirect fiscal benefits and its decomposition as expressed in equation 21. In order to evaluate this equation, we need estimates of the following:

1. $\left(w_{m}, w_{c}, w_{s}\right)$ - the task prices of manual, communication, and cognitive tasks.

2. $\left(\sigma, \sigma_{u}\right)$ - the elasticities of substitution between high-skilled and low-skilled workers, and between manual tasks and cognitive tasks.

3. $\left(\eta_{c}^{f}, \eta_{f}^{m}, \eta_{d}^{c}, \eta_{d}^{m}\right)$ - the elasticities of task intensities with respect to immigrant inflows.

4. $\left(N_{f}, N_{d}, N_{s}\right)$ - the number of low-skilled immigrants, low-skilled natives and high-skilled workers.

5. $\left(c_{f}, c_{d}, m_{f}, m_{d}\right)$ - the task intensities of low-skilled natives and immigrants

6. $\left(\bar{T}_{f}^{\prime}, \bar{T}_{d}^{\prime}, \bar{T}_{s}^{\prime}\right)$ - marginal tax rates faced by low-skilled immigrants, low-skilled natives, and high-skilled workers.

We take estimates of items (1) - (3) directly from Peri and Sparber (2009). Specifically, Peri and Sparber (2009) estimate the state level task prices of manual and cognitive tasks, $w_{m}$ and $w_{c}$, using variation in task supplies and wages across occupations. We take the national average of these task prices for our measures of $w_{m}$ and $w_{c}$. Peri and Sparber (2009) estimate the elasticity of substitution between manual and communication tasks, $\sigma_{u}$, using state level variation in immigrant inflows. We set $\sigma_{u}=1$ as the preferred estimates from 
Peri and Sparber (2009) and set the elasticity of substitution between low- and high-skilled workers as $\sigma=1.75$, based on the calibration in Peri and Sparber (2009). Peri and Sparber (2009) also use across-state immigrant variation to estimate the elasticities of task supplies with respect to the immigrant share of low-skilled workers. They find that natives respond to low-skilled immigrant inflows by increasing their communication task supply but do not change their manual task supply, and that immigrants do not change their task supplies in response to immigrant inflows. We therefore set $\eta_{f}^{c}=\eta_{f}^{m}=\eta_{d}^{m}=0$ and take $\eta_{d}^{c}=0.33$ from their estimates.

To measure (4)-(6) we follow Peri and Sparber (2009) closely using data from the 2017 ACS downloaded from IPUMS (Ruggles, Alexander, Genadek, Goeken, Schroeder, and Sobek, 2010) and data on task composition of occupations from ONET. We define low-skilled workers as workers with a high school degree or less. We can therefore calculate $N_{f}, N_{d}$ and $N_{s}$ directly from the 2017 ACS as the number of low-skilled immigrants, low-skilled natives and high-skilled workers. To estimate the task supplies, we proceed in two steps. The ONET dataset measures the task requirement for each census occupation code. We use the procedure described in Peri and Sparber (2009) to assign a manual and communication intensity to each occupation. Then, for each worker in the ACS, we calculate the manual and communication task requirements associated with the worker's occupation. Let $\tilde{c}_{j}$ and $\tilde{m}_{j}$ represent the average communication and manual task intensity of workers of type $j$.

Recall that the task supplies are defined as the task intensities multiplied by labor supply: $c_{j}=h_{j} \tilde{c}_{j}$ and $m_{j}=h_{j} \tilde{m}_{j}$. Note that the worker's budget constraint can be rewritten as

$$
y_{j}=h_{j}\left(\tilde{c}_{j} w_{c}+\tilde{m}_{j} w_{m}\right)
$$

where task prices, $w_{c}$ and $w_{m}$, are known values from Peri and Sparber (2009), and the average income of workers of type $j, y_{j}$, can be estimated directly from the ACS. We can therefore use this equation to solve for $h_{j}$ for low-skilled immigrants and natives and therefore for all four task supplies, $c_{f}, c_{d}, m_{f}$, and $m_{d}$.

\section{Further Quantitative Results}

\section{C.1 Indirect Fiscal Effects in Canonical Model with Real Interest Rate $=2$}

In Section 3 we chose a real interest rate of $1 \%$. In Table 11 we replicated our baseline results under the assumption of a real interest rate of $2 \%$. The table shows the indirect fiscal effects of the average low-skilled immigrant. The effects range from $\$ 682$ to $\$ 1,309$. 


\begin{tabular}{|c|c|c|c|}
\hline Object & Value & Desription & Source \\
\hline \multicolumn{4}{|l|}{ Task Prices } \\
\hline$w_{m}$ & 773 & Manual task wage & PS inflated to 2017 \\
\hline$w_{c}$ & 820 & Communication task wage & PS inflated to 2017 \\
\hline$w_{s}$ & 69,311 & Skilled income & $\mathrm{ACS}$ \\
\hline \multicolumn{4}{|c|}{ Production Parameters } \\
\hline$\sigma$ & 1.75 & Elasticity of substitution, skilled and unskilled workers & PS \\
\hline$\sigma_{u}$ & 1 & Elasticity of substitution, manual and communication tasks & PS \\
\hline \multicolumn{4}{|c|}{ Task Supply Elasticities } \\
\hline$\eta_{c}^{d}$ & .33 & Elasticity of native communication task supply with respect to immigrants & PS \\
\hline$\eta_{m}^{d}, \eta_{m}^{f}, \eta_{c}^{f}$ & 0 & Other task supply elasticities & PS \\
\hline \multicolumn{4}{|l|}{ Population Shares } \\
\hline$\frac{N_{f}}{N}$ & 0.069 & Low-skilled immigrants as fraction of population & ACS \\
\hline$\frac{N_{d}}{N}$ & 0.318 & Low-skilled natives as fraction of population & $\mathrm{ACS}$ \\
\hline$\frac{N_{s}}{N}$ & 0.613 & Hig- skilled workers as fraction of population & $\mathrm{ACS}$ \\
\hline \multicolumn{4}{|l|}{ Task Supplies } \\
\hline$c_{f}$ & 12.47 & Communication task supply of low-skilled immigrants & ONET and ACS \\
\hline$c_{d}$ & 19.15 & Communication task supply of low-skilled natives & ONET and ACS \\
\hline$m_{f}$ & 27.71 & Manual task supply of low-skilled immigrants & ONET and ACS \\
\hline$m_{d}$ & 29.18 & Manual task supply of low-skilled natives & ONET and ACS \\
\hline \multicolumn{4}{|c|}{ Marginal Tax Rates } \\
\hline $\bar{T}_{f}^{\prime}$ & 0.299 & Marginal tax rate of low-skilled immigrants & Tax quantification \\
\hline$\vec{T}_{d}^{\prime}$ & 0.293 & Marginal tax rate of low-skilled natives & Tax quantification \\
\hline $\bar{T}_{s}^{\prime}$ & 0.369 & Marginal tax rate of high-skilled workers & Tax quantification \\
\hline
\end{tabular}

Table 10: Summary of data sources and calibrated values. "PS" refers to estimates taken from Peri and Sparber (2009).

\begin{tabular}{lrrr}
\hline & \multicolumn{3}{c}{ Elasticity of Substitution } \\
\cline { 2 - 4 } & 1.5 & 2.0 & 2.5 \\
\hline I. No Labor Supply Responses & 1,141 & 856 & 685 \\
II. Intensive Only & & & \\
$\quad$ Common Elasticity & 1,244 & 977 & 804 \\
$\quad$ By Gender and Marital Status & 1,145 & 860 & 689 \\
$\quad$ By Income, Gender and Marital Status & 1,188 & 896 & 719 \\
III. Extensive Only & & & \\
$\quad$ Common Elasticity & 1,233 & 959 & 784 \\
$\quad$ By Gender and Marital Status & 1,181 & 903 & 730 \\
$\quad$ By Income, Gender and Marital Status & 1,110 & 845 & 682 \\
IV. Intensive and Extensive & & & \\
$\quad$ Common Elasticity & 1,309 & 1,055 & 884 \\
$\quad$ By Gender and Marital Status & 1,185 & 907 & 734 \\
$\quad$ By Income, Gender and Marital Status & 1,155 & 883 & 715 \\
\hline
\end{tabular}

Table 11: Indirect Fiscal Effects with intensive and extensive margin labor supply responses with real interest rate of $2 \%$. 


\begin{tabular}{lrrr}
\hline & \multicolumn{3}{c}{ Elasticity of Substitution } \\
\cline { 2 - 4 } & 1.5 & 2.0 & 2.5 \\
\hline No Labor Supply Responses & 1,221 & 916 & 733 \\
II. Intensive Only & & \\
$\quad$ Common Elasticity & 1,332 & 1,046 & 861 \\
$\quad$ By Gender and Marital Status & 1,222 & 919 & 736 \\
$\quad$ By Income, Gender and Marial Status & 1,266 & 955 & 766 \\
Extensive Only & & & \\
$\quad$ Common Elasticity & 1,295 & 1,008 & 824 \\
$\quad$ By Gender and Marital Status & 1,245 & 952 & 770 \\
$\quad$ By Income, Gender and Marital Status & 1,181 & 898 & 725 \\
Intensive and Extensive & & & \\
$\quad$ Common Elasticity & 1,381 & 1,113 & 932 \\
$\quad$ By Gender and Marital Status & 1,246 & 954 & 773 \\
By Income, Gender and Marital Status & 1,223 & 935 & 757 \\
\hline
\end{tabular}

Table 12: Indirect Fiscal Effects with intensive and extensive margin labor supply responses with alternative skill definition.

\section{C.2 Indirect Fiscal Effects in Canonical Model with Alternative Skill Definitions}

In Section 3, we followed Borjas (2003), Peri and Sparber (2009) and Ottaviano and Peri (2012) and defined low-skilled workers as those with no college experience and defined highskilled workers as individuals with some college and college graduates. An alternative way to delineate skills is to divide individuals with some college between low-skilled and high-skilled workers, as in Card (2009) or Katz and Murphy (1992).

In this section we replicate our baseline results from Section 5, except we define skill groups as in Card (2009), by dividing individuals with some college evenly between the groups. Overall the indirect fiscal effects here are slightly smaller than our baseline result. This makes sense, the skill definitions we use in this section imply a smaller high-skilled share of income and therefore a smaller own-wage elasticity for low-skilled workers, holding the parameter $\sigma$ constant. However, the results are still in the same ballpark as those presented in Section 5 .

\section{C.3 Indirect Fiscal Effects in Canonical Model with for High School Dropouts and High School Graduates}

Tables 13 and 14 show the indirect fiscal effects for the average high school dropout immigrant and the average high school graduate immigrant. 


\begin{tabular}{lrrr}
\hline & \multicolumn{3}{c}{ Elasticity of Substitution } \\
\cline { 2 - 4 } & 1.5 & 2.0 & 2.5 \\
\hline I. No Labor Supply Responses & 1,108 & 831 & 665 \\
II. Intensive Only & & & \\
$\quad$ Common Elasticity & 1,208 & 949 & 781 \\
$\quad$ By Gender and Marital Status & 1,112 & 835 & 669 \\
$\quad$ By Income, Gender and Marital Status & 1,149 & 866 & 695 \\
III. Extensive Only & & & \\
$\quad$ Common Elasticity & 1,177 & 916 & 749 \\
By Gender and Marital Status & 1,139 & 870 & 704 \\
$\quad$ By Income, Gender and Marital Status & 1,082 & 823 & 665 \\
IV. Intensive and Extensive & & & \\
$\quad$ Common Elasticity & 1,254 & 1,011 & 847 \\
$\quad$ By Gender and Marital Status & 1,142 & 874 & 708 \\
$\quad$ By Income, Gender and Marital Status & 1,120 & 857 & 694 \\
\hline
\end{tabular}

Table 13: Indirect Fiscal Effects for high school dropouts with intensive and extensive margin labor supply responses. See description from Table 3.

\begin{tabular}{lrrr}
\hline & \multicolumn{3}{c}{ Elasticity of Substitution } \\
\cline { 2 - 4 } & 1.5 & 2.0 & 2.5 \\
\hline I. No Labor Supply Responses & 1,433 & 1,075 & 860 \\
II. Intensive Only & & \\
$\quad$ Common Elasticity & 1,563 & 1,227 & 1,010 \\
$\quad$ By Gender and Marital Status & 1,438 & 1,080 & 865 \\
$\quad$ By Income, Gender and Marital Status & 1,485 & 1,120 & 899 \\
III. Extensive Only & & & \\
$\quad$ Common Elasticity & 1,523 & 1,184 & 969 \\
$\quad$ By Gender and Marital Status & 1,473 & 1,125 & 911 \\
$\quad$ By Income, Gender and Marital Status & 1,399 & 1,065 & 859 \\
IV. Intensive and Extensive & & & \\
Common Elasticity & 1,622 & 1,308 & 1,095 \\
$\quad$ By Gender and Marital Status & 1,477 & 1,130 & 915 \\
$\quad$ By Income, Gender and Marital Status & 1,449 & 1,108 & 897 \\
\hline
\end{tabular}

Table 14: Indirect Fiscal Effects for high school graduates with intensive and extensive margin labor supply responses. See description from Table 3. 